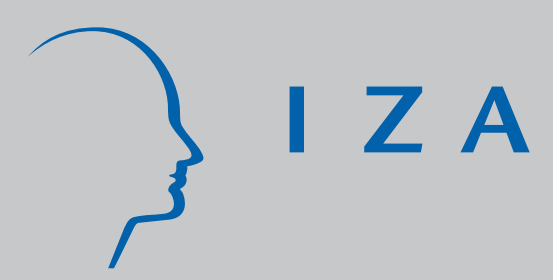

IZA DP No. 5904

Migration and Stratification

Guillermina Jasso

August 2011

Forschungsinstitut zur Zukunft der Arbeit Institute for the Study of Labor 


\title{
Migration and Stratification
}

\author{
Guillermina Jasso \\ New York University \\ and IZA
}

\section{Discussion Paper No. 5904 \\ August 2011}

\author{
IZA \\ P.O. Box 7240 \\ 53072 Bonn \\ Germany \\ Phone: +49-228-3894-0 \\ Fax: +49-228-3894-180 \\ E-mail: iza@iza.org
}

\begin{abstract}
Any opinions expressed here are those of the author(s) and not those of IZA. Research published in this series may include views on policy, but the institute itself takes no institutional policy positions.

The Institute for the Study of Labor (IZA) in Bonn is a local and virtual international research center and a place of communication between science, politics and business. IZA is an independent nonprofit organization supported by Deutsche Post Foundation. The center is associated with the University of Bonn and offers a stimulating research environment through its international network, workshops and conferences, data service, project support, research visits and doctoral program. IZA engages in (i) original and internationally competitive research in all fields of labor economics, (ii) development of policy concepts, and (iii) dissemination of research results and concepts to the interested public.
\end{abstract}

IZA Discussion Papers often represent preliminary work and are circulated to encourage discussion. Citation of such a paper should account for its provisional character. A revised version may be available directly from the author. 


\section{ABSTRACT \\ Migration and Stratification}

Migration and stratification are increasingly intertwined. One day soon it will be impossible to understand one without the other. Both focus on life chances. Stratification is about differential life chances - who gets what and why - and migration is about improving life chances - getting more of the good things of life. To examine the interconnections of migration and stratification, we address a mix of old and new questions, carrying out analyses newly enabled by a unique new data set on recent legal immigrants to the United States (the New Immigrant Survey). We look at immigrant processing and lost documents, depression due to the visa process, presentation of self, the race-ethnic composition of an immigrant cohort (made possible by the data for the first time since 1961), black immigration from Africa and the Americas, skin-color diversity among couples formed by U.S. citizen sponsors and immigrant spouses, and English fluency among children age 8-12 and their immigrant parents. We find, inter alia, that children of previously illegal parents are especially more likely to be fluent in English, that native-born U.S. citizen women tend to marry darker, that immigrant applicants who go through the visa process while already in the United States are more likely to have their documents lost and to suffer visa depression, and that immigration, by introducing accomplished black immigrants from Africa (notably via the visa lottery), threatens to overturn racial and skin color associations with skill. Our analyses show the mutual embeddedness of migration and stratification in the unfolding of the immigrants' and their children's life chances and the impacts on the stratification structure of the United States.

JEL Classification: F22, J15, J16, J24, K42

Keywords: immigration, immigrant visas, social stratification, gender, race, Hispanic origin, skin color, presentation of self, visa depression, illegal experience, English fluency, spouse selection, children of immigrants, nativity premium, New Immigrant Survey

Corresponding author:

Guillermina Jasso

Department of Sociology

New York University

295 Lafayette Street, $4^{\text {th }}$ Floor

New York, NY 10012-9605

USA

E-mail: gj1@nyu.edu

\footnotetext{
*A definitive version will be published in Social Science Research.

The New Immigrant Survey project is supported by the U.S. National Institutes of Health (NICHD and NIA) under grant HD33843, with partial support from the U.S. National Science Foundation, the U.S. Citizenship and Immigration Services, and the Pew Charitable Trusts. Earlier versions of portions of this paper were presented at the Workshop on Children in Immigrant Families, National Institutes of Health, May 2005; the annual meeting of the American Association for the Advancement of Science, San Francisco, California, February 2006; the IZA Meeting on Migrant Ethnicity, Bonn, Germany, May 2006; the Metropolis Conference, Lisbon, Portugal, October 2006; the Migration Conference, Africa House, New York University, December 2006; the Inaugural Conference of the Center for Research on Inequalities and the Life Course, Yale University, May 2007; the Fourth IZA Annual Migration Meeting, Bonn, Germany, May 2007; and the Center for Public Policy, University of Houston, Houston, Texas, March 2008. I am grateful to participants at those meetings and other colleagues for many valuable comments and suggestions, especially Lynne C. Burkhart, Rebecca Clark, Herbert Gans, Linda Gordon, Monica Espinoza Higgins, Michael Hoefer, Samuel Kotz, Eric Larson, Jennifer Martin, Douglas S. Massey, Lisa Roney, Robert Warren, the USCIS History Office, and the Editor. I also gratefully acknowledge the intellectual and financial support of New York University.
} 


\section{INTRODUCTION}

Migration and stratification are intimately and irrevocably linked, sharing a core focus on what Weber (1922) insightfully called life chances. Stratification is about differential life chances - who gets what and why - and migration is about improving life chances - getting more of the good things of life. Moreover, the long reach of stratification is visible in migration, and, concomitantly, migration effects are visible in the stratification structures at both origin and destination.

All the grand themes in the study of social stratification find expression in the migration process - discrimination, the pervasive effects of race and gender, the struggle of body and soul to survive, and the march to equality and full membership in society. And all the grand themes in the study of migration involve, in one way or another, stratification mechanisms - who is allowed to migrate, who actually migrates, how they fare in the destination society, what happens to their children, what happens to those left behind and to natives of the new country.

Since Weber's (1892) pioneering examination of Polish workers in Germany and, later, Thomas and Znaniecki's (1927) pathbreaking work, The Polish Peasant in Europe and America, sociologists and other social scientists have explored crucial aspects of the migrationstratification link, providing innovative ideas and theories - for example, self-selection, cumulative causation, contexts of reception, modes of incorporation, segmented assimilation, ethnic enclave, options for ethnic identity, tied movers, oppositional culture - and reinvigorating scholarship on ascriptive factors in migration - gender and race, for example - and differential life chances among migrants - in health and healthcare, housing, employment, and earnings. ${ }^{1}$

This paper examines stratification processes in six dimensions of immigration to the

1 The voluminous literature includes - among others - Akresh and Frank (2008), Alba and Nee (2003), Bean and Stevens (2003), Curran, Garip, Chung, and Tangchonlatip (2005), Donato, Gabaccia, Holdaway, Manalansan, and Pessar (2006), Elo, Mehta, and Huang (2011), Fernández-Kelly (1995), Gans (1999, 2005, 2007), Hersch (2007), Jasso and Rosenzweig (1990), Massey (2003), Massey, Alarcón, Durand, and González (1987), Massey, Arango, Hugo, Kouaouci, Pellegrino, and Taylor (1993), Mincer (1978), Ogbu (1974), Portes and Rumbaut (1990, 2001, 2006), Rumbaut, Massey, and Bean (2006), Valdés (2003), Waldinger (2001), and Waters $(1990,1999)$. 
United States which exemplify the links between migration and stratification: (1) U.S. government processing of new immigrants, in particular the phenomenon of lost documents, which can wreak havoc on carefully made plans and lengthen the visa process; (2) depression due to the process of applying for an immigrant visa; (3) presentation of self among new immigrants; (4) racial composition of new immigrants; (5) skin color and spouse selection among U.S. citizen sponsors of immigrant spouses; and (6) English fluency among adult new immigrants and their young children. Each of the six dimensions is evocative of the grand questions of migration and stratification, and these analyses represent an early step on the path to further exploration of their interconnections.

The six analyses reported in this paper also represent early work in a new generation of research on questions or aspects of questions for which there was a lively oral tradition but until recently little data, including aspects of classic questions such as those embodied in the last three of the six analyses as well as relatively new questions such as the first three. Indeed, questions such as the ones examined in this paper were raised again and again in immigration panels and workshops dating to the late 1970 s, leading the panels to propose and progressively sharpen a new design for a large-scale data collection project on immigration, the New Immigrant Survey which now provides the data to address those questions. In the spirit of Abbott (2004) and using his words, "new ideas" inspired "new data", and the two together are inspiring new research, of which the present paper is an example.

The New Immigrant Survey (NIS) is a set of planned longitudinal studies of several cohorts of U.S. legal immigrants. To date, the NIS has carried out a short pilot panel study of the Fiscal Year 1996 cohort and two surveys of the Fiscal Year 2003 cohort.

It is not difficult to imagine a wealth of new research undertaken not only by immigration researchers but also by scholars across diverse fields who find in the new data the possibility of addressing longstanding questions, even foundational questions, much as is occurring with internet blogs and networking sites. Moreover, because the data are massively rich, one can envision dozens of articles, dissertations, and books on each of many topics. Finally, because the 
data are longitudinal, it will be possible to observe intertemporal dynamics. To illustrate, the third analysis in this paper - on presentation of self - is inspired by Goffman's (1959) foundational insights and the quintessential American possibility of self re-invention, and represents a simple first step into what could become a key empirical ingredient of several research careers.

The data used in this paper are drawn from the baseline survey of the immigrant cohort of 2003 (NIS-2003-1). The data enable examination of race, gender, religion, origin country, and language in the behavior and activities of four sets of actors: U.S. government personnel, U.S. citizen sponsors of immigrants, adult immigrants, and the children of immigrants, including those born in the United States.

Two themes permeate the paper. First is the life chances of individual immigrants. Second is the effect of immigration on the stratification structure of the United States. Together these encapsulate substantial segments of both the migrant experience in the United States and the social effects of immigration. Put differently, the stratification structure grows out of the actions and experiences of many people, and so do migration flows and the incorporation of immigrants. $^{2}$

\section{THEORETICAL AND EMPIRICAL FRAMEWORK}

The work reported in this paper can be situated within the general social scientific theory of migration, a theory which addresses the selection, adaptation, and impacts of immigrants, together with the adaptation and impacts of their children, and which has developed in a series of contributions by diverse scholars (see, for example, Alba and Nee 2003; Bean and Stevens 2003; Jasso and Rosenzweig 1990; Massey et al. 1993; Portes and Rumbaut 2006). In the subsections that follow, we examine the basic actors and elements in the U.S. immigration process, and then

2 Of course, immigration to the United States also affects the stratification structure of the origin country and affects as well the world stratification structure; those effects, however, are outside the scope of this paper. 
consider their relevance to stratification processes and the ways that they combine to define substantively appropriate samples and subsamples or appear as explanatory factors in the six analyses. We take special care describing the main elements in the immigration process, as these shape the environment faced by prospective immigrants and new immigrants and thus will play important parts in the analyses to follow. We also describe major features of the data.

\subsection{Basic Actors in the U.S. Immigration Process}

Four kinds of actors play parts in the U.S. immigration process. The first is the U.S. government, which processes all legal immigrants, via the personnel who staff the agencies responsible for immigrant visa processing - the Department of State (DOS), the Department of Homeland Security (DHS), and the Department of Labor (DOL). The second is the U.S. resident or firm that sponsors the largest set of immigrants, namely, those with family or employment visas -- who together constitute almost 80 percent of the approximately one million new legal immigrants every year. The third is, of course, the immigrant him- or herself. The fourth is the young children of immigrants, including children born in the United States.

In general, everyone who comes in contact with a prospective immigrant - e.g., everyone involved in visa processing at a variety of U.S. government agencies in the United States and around the world -- affects the new immigrant's life chances. Thus, the first two actors shape the life chances of the last two, and, with them, also shape the life chances of many others, including, notably, those left behind in the origin country and the natives of the destination country.

\subsection{Basic Elements of the U.S. Immigration Process}

A growing insight in immigration scholarship is that immigrant behavior cannot be understood without understanding immigrants' legal status in the United States -- how they came and whether they have the coveted "green card" and, if so, how they got it, in the face of numerous obstacles and the daily deportations reported in the press (Smith and Edmonston 1997). For example, understanding labor force attachment and work ethic requires information about work authorization; understanding home ownership requires understanding the risk of deportation; and understanding the children of immigrants requires understanding whether they 
have a claim to U.S. citizenship. Similarly, understanding the "emotional costs" of migration (Levine, Hill, and Warren 1985:3) requires understanding the process by which immigrants reach the United States and acquire their immigration status. This tight link between the immigrant biography and migration outcomes is exemplified by the nine stories which open Portes and Rumbaut's (2006) examination of American immigration. As well, it is increasingly appreciated that a move from illegal to legal represents a highly consequential upward social mobility.

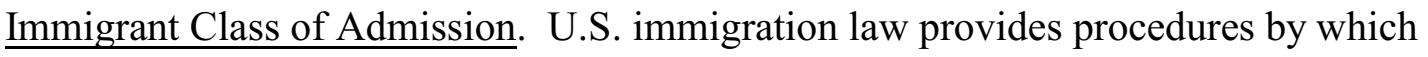
persons from other countries may apply for and obtain lawful permanent residence (LPR) in the United States, a legal status which authorizes foreign-born persons to reside permanently in the United States, to engage in any occupation except those reserved for citizens, and, after satisfying residence and other conditions, to become citizens of the United States (and then engage in any occupation except President and Vice-President of the United States, which are reserved for native-born citizens, as established by the U.S. Constitution, in Article 2, Section 1, Clause 5, and the Twelfth Amendment). ${ }^{3}$

LPR classes of admission are of two main types, numerically unlimited and numerically limited. Numerically unlimited LPR is granted to the spouses, minor children (under age 21), and parents of adult U.S. citizens (a set collectively called "immediate relatives of U.S. citizens"). Numerically limited LPR is granted to three main categories of immigrants: (1) family immigrants, comprised of the adult children and siblings of U.S. citizens (a set collectively called "close relatives of U.S. citizens" to distinguish them from "immediate relatives of U.S. citizens") and the spouses and unmarried children of LPRs; (2) employment immigrants, comprised of five subcategories; and (3) diversity immigrants (winners of the lottery

3 On all matters pertaining to immigration law and procedure, three excellent sources are the websites of the U.S. Department of State (Bureau of Consular Affairs), the U.S. Department of Homeland Security (USCIS and Immigration Statistics), and the U.S. Department of Labor (Office of Foreign Labor Certification). These websites provide a wealth of information, including pertinent legislation, such as the Immigration and Nationality Act, the relevant portions of the Code of Federal Regulations, and the USCIS Adjudicator's Field Manual, together with useful Glossaries, "How Do I" Customer Guides, and relevant forms and associated instructions. 
visas designated for persons from countries underrepresented in recent immigration). Two additional categories of LPR admission have subsets of both numerically limited and numerically unlimited type. These are (4) humanitarian immigrants, including refugees, asylees, and parolees (RAP) and (5) legalization immigrants, that is, illegal immigrants who are becoming legal, including registry-provision immigrants who qualify in virtue of length of residence) and cancellation-of-removal immigrants, plus immigrants targeted by special legalization legislation (such as the Nicaraguan Adjustment and Central American Relief Act of 1997, or NACARA). ${ }^{4}$

The number of numerically limited LPR visas granted annually is about 226,000 to family immigrants, 140,000 to employment immigrants, and 50,000 to diversity immigrants. The family and employment visas are also subject to a country ceiling of 7 percent of the total. The exact number of numerically limited family and employment visas available each year is published in the Visa Bulletin issued monthly by the State Department and in the Annual Flow Report - U.S.

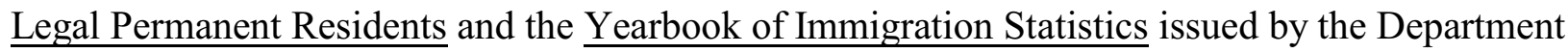
of Homeland Security (in the latter publication only in the years before the narrative text was eliminated in 2004, such as the 2003 Yearbook of Immigration Statistics, Appendix 1). The total number of persons granted LPR is currently about a million a year.

4 Legalization via registry provisions has been a feature of U.S. law since 1929, when persons who had resided illegally in the United States since 1924 - soon after quantitative restrictions were imposed on immigration in 1921 - were allowed to legalize. Since then the qualifying date for inception of illegal residence has changed several times - to 1921 (in 1939), back to 1924 (in 1940), to 1940 (in 1958), to 1948 (in 1965), and to 1972 (in 1986). Thus, the qualifying period of residency has ranged from 5 years in 1929 to 38 years in 1986, when passage of IRCA reduced it to 14 -- and now to 39 years. The notion, popular in discussions of immigration policy, that the United States "does not reward lawbreakers" is patently a fiction. Indeed, note that from the perspective of the registry provisions, the longer the period of illegal residence the better. Note also that, as has been understood at least since Portes (1979), it makes little sense to think of two distinct populations, one legal, the other illegal, for in reality, a large fraction of U.S. foreign-born are (sequentially) both illegal and legal, with spells of legality and illegality interspersed in the immigrant biography. For further discussion of this and other policy matters, see Jasso (2010).

5 Other foreign-born in the United States include persons with legal temporary documents (such as "nonimmigrants" and persons admitted with refugee status or granted asylee status) and illegal immigrants, the latter an obvious reflection of the gap between the desire to immigrate and the supply of visas. 
Visa Sponsorship - Sponsored and Nonsponsored Immigrants. Most family and employment immigrants require a sponsor. In the case of family immigrants, the sponsor is the relative who is already a citizen or legal permanent resident of the United States (for example, the U.S. citizen spouse or parent of a prospective immigrant). In the case of employment immigrants, the sponsor is the employing individual or firm. The sponsor files the initial petition that establishes the prospective immigrant's eligibility and starts the visa process. The requirement for a sponsor may be waived in certain cases. In the family visa classes, the sponsor requirement may be waived for the widow(er) and child of a deceased U.S. citizen (in a marriage that had existed for at least two years before the U.S. citizen's death) or for the spouse and child of an abusive citizen or LPR. In the case of employment visas, the sponsor requirement may be waived for certain classes of immigrants, including investors as well as immigrants of great renown. Sponsored immigrant cases thus require both the sponsor's petition and the prospective immigrant's application; nonsponsored immigrant cases in general require only the prospective immigrant's application. ${ }^{6}$

Principals and Accompanying Relatives. The "principal" is the person who qualifies for the visa. The three categories of immediate relatives of U.S. citizens - spouse, parent, minor child - are for principals only. ${ }^{7}$ All other categories provide LPR visas not only for the principal but also for the spouse and minor children of the principal, except for the category for spouses of LPRs and a few categories designated for "unmarried" principals, in which case "accompanying relative" visas are available only for minor children. Accompanying relatives are also called "derivatives". The characteristics of the principal are the key characteristics in an immigration

6 In immigration law and procedure, the term "sponsor" is also used in a second sense, namely, as the person who completes an affidavit of support (I-864) for an immigrant visa applicant. In this paper, the term "sponsor" is used exclusively in the first sense of the person who submits an immigrant visa petition and starts the immigration process for a prospective immigrant. The NIS has information on both types of sponsors, which we may call visa sponsor and financial sponsor. See the Glossaries provided by DHS and DOS on their websites, as well as the forms for petitioning for relatives and employees.

7 An exception is made for widowed and other self-petitioning spouses of U.S. citizens, who may bring their minor children. 
case (although, as will be seen, sponsor characteristics may also play a part), and thus in our examination of lost documents, below, in which the case is the unit of analysis, the sample is restricted to principals. Of course, if documents are lost, this affects everyone in the case, principal as well as nonprincipals.

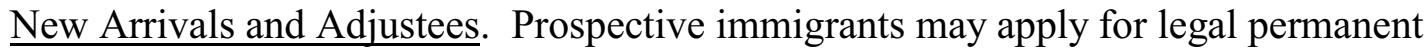
residence abroad or in the United States, if they are already residing in the U.S., having been admitted with a temporary nonimmigrant visa or possibly having gained entry surreptitiously (“entry without inspection" or "EWI”). If abroad, they apply at an embassy or consular post of the State Department; if in the United States, they apply with U.S. Citizenship and Immigration Services (USCIS), an agency of the Department of Homeland Security (and, prior to March 2003, with the Immigration and Naturalization Service (INS), an agency of the Department of Justice). Applicants for employment-based LPR who are already living in the United States may elect consular processing. Applicants for lottery visas start the application process on the internet, and if selected as a possible winner continue the application process where they are residing, either abroad or in the United States.

Before 1977, only persons from the Eastern Hemisphere could apply to adjust status to LPR in the United States, and not surprisingly the proportion adjusting status has increased steadily since then. During the ten-year period from 1996 to 2005, the number of adjustees exceeded that of new arrivals in every year except three (1998, 1999, and 2003, years in which administrative and processing conditions produced large backlogs in immigrant visa processing in INS offices), and for the entire period, the proportion adjustees was 55.8 percent, increasing to $64.7 \%, 59 \%, 57.9 \%$, and $59.1 \%$ in 2006 to 2009 , respectively. ${ }^{9}$

8 Technically, a visa is issued overseas and permits the holder to travel to a U.S. port of entry and request permission to enter. However, the word "visa" has come to be used to refer to an immigration slot - as in "allotment of immigrant visas" in the similarly titled Visa Bulletin and in "visa number" (Glossary on the DOS website) and "Diversity Immigrant Visa Program." In this paper the word "visa" is used in this more extended sense.

Adjustees include holders of both numerically limited and numerically unlimited LPR visas. For example, in Fiscal Year 2009, 18.8\% of numerically limited family immigrants were 
The set of new arrivals includes two subsets who are already living in the United States, the employment immigrants mentioned above who choose consular processing and some illegal immigrants who do not qualify for adjustment of status and go through the visa process as if they are living abroad.

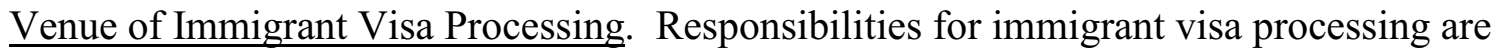
shared by the Department of Homeland Security and the Department of State, with employmentbased applications also involving the Department of Labor. As discussed above, in sponsored immigrant cases, the sponsor files the initiating petition with USCIS, and the prospective immigrant files either with State or with USCIS, depending on place of residence, eligibility to adjust, and employment immigrants' venue choice. Initial diversity applications are processed for the lottery at the Kentucky Consular Center operated by the State Department. Cases involving a numerically limited visa in which there is a backlog are sent to the National Visa Center operated by the State Department in Portsmouth, New Hampshire.

These processing practices imply that, in general, visa processing venue differs (1) between new arrivals and adjustees, (2) between sponsored and nonsponsored immigrants, (3) between numerically limited and numerically unlimited visas, and (4) between diversity and nondiversity visas. Thus, the combination of visa type and information on arrival/adjustment is useful for discerning processing venue. ${ }^{10}$

Accordingly, immigrant cases may straddle two venues. For example, family and employment cases may involve a sponsor submitting documents in the United States and the prospective immigrant submitting documents abroad. And it is possible to trace the case file's journey across State and USCIS facilities. To illustrate, in the case of a sponsored family

adjustees, as were $88.3 \%$ of employment immigrants and $76.3 \%$ of spouses of U.S. citizens (USCIS Yearbook 2009). The notion that prospective numerically limited immigrants wait their turn abroad is somewhat a fiction of popular immigration discussions.

10 This discussion pertains to immigrant visa processing. All new arrivals, in possession of an immigrant visa processed abroad, are also inspected at the port of entry by an agent of the Customs and Border Protection unit of DHS. 
immigrant, the sponsor's petition goes to USCIS and upon approval, if the visa is numerically limited and there is a backlog, the petition goes to the National Visa Center; when the visa becomes available, the sponsor's petition goes to State if this is a new-arrival case or to USCIS if it is an adjustee case. Meanwhile, the prospective immigrant's application is filed with State if it is a new-arrival case or wtih USCIS if it is an adjustee case.

The foregoing information can be distilled into two broad-brush generalizations:

$\S$ New-arrival immigrants are always processed by State, with USCIS doing some processing for sponsored immigrants.

$\S$ Adjustee immigrants are always processed by USCIS, with State-NVC doing some processing for numerically limited visas in which there is a backlog and State-KCC doing some processing for diversity immigrants.

Duration of Visa Processing. The processing period, from filing of the first document to admission to legal permanent residence, has two components. The first component applies only to numerically limited visas, and it refers to the time waiting in the queue for an immigrant slot (visa number) to become available for the particular combination of visa category and origin country. This component (the visa number wait) starts on the date of the filing of the first document in the case (called the "priority date") and ranges from zero time (for visa-country combinations which are "current") to twenty years or more (for visa-country combinations for which there are large backlogs). The case of persons immigrating from the Philippines as siblings of U.S. citizens illustrates the upper extreme (in April 2011 visas became available for applicants with a priority date of 8 March 1988 - a waiting period of 23 years); at the other extreme, visas in some of the employment-based categories (such as that for priority workers, including world-renowned scientists) are available immediately (DOS, Visa Bulletin).

The second component consists of the processing that all cases undergo, including document checks, background checks, and personal interviews. Duration of this component varies across USCIS offices and consular posts, depending on caseload and staffing. For example, the processing time at USCIS offices can increase if personnel are deployed to other 
duties, such as processing naturalization cases. Finally, lottery immigrants receive somewhat expedited processing, as each year's winning visas have to be used within a single fiscal year; for example, winners in the DV-2011 lottery (who applied in the fall of 2009 - and were among the 12 million principals who submitted applications covering 16.5 million prospective immigrants - and were notified in the summer of 2010 that they had won) must complete all processing by 30 September 2011 (the end of Fiscal Year 2011).

Previous Illegal Experience. New LPRs may have spent time in the U.S. illegally, either immediately before acquiring LPR or at some earlier time. A foreign-born person becomes illegal in one of three main ways: (1) surreptitious entry; (2) overstaying a temporary visa; and (3) working without authorization. Previous illegal experience may be discerned from the immigrant visa and the nonimmigrant visa. As discussed above, some immigrant visas are explicitly legalization visas (including registry, cancellation-of-removal, and NACARA visas). Regardless of the type of immigrant visa - a legalization visa or, say, a family or employment visa - new immigrants who adjust from the EWI form of illegality are given a special code in the adjustee nonimmigrant visa field (EWI or WI). In recent years, a new code has appeared, a code for unknown (UU, sometimes UN), as well as a tendency to leave the field blank. ${ }^{11}$ It is widely believed that both the UU code and missing data are a euphemism for illegal status. Finally, if the nonimmigrant visa is a visitor for pleasure visa (B2) and the most recent recorded entry is six years prior to LPR, it is reasonable to believe the person has overstayed the visa (Warren 2003, unpubl).

Accordingly, there are five types of adjustees, those who had a valid temporary visa, those who entered without inspection, those for whom a code of unknown is entered, those for whom there is no code, and those who overstay a tourist visa. Of course, persons adjusting from a valid temporary visa may have had a stint of illegal experience in the past. New arrivals may

11 For example, the 2003 issue of the USCIS Statistical Yearbook notes, "Missing values were a problem especially for adjustment of status cases for certain variables including occupation, nonimmigrant class of entry, and nonimmigrant year of entry" (p. 10). 
have been illegal immediately prior to obtaining LPR or at some previous time.

$\underline{\text { Pathway from a Legal Temporary Visa to Legal Permanent Residence. }}$ Most legal temporary residents have no claim on a future immigrant visa. But some are virtually guaranteed LPR and others have a smoother pathway. Persons who are admitted with refugee status or granted asylee status or who enter with a nonimmigrant $\mathrm{K}$ visa (for fiancé(e)s or for spouses whose application is pending) are virtually assured of progressing to LPR, provided, of course, that no impediments arise. Persons with a select type of temporary visa, such as the H-1B and L1 visas for specialty workers and intracompany transferees, respectively, while not assured of a future LPR visa, nonetheless have the advantage that they are not required to prove that they have no intention of abandoning their country of residence in order to qualify for a temporary visa.

Conditional Legal Permanent Residence Two sets of immigrants receive conditional visas at LPR. These are (1) spouses of U.S. citizens and of LPRs in marriages of less than two years' duration, and (2) employment-based investor immigrants. The visas are conditional for two years and a special application is made for removal of the conditionality restrictions.

\subsection{Immigrant Visa Characteristics and Their Stratification Relevance}

Combining Visa Characteristics. We begin by combining the visa characteristics highlighted in the previous section. As shown in Table 1, not all levels of all characteristics can occur together. For example, as noted above, not all visa types require a visa sponsor, and not all visa types permit an accompanying spouse. Similarly, immigrants with legalization visas unambiguously had previous illegal experience, although immigrants with all other kinds of visas may also have had previous illegal experience.

\section{- Table 1 about here -}

Generating Subsamples and Explanatory Factors. The characteristics described in the previous section and listed in Table 1 are used to construct substantively appropriate subsamples for some of the analyses; in others they operate as explanatory factors. To fix ideas, consider two examples.

First, consider the distinction between principal and accompanying relative. In the 
analysis of lost documents, the case is the unit of analysis and thus the sample is restricted to principals. In the analysis of declaring oneself the principal, it is substantively appropriate to conduct separate analyses for principals and nonprincipals. In the other analyses, the visa categories used as explanatory factors distinguish between principals and nonprincipals.

Second, consider processing venue. The discussion above indicates that there are three subsets of processing venue, relevant to the prospective immigrant's life chances and in particular the possibility of lost documents: (1) processing by the State Department only; (2) processing by INS/CIS only; and (3) processing by both. Table 2 provides the processing venue circa 2003 by visa type and whether the immigrant is a new arrival or an adjustee. In 2003 employment-preference adjustees were processed by INS/USCIS alone because visas were not backlogged (DOS, Visa Bulletin, various issues).

- Table 2 about here -

Visa Type and the Human and Social Capital of Immigrants. The human and social capital of the new immigrant and the immigrant's children, as well as their prospects for integration into the United States, may be closely linked to the type of visa. Family immigrants already have a foothold in the United States -- and a counselor and advocate as well as a fountain of information on job search, housing search, medical care, etc. Obviously, the extent of this foothold and the social capital it signals varies with the type of relationship (blood kin or marital kin) and its closeness (e.g., spouse versus sibling) and whether the U.S. kin is a citizen or not. In particular, immigrant spouses of U.S. citizens may both be intensely screened and also acquire a readymade American network (Jasso and Rosenzweig 1995); additionally, these mechanisms may be intensified among spouses of native-born U.S. citizens, who thus may experience “quicker social integration” (Bean and Stevens 2003:176). Employment immigrants already have a job and an employer. Humanitarian immigrants may receive various kinds of pecuniary and nonpecuniary assistance from specialized resettlement agencies. In contrast, lottery immigrants may have nothing except their own resources - which, however, may not be 
inconsiderable, given the schooling and occupational requirements for eligibility. ${ }^{12}$

Visa Type and the Citizenship Stratification Structure. Immigrants who acquire LPR as spouses of U.S. citizens are entering a household that already has an adult U.S. citizen. They will be in a quite different situation from immigrants entering households without a single adult U.S. citizen. Other immigrants acquiring LPR as relatives of U.S. citizens will also have close access to a U.S. citizen, whether or not they reside in the same household.

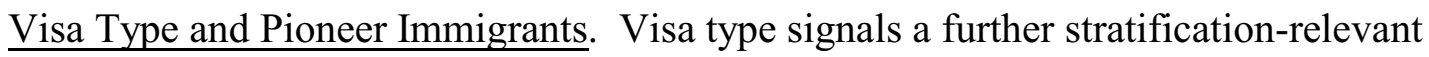
distinction - between pioneer immigrants (including marital, employment, humanitarian, and diversity immigrants) and subsequent family immigrants (such as parents, siblings, and children of previous immigrants). Pioneer immigrants are thought to be more intensely positively selfselected than consanguineous family immigrants, although these distinctions may sometimes blur, as when the employment sponsor is actually a relative. ${ }^{13}$

Visa Type and Social Mobility. All new LPRs are moving up in the citizenship stratification structure. A move from illegality to legality is a move up, as is a move from a temporary to a permanent visa or a move from no visa (as with true new arrivals) to LPR (see Bean and Stevens 2003:111-112; Jasso, Massey, Rosenzweig, and Smith 2008; Jasso and Rosenzweig 1990; Massey et al. 1987; Powers and Seltzer 1998; Powers, Kraly, and Seltzer 2004). Some LPRs are making large jumps - notably those who are making the transition from illegality to LPR, bypassing a legal temporary visa. Others have previously made the transition from illegality to legal nonimmigrant (including, for example, some asylees) and are now moving from legal nonimmigrant to LPR.

12 Eligibility for the diversity lottery program requires either a high-school degree or two years of work experience within the past five years in an occupation requiring at least two years of training or experience. Currently, the qualifying work experience must be in an occupation designated as Job Zone 4 or 5 (out of five job zones) in the Department of Labor's O*Net Online database and classified in a Specific Vocational Preparation (SVP) range of 7.0 or higher (out of nine levels of preparation).

13 For further insight into social capital and its operation among immigrants, see Curran, Garip, Chung, and Tangchonlatip (2005), Kao (2004), Kao and Rutherford (2007), Massey, Alarcón, Durand, and González (1987), and Portes (1998). 
New Arrivals, Adjustees, and Two Sources of Stress. LPR applicants and new legal permanent residents are subject to two distinct sources of stress, (1) stress associated with acquiring LPR (visa stress), and (2) stress associated with adjusting to a new country (migration stress). In general, new arrivals endure the two sources of stress sequentially, first going through visa stress (in their home country) and then going through migration stress; adjustees, on the other hand, go through both kinds of stress simultaneously (Jasso, Massey, Rosenzweig, and Smith 2005). Thus, in a conjecture reminiscent of the classic insight of Simmons and Blyth (1987) about the stress adolescents face if they must go through puberty and a school transition simultaneously, we would expect adjustees to have a more difficult time than new arrivals in the period immediately preceding LPR. Of course, there are many special cases that operate differently - for example, refugees and asylees may endure very little (LPR) visa stress because for them the daunting part of the migration process was obtaining the initial refugee or asylee status, with the subsequent adjustment to LPR being somewhat pro forma. Similarly, an LPR visa applicant who is a long-time "temporary" resident (say, someone who spent ten years on a student visa and is now in the sixth year of a temporary work visa) may have completed the process of adjustment to the United States before beginning the LPR visa application process. ${ }^{14}$

Remark on Two Meanings of "Status". In the foregoing discussion, the word "status" has been used in the meaning of "condition" - for example, legal status, refugee status, asylee status, adjustment of status, immigrant status (joining other similar uses in sociology, such as "marital status"). The word "status" is also used in the "condition" sense to refer to a person's legality; for example, compliance with the terms of a visa "maintains status" and the visa holder remains "in status", while violating the terms of a visa renders the visa holder "out of status." This being

14 Note that the distinction between visa stress and migration stress paves the way for new research to identify their specific effects (short-term and long-term) by contrasting NISbased results with samples experiencing only one or the other, for example: (1) persons who experience migration stress but not visa stress, such as migrants from Puerto Rico or persons born in the U.S. to foreign-student parents but raised abroad since infancy; and (2) persons who experience visa stress but not migration stress, such as persons raised in the U.S. since early childhood by illegal or nonimmigrant parents. 
a paper that aspires to link migration and stratification, the word "status" will also be used in the sense of "prestige" or "honor" or any of the synonyms collected by Zelditch (1968). Given the importance of language as a carrier of stratification, it is worth noting that a new pronunciation appears to be gaining root to distinguish the two senses. In this new pronunciation, which in the spirit of Humpty-Dumpty may be regarded as the special payment owed multi-meaning words, the "condition" version is pronounced with a short a, as in "map", and the "prestige" with a long a, as in "day". 15

\subsection{New Immigrant Survey Data}

Data are drawn from the first round of the 2003 cohort of the New Immigrant Survey (NIS), a longitudinal study of immigrants admitted to legal permanent residence in different cohorts. The 2003 cohort is the first full cohort to be surveyed; a pilot was carried out on the 1996 cohort. The sampling frame consists of all new LPRs whose records were compiled in the 7-month period May-November 2003. On average, interviews were conducted approximately four months after admission to LPR (mean time elapsed between LPR and interview was 17 weeks and median time was 14 weeks). All respondents were interviewed in the language of their choice; a total of 95 languages were used. The analyses reported in this paper pertain to the Adult Sample, including the main sampled immigrant $(N=8,573)$, the spouse of the main sampled immigrant $(N=4,334)$, and a sample of the immigrant's biological children aged 8-12 $(N=1,014)$. Some of the main sampled immigrants were overseas temporarily at the time of fieldwork $(n=321)$, and they were administered a short telephone interview. The response rate for the main sampled immigrants in the Adult Sample was 68.6 percent. Appendix Table A.1

15 There is an additional link between stratification and the "status" vocabulary for being legal and illegal. Because poor people are ineligible for temporary visas and thus cannot violate their terms, poor people, who enter surreptitiously, are illegal but not "out of status". Only the non-poor can fall into the condition of being "out of status". See the Glossary on the State Department website for extensive discussion of the several "status" terms for legality and illegality. 
reports the basic survey characteristics for the Adult Sample. ${ }^{16}$

For each sampled immigrant, the information on the immigrant record in the sampling frame includes the characteristics described in the previous section, for example, whether the immigrant is a new arrival or an adjustee, a principal or an accompanying relative, the type of immigrant visa (for example, spouse of U.S. citizen versus refugee versus diversity), the temporary nonimmigrant visa from which adjustees are adjusting, and the immigrant's country or area of birth.

Immigrants who gain LPR as the spouses of U.S. citizens constitute the largest single category of adult immigrants to the United States, hovering about $33 \%$ of all adult LPRs. Meanwhile, employment and diversity principals, in whom there is great interest, comprise far smaller percentages of adult immigrants (5-8\% and 4-5\%, respectively). Accordingly, the Adult Sample undersampled spouse-of-U.S.-citizen immigrants and oversampled employment and diversity principals. The data include sampling weights, and all percentages and descriptive statistics reported in this paper on based on weighted data (except Appendix Table A.1).

Table 3 summarizes the immigration characteristics of the main adult sampled immigrants and their interviewed spouses. Approximately 89 percent of the adult sampledimmigrant respondents are principals. The spouses of the main adult sampled immigrants include not only principals and nonprincipals, as shown, but also native-born U.S. citizens and previous immigrants (the latter including both LPRs and naturalized citizens). Married couples in which both spouses were interviewed contain one partner from each column. For example, main adult sampled immigrants who are nonprincipals and married are married to spouses who are principals (the second row in the Main Adult column and the first row in the Spouse column); main adult sampled immigrants who are principals and married may have spouses in the third through last rows of the Spouse column (their spouse may be a sponsor, accompanying spouse,

16 For succinct overview of the NIS project, see Jasso (2008); for fuller overview, see Jasso et al. (in press). For data or documentation, see the project website (http://nis.princeton.edu ). 
contemporaneous legal immigrant, illegal immigrant, etc.).

- Table 3 about here -

Thus, married couples in the NIS-2003 are of three broad types: (1) principal and sponsor; (2) principal and accompanying spouse; and (3) principal and other. Interviewed spouses of main sampled immigrants appear in Table 3 as follows: in the principal-and-sponsor type of marriage they are in the third, fifth, and seventh rows of Table 3 ; in the principal-andaccompanying-spouse type of marriage they are in the first and eighth rows; and in the principaland-other type of marriage they are in the fourth, sixth, and ninth rows. Except for the analyses which focus on couples and parent-child pairs, all analyses in this paper are based on the main sampled immigrants.

Close to $78.7 \%$ of the principals are sponsored. Of course, if the principal is sponsored, so is the accompanying spouse, if any. Inspection of the visa categories of the adult sampled immigrants (whether principals or nonprincipals) indicates that close to $77.3 \%$ are sponsored. ${ }^{17}$

U.S. citizens who sponsor spouses may be native-born (NB) or naturalized foreign-born (FB) former immigrants. NIS data include information on the spouse's nativity. Thus, to test for a variety of effects of the sponsor's nativity in the models below, we separate the spouse-of-U.S.citizen category into the two subcategories. The respective percentages are $47.4 \%$ NB sponsors and $52.6 \%$ FB sponsors.

Table 4 provides the visa-category composition of the main sampled immigrants and provides as well, for each visa category, the proportion female and, separately by sex, the average age and schooling and the proportions adjustee and interviewed in English only.

- Table 4 about here -

Figure 1 provides a closer look at age and schooling by presenting the quantile functions associated with their distributions, separately by sex. The quantile functions depict age and

17 We say "close to" because, as noted in the preceding section, sponsorship is sometimes waived within a visa category, for example, for internationally renowned artists and scientists in the employment categories. 
schooling as functions of relative rank and thus simultaneously enable a look at both the position (quantity and rank) of particular individuals as well as the whole distribution.

- Figure 1 about here -

The plots for age (panels A and B, Figure 1), together with the underlying data, show that the men's and women's age distributions track each other closely, with women slightly older than men in the region below the percentage rank of 8.4, in the regions bounded by 46.3 and 47.4 and by 51.9 and 98.1 , and again in the region above 99.9 percent. Thus, and simplifying greatly, men tend to be slightly older in the bottom half of the distribution and slightly younger in the top half of the distribution. The largest difference occurs at the 89.1 percentile, when men's age is 57.2 and women's age is 59.9 - reflecting the larger proportion female in the parent-of-U.S.citizen category (Table 4).

The plots for schooling (panels C and D, Figure 1) indicate that men have more schooling than women at every point in the distribution except among the top .2 percent. While 1.7 percent of the men report no schooling whatsoever, 4.13 percent of the women do so. At the other extreme, 13.5 percent of the men report $17+$ years of schooling, compared to 10.8 percent of the women. The average (Table 4) is higher for men by about seven-tenths of a year.

The sampled adult immigrants in NIS-2003 were born in 168 countries. Table 5 reports the top ten countries of birth. All are in Asia or the Americas. As shown, Mexico has the largest contingent (17.5\%). Thus, the new NIS data on LPRs from Mexico may help remedy the longstanding neglect of Mexican legal migration relative to Mexican illegal migration (Bean and Stevens 2003:44-45). ${ }^{18}$

- Table 5 about here --

Previous illegal experience is estimated by combining information from the official administrative record and from the survey, following the procedures in Jasso, Massey,

18 The information on country of birth was constructed from two data series, in the government immigrant record and collected in the survey, with additional information from both the administrative record and the survey used to resolve discrepancies. 
Rosenzweig, and Smith (2008). The main pieces of information based on the immigrant record are: (1) legalization visa (Table 4); (2) nonimmigrant code EWI/WI, UU/UN, or missing; and (3) the Warren (2003, unpubl) measure (nonimmigrant tourist visa B2 and reporting the most recent entry six years or more earlier). The information based on the survey is drawn from questions in the trip history, which ask what kind of documents were used on each trip to the United States.

Table 6 reports the proportions by component of the estimate together with the total combined estimates. As shown, the estimated previous illegal experience based on the immigrant record alone is 35.7 percent; this covers illegal experience immediately before adjusting to LPR. The estimate including the survey measures, which cover earlier spells of illegality, is 39.6 percent. A conservative lower bound, including only respondents with a legalization visa or an EWI/WI nonimmigrant code, would be 11.4 percent. ${ }^{19}$

- Table 6 about here -

Thus, it appears that for approximately 40 percent of the cohort a period of illegality is de facto a stage on the road to legality - notwithstanding popular political images to the contrary. From a stratification perspective, legalizing constitutes massive upward mobility.

The top three countries of birth in the subset with either a legalization immigrant visa or an EWI/WI nonimmigrant code are El Salvador (79.8\%), Guatemala (66.7\%), and Mexico $(18.8 \%)$. Including all the information based on the immigrant record yields the same top three countries: El Salvador (89.9\%), Guatemala (81.5\%), and Mexico (71.3\%). Including as well the survey measures preserves the rank ordering and increases the estimates to: El Salvador (92.5\%), Guatemala (86.7\%), Mexico (77.6). ${ }^{20}$

19 NIS data can be used to shed light on the UU nonimmigrant code. Among respondents with legalization immigrant visas, $87.5 \%$ have the UU code, and an additional $3.07 \%$ have the UN variant of the designations for unknown nonimmigrant visa, for a total of $90.5 \%$. Only $7.93 \%$ have the EWI nonimmigrant code, and the remaining $1.53 \%$ have tourist visas (both tourist for business and tourist for pleasure - B1 and B2 visas).

20 Portes (1979:427) estimates that among new legal immigrants from Mexico in 197273 , some $69.9 \%$ had previous illegal experience - remarkably similar to the estimate based on the immigrant record alone of $71.3 \%$ in 2003 . Future research might undertake an exhaustive study of all pieces of estimates in order to assess whether previous illegal experience has been a stable 
A race/ethnicity variable was constructed from the responses to the two standard questions on Hispanic origin and race (used in all NIH-funded research and in other surveys, such as the CPS). The five categories to be used in most of the analyses and their (weighted) percentages are: Hispanic, no race (5.63\%), Hispanic white (28.5\%), nonHispanic Asian (28.2\%), nonHispanic black (10.6\%), and nonHispanic white (19.5\%). The excluded category contains $7.58 \%$ of the sample and consists of other race-ethnicity combinations, including multiple-race and nonHispanic, no-race categories. In the fourth analysis below, all the raceethnicity combinations will be examined, including, for example, Hispanic blacks. ${ }^{21}$

From the NIS data on religion, we constructed a variable with the following categories and (weighted) percentages: Catholic (41.3\%), Orthodox Christian (8.71\%), Protestant (16.6\%), Muslim (6.96\%), Jewish (1.27\%), Buddhist (4.25\%), Hindu (5.57\%), other (1.70\%), no religion (12.4\%). An additional 1.23\% did not provide any information on religion. The excluded category in multivariate analyses is no religion. Because of small sample sizes, in some analyses the Jewish, Buddhist, and Hindu categories are placed in the other-religion category. A similar variable was constructed for childhood religion, based on the question, "What religious tradition, if any, were you raised in?"22

The NIS survey also asked respondents about their family income when they were age 16, compared to families in the origin country. Five response categories were provided: far below average, below average, average, above average, and far above average. Table 7 reports the percentage distributions, by sex, and Figure 2 graphs the responses. As shown, there is little

feature of legal Mexican immigration to the U.S. for the past forty years or whether instead it has increased or decreased in recent years. Such a study would have important implications for a clearer understanding of the Mexico-born migration stream and its life chances in the United States.

21 The two race and ethnicity questions adopted by NIH (as described in NOT-OD-01053) are based on the standards set by OMB Directive 15, issued in 1997 (see http:/grants.nih.gov/grants/guide/notice-files/NOT-OD-01-053.html ). Christian.

22 The term "Protestant" is used as a convenient shorthand for post-Reformation 
difference between the two sex-specific distributions. Over half of the respondents reported average family income -54.2 percent of the women and 51.7 percent of the men. The left tails are fatter than the right, with 28-30 percent reporting below average income versus 18-19 percent reporting above average income.

- Table 7 about here -

- Figure 2 about here -

Legislation creating the Department of Homeland Security (DHS) was enacted in November 2002, and immigrant processing previously carried out by INS transitioned to the new U.S. Citizenship and Immigration Services in March 2003. Thus, many, perhaps most, of the immigrants in the NIS-2003 were processed by both the old INS and the new USCIS. Accordingly, we use "INS" and "USCIS" interchangeably as shorthand for the more precise INS/USCIS.

\section{LOST DOCUMENTS, DURATION OF VISA PROCESS, AND LIFE CHANCES}

\subsection{Lost Documents and the Immigration Context}

In the world of U.S. immigration and U.S. travel, two complaints are universal: (1) lack of courtesy among U.S. personnel who deal with the foreign-born - (a) abroad, in the visa sections of embassy and consular posts, administered by the State Department; (b) at ports of entry into the United States, staffed by U.S. Customs and Border Protection, an agency of DHS, since March 2003 and previously by INS; and (c) in the United States, in offices of USCIS and previously in INS offices -- and (2) the propensity of U.S. government immigration agencies to lose documents from case files. There is hardly an academic conference without some story of lack of courtesy or lost documents.

Not surprisingly, lost documents have become a staple of internet immigration blogs and forums. For prospective immigrants to the United States, lost documents are more than an irritation. Lost documents can prolong the visa process, wreak havoc on carefully-made plans for housing (at origin and at destination) or for children's schooling (at origin and at destination) and 
lengthen the visa process, or, indeed, even jeopardize the entire immigration process. Lost documents contribute to what Levine, Hill, and Warren (1985:3) call the "emotional costs" of migration, epitomizing a corner of the life chances landscape. ${ }^{23}$

Of course, government agencies are not unaware of the problem. The official USCIS document, Welcome to the United States: A Guide for New Immigrants (USCIS 2005:14) offers the following advice:

TIP: Keep copies of all forms you send to USCIS and other government offices. When sending documents, do not send originals. Send copies. Sometimes forms get lost. Keeping copies can help avoid problems.

And lost documents have come to the attention of the USCIS Ombudsman (2007:62).

This section examines rates of lost documents by processing venue, whether the immigrant is a new arrival or an adjustee, origin country, visa type, and gender, and reports an initial set of multivariate analyses. A priori, rates and probabilities of lost documents would be expected to differ by venue (due to differences in caseloads and staffing), by visa type (due to the length of time that a case is in the system and thus at risk of having documents lost), by origin country (due not only to venue effects but also to the effect of country on duration of the visa process for numerically limited visas), by previous illegal experience (as, net of visa type, it may trigger further checks and thus affect the length of time that a case is in the system), and by the principal's number of accompanying relatives (as the greater the number of documents in the case, the greater the risk of having a document lost). A priori one might think that given both the popular image and the concern expressed in both A Guide for New Immigrants and the CIS Ombudsman's report, lost documents are more of a problem at INS/USCIS than at the State Department; and certainly differences in workload and agency funding would point in that

23 Among nonimmigrant visitors to the United States, the greatest complaint concerns the delays in visa processing since the terrorist attacks in 2001; complaints about rudeness of U.S. personnel are universal and apply to all processing venues (Sharkey 2006; Welch 2007). 
direction as well.

Beyond such case factors, lost documents may also reflect social mechanisms. For example, State Department personnel, who are living abroad, may be more sympathetic to visa applicants than INS/USCIS personnel in the United States. Further, lost documents may reflect a certain lack of care, a lack of care which may differ systematically across immigrants by their race, gender, religion, or national origin. ${ }^{24}$

\subsection{Empirical Setup and NIS Data for Analysis of Lost Documents}

Consistent with the foregoing discussion, we set up an analytic framework in which the case is the unit of analysis (the sample is restricted to principals, who, as shown in Table 3 and discussed above, comprise 89 percent of the main-adult sampled respondents). There are two parallel lines of inquiry. The first assesses the effect of processing venue, distinguishing between cases processed only by the State Department, cases processed only by INS/CIS, and cases processed in both venues, as shown in Table 2. The second examines differences in lost documents across new arrivals and adjustees. All analyses are carried out separately by gender but include as well pooled versions that test the direct effect of gender. Most specifications include country of birth. Specifications that test for discrimination also include ethnicity, represented by race, Hispanic origin, and religion.

The NIS-2003-1 asked a series of questions about the process which led to acquiring the immigrant visa - many of these stimulated by the lively oral tradition concerning aspects of the visa process -- and a randomly selected half of the main adult respondents were asked, "Were any

24 The United States has a historic commitment of almost half a century to eradicate discrimination on such grounds. It is fifty years since President John F. Kennedy issued the groundbreaking Executive Order 10925 prohibiting discrimination in government employment and employment by government contractors on the basis of "race, creed, color, or national origin" (6 March 1961) and almost as long since he signed the Equal Pay Act (10 June 1963) extending to gender the protection against discrimination. The new spirit quickly reached the field of immigration, and Congress passed Public Law 87-301 (enacted 26 September 1961), which eliminated the requirement that visa applicants provide their race. 
documents or files lost during the process?" This is the question analyzed in this section. ${ }^{25}$

\subsection{Migration and Stratification: Lost Documents}

Table 8 reports the proportion of principals in whose cases documents were lost, by processing venue. As shown, the overall rate was 11.3 percent, with slightly more male principals than female principals experiencing lost documents -12.2 versus 10.6 percent. There is large variation by processing venue, a variation which mimics caseload. Cases processed by the State Department alone total only 5.7 percent of the cases, and in this set the proportion with lost documents is 3.52 percent. At the other extreme, cases processed by INS/USCIS alone total 55 percent, and the proportion with lost documents is 13.5 percent. Finally, cases processed by both State and INS/USCIS total 39.3 percent, and, as would be expected, have a larger proportion with lost documents than those processed by State alone but a smaller proportion than those processed by INS/USCIS alone -9.27 percent. Thus, it seems clear that the a priori conjectures are correct and that documents are more likely to be lost in INS/USCIS offices than in consular posts overseas or the U.S. facilities operated by the State Department (notably the National Visa Center and the Kentucky Consular Center). Of course, this may reflect the type of cases processed at the different venues, in particular, cases involving principals with previous illegal experience, a possibility examined in multivariate analyses below.

$$
\text { - Table } 8 \text { about here - }
$$

Table 9 shifts perspective, reporting rates of lost documents separately for new arrivals and adjustees and providing a look by country and visa type. Adjustees are substantially more likely to experience lost documents than new arrivals -13.7 versus 7.56 percent (panel C).

$$
\text { - Table } 9 \text { about here - }
$$

Of the 168 countries of birth represented in the Adult Sample, 147 are represented in

25 Analysis is restricted to respondents who are both main sampled immigrants and principals (Table 3 ) and does not include respondents who are principals and spouses of the main sampled immigrants, because the information on lost documents is obtained from the respondent and because information on principals who are spouses of respondents is limited to information provided by the respondent or by the subset of spouses who were interviewed. 
cases involving principals in the subsample asked the lost documents question. Among these 147 countries, 65 have no emigrants reporting lost documents. More sharply, within the four subsets defined by gender and adjustee status, there are no cases of lost documents for 76 out of 104 countries among new-arrival men, 68 out of 103 among new-arrival women, 64 out of 116 among adjustee men, and 49 out of 102 among adjustee women. Thus, lost documents appear not to be a universal phenomenon.

Table 9, panel A, reports the lost document rates for the top ten origin countries (Table 5). These figures underscore the variation in lost documents across country. For example, among adjustee women from the top ten origin countries, the rates vary from less than $1 \%$ for those born in China to more than 14\% for those born in Mexico; among new arrivals, the rates vary from lows of $1.66 \%$ and $2.56 \%$ among women from China and men from India, respectively, to over $11 \%$ for both men and women from the Dominican Republic. Gender appears to be a factor; contrast the rates of lost documents among adjustees from China; women, as noted, have the lowest rate, but men the highest - 16.3 percent. Again, these country and gender effects invite multivariate scrutiny.

Visa category shows even greater variation than country of birth (Table 9, panel B). The largest rates are for adjustee adult unmarried daughters of U.S. citizens, over a quarter of whom experience lost documents. The lowest rates (not shown) are among new-arrival women with diversity and married-daughter-of-U.S.-citizen visas - 2.36 and 2.34 percent, respectively.

A result which catches the eye is that in three of the four subsets in Table 9, spouses of foreign-born U.S. citizens have higher rates of lost documents than spouses of native-born U.S. citizens - for example, 20.1 versus 16 percent and 15.2 versus 12 percent among adjustee husbands and wives of U.S. citizens, respectively. The exception is among new-arrival wives wives of native-born U.S. citizens have a lost document rate of 13.8 percent versus 11 percent among wives of foreign-born U.S. citizens. As with origin country, visa type also invites multivariate scrutiny.

Table 10 reports the results of two sets of multivariate analysis, designed to more sharply 
assess the processing venue and adjustee effects. Each set includes three specifications for each sex. The first two are binary logit, with robust standard errors. Specification (3) is a fixedeffects logit, with fixed effects for the full set of countries. Specifications (2) and (3) also include previous illegal experience. The processing venue results, reported in panel A, indicate that processing venue is statistically significant in all specifications, and the effect is exactly in line with the raw rates. Cases processed only by INS/USCIS have the highest probability of lost documents, followed by cases processed by both INS/USCIS and State, and cases processed by State only have the lowest probability. Previous illegal experience increases the probability of lost documents but is statistically significant only in the women's fixed-effects logit specification. $^{26}$

- Table 10 about here -

Versions pooled by sex did not find a statistically significant effect of sex, although the signs indicate that men are more likely to experience lost documents than women. Additional versions, incorporating race and Hispanic origin, as well as religion, did not find religion effects; the only notable effect is that among women, nonHispanic blacks have a substantially lower probability of having lost documents than immigrants of other race and Hispanic origin combinations.

Panel B reports the results for the specifications assessing the adjustee effect. This set also incorporates visa type. In all specifications, the adjustee effect is positive, and it achieves statistical significance in all the women's specifications and one of the men's. Previous illegal experience is also uniformly positive, but statistically significant only in one of the men's specifications. Visa type is statistically significant in two of the women's equations. The point estimates indicate that in all the specifications, spouses of foreign-born U.S. citizens have higher probability of lost documents than spouses of native-born U.S. citizens. In the women's equations, employment principals have the highest probability of lost documents, but the

26 Visa type and adjustee cannot be included in the processing venue equations as they were used to define processing venue and are thus collinear with it (Table 2). 
documents could have been lost in the Department of Labor. Parents of U.S. citizens have among the lowest probabilities of lost documents.

As with the venue regressions, we tested for effects of gender, race and Hispanic origin, and religion (not shown). None were statistically significant. The effect of gender was close to zero.

\subsection{Aftermath of Lost Documents: Lengthening the Visa Process for Adjustees}

Overall, documents were lost in 11.3 percent of the immigration cases in the NIS-2003 sample. Are there negative consequences for the new immigrants? Was it a minor irritation, or will there be lasting consequences? Because the NIS is a longitudinal study, future rounds of the survey will make it possible to examine the long-term effects, if any, of having documents lost including diminished attachment to the United States, visible in naturalization, emigration, and voting. For now, we focus on two more immediate consequences, both of which could also have longer-lasting effects of their own: lengthening the processing period and becoming depressed. Visa depression will be analyzed in the next section. Here we concentrate on the consequences of lost documents for the length of the visa process.

We begin with a look at processing time. As already noted, the visa process lasts from the filing of the first document to granting of legal permanent residence. A priori there are several mechanisms affecting duration of the visa process, some of which work at cross purposes. First, the visa process should be longer for numerically limited visas which are backlogged - in 2003 these were family preference visas (State Dept, Visa Bulletins). Other visas are not subject to waiting for a visa number; moreover, diversity visas must be processed within the fiscal year. Second, the visa process should be longer for adjustment of status cases than for new-arrival cases, because the volume is larger stateside (Tables 2 and 8) and the percase resources appear to be lower than in U.S. consulates abroad. Third, however, the visa process should be longer for new-arrival cases because, while among adjustees approval leads immediately to LPR (indicated by a stamp in the passport), among new arrivals that same approval is only the first of two approvals, yielding a visa which is valid for six months as the 
prospective immigrant prepares to travel to the United States, where a U.S. agent conducts an inspection and provides the second approval, authorizing admission to LPR (again indicated by a stamp in the passport). Fourth, within visa categories that provide visas for both principals and accompanying spouses, new arrivals granted LPR as spouses of principals should have a shorter visa process than principals because the marriage might have occurred after the initial petition was filed. Fifth, however, new arrivals granted LPR as spouses of principals should have a longer visa process because they are allowed an additional six months for "following to join" the principal. Sixth, employment cases requiring labor certification (second and third preference categories) should have a longer visa process than cases not requiring it. Finally, country of birth also affects duration of the visa process in the numerically limited preference categories. ${ }^{27}$

Note that the second and third mechanisms have opposite effects, as do the fourth and fifth. Which mechanism is stronger is an empirical question to be examined below.

Table 11 reports the duration of the visa process in the NIS-2003 cohort, separately for new arrivals and adjustees, for principals and spouses, and by gender. The first result which hits the eye is a result not anticipated from the mechanisms listed above: In each of the four subsets, visa processing takes longer for spouses of foreign-born U.S. citizens than for spouses of nativeborn U.S. citizens. The reason is not immediately obvious. Inspection of the requisite Form I130 ("Petition for an Alien Relative") which must be filed by the sponsor indicates that the only difference between the two types of sponsors pertains to the evidence of their citizenship that must be presented, namely, while both native-born and foreign-born citizens can present a passport, other evidence includes a birth certificate for a native-born citizen and a certificate of naturalization (or of citizenship) for a foreign-born citizen. Thus, there are two further avenues to explore: (1) whether marriage cases involving foreign-born U.S. citizens are more complicated in an immigration sense (i.e., are higher-order marriages for one or both spouses, the

27 For further information about processing for highly skilled employment-based immigrants and their characteristics in the NIS 2003 cohort, see Jasso (2009) and Jasso, Wadhwa, Gereffi, and Freeman (2010). 
sponsored spouse has difficulty accessing the requisite documents, such as military and police records, or the documents have to be translated from a non-Roman alphabet, etc.), and (2) whether marriage cases involving foreign-born U.S. citizens receive greater scrutiny from U.S. officials. Both are outside the scope of this paper. But note that the NIS data provide sufficient information to establish differences between the two types of marriage cases that may affect processing times. Note also that the longer visa process for spouses of foreign-born U.S. citizens than for spouses of native-born U.S. citizens may reflect the effect of lost documents, to be examined below.

\section{- Table 11 about here -}

Other results illuminate the mechanisms described above. As expected, numerically unlimited cases (spouses, parents, and minor children of U.S. citizens), diversity cases, and employment cases have the shortest visa process. Sibling cases have the longest visa process.

Contrasting adjustee and new-arrival visa process times within subsets of principals indicates that in almost every visa type, the adjustee process is longer than the new-arrival process, suggesting that the agency mechanism trumps the behavioral mechanism (new arrivals taking up to six months to settle affairs before traveling to the United States). For example, the visa process for spouses of native-born U.S. citizens lasts 1.23 and 1.1 years, on average, for men and women, respectively, who are new arrivals, but almost twice as long for adjustees -2.39 and 2.15 years for men and women, respectively. These figures also provide an empirical grounding for the perennial discussion among visa applicants and immigration lawyers concerning the relative merits of adjustment of status and consular processing (a search of immigration forums and chatrooms on the internet will quickly yield pertinent anecdotes), as well as to the policy of permitting employment-based visa applicants residing in the United States to choose consular processing (as shown in Form I-140, "Petition for Alien Worker").

Within new arrivals, spouses of principals have shorter visa process than principals among numerically limited married children and siblings of U.S. citizens - indicating that they may have married after the principal entered the visa queue. Differences in duration of the visa 
process between principals and spouses are trivial among employment and diversity immigrants, except among employment new arrival women, who exhibit the opposite pattern - longer visa process for spouses of principals - presumably because the visa wait is shorter and the spouses follow later.

For visual illustration, Figure 3 provides the quantile functions of the duration distributions for the two extremes of the visa process - among spouses of native-born U.S. citizens and siblings of U.S. citizens - separately for new arrivals and adjustees and by gender. The plots for the spouses vividly show the longer duration among adjustees than among new arrivals. The expected discrepancy between new arrivals and adjustees among siblings is more ambiguous, possibly because the arrival-adjustee subsets contain a different origin-country mix, and the wait for these numerically limited visas differs by country.

- Figure 3 about here -

But the main question in this section concerns the effect of lost documents on duration of the visa process. Table 12 reports OLS estimates of the effect of lost documents, controlling for visa type (which as expected from immigration law and as documented in both Table 11 and Table 12 has its own effect). Having documents lost has a statistically significant effect on the duration of the stateside visa process, prolonging it by one year, on average, for men adjustees and by almost eleven months for women adjustees (coefficients of 1.017 and .899 , respectively). Among new arrivals, the effect of lost documents does not reach statistical significance for either sex, and the point estimates indicate a lengthening of the visa processing period by about half a year for men and nothing for women (coefficients of .572 and -.018, respectively). The reason for the venue differential in the effect of lost documents on the length of the visa-processing period may be that documents are easier to replace in the origin country than in the United States. - Table 12 about here -

Table 12 shows that the pattern of longer visa process for spouses of foreign-born U.S. citizens than for spouses of native-born U.S. citizens persists after controlling for lost documents. Table 12 also shows that, as expected, among adjustees, those immigrants whose official records 
indicate previous illegal experience had a longer visa process. Sharp understanding of the patterns revealed in the coefficients, however, requires further research. ${ }^{28}$

\section{VISA DEPRESSION AND LIFE CHANCES}

The "emotional costs" of applying for an immigrant visa have long been noted (Levine, Hill, and Warren 1985:3). Both the outcome and its timing are uncertain; moreover, as we have seen, documents may be lost. NIS data enable examination of an extreme form of some of these emotional costs, namely, experiencing sadness and depression due to the process of applying for a visa - visa stress. Approximately $17 \%$ of the new immigrants report experiencing visa depression. This section explores risk factors and protective factors, focusing in particular on links with race and gender, visa category and previous illegal experience, and religion. As well, this section provides estimates of the effect of having documents lost on visa depression.

A priori, we expect visa stress to differ by conditions and characteristics associated with the visa process. Diversity immigrants are expected to have less visa stress, in part because, as noted above, the entire process must be concluded in a relatively short period of time (section 2.2 above). Refugees and asylees, too, are expected to have less visa stress in the period just before admission to LPR because for them the daunting and uncertain part was obtaining the initial refugee or asylee status, with adjustment to LPR being more routine (sections 2.2 and 2.3). However, as noted above, adjustees are expected to have more visa stress than new arrivals because, following the logic of Simmons and Blyth's (1987) argument concerning puberty and school transitions, they undergo both the visa process and the process of adjusting to the United States at the same time (section 2.3).

\subsection{Empirical Setup and NIS Data for Analysis of Visa Depression}

Two sets of analyses are carried out, the first on the full sample of the NIS-2003 main

28

Many other further analyses can be undertaken, zeroing in on aspects of each case discernible in the data and taking into account the waiting times for visa-country combinations in the Visa Bulletins, in particular, for the three countries which experienced longer waits for numerically limited visas than other countries in 2002-2003 - India, Mexico, and the Philippines. 
sampled immigrants (Table 3), the second on the half-sample who were asked the lost documents question.

The NIS-2003-1 (attentive to the speculation in the oral tradition) asked all main sampled immigrants except the 321 overseas respondents (section 2.4 and Appendix Table A.1) the question, "During the past 12 months, have you ever felt sad, blue, or depressed because of the process of becoming a permanent resident alien?” Approximately 17.4 percent of the new immigrants reported becoming depressed due to the visa process. Moderately more women than men became depressed $-18.5 \%$ of the women versus $15.9 \%$ of the men - and moderately more adjustees than new arrivals became depressed $-18.7 \%$ of adjustees versus $15.5 \%$ of new arrivals.

The other new variable introduced in the analysis of visa depression pertains to having suffered harm. A question in the NIS-2003-1 asked, "Did you or your immediate family ever suffer any harm outside of the United States because of your political or religious beliefs, or your race, ethnicity, or gender?” Approximately 7 percent of the sample answered yes. These respondents are concentrated in the refugee/asylee/parolee categories $-46 \%$ and $49 \%$ of principals and spouses, respectively - together with $14.9 \%$ of legalization immigrants. Within these visa categories, there is a further concentration by origin country; in the RAP categories $12.2 \%$ of those who suffered harm are from Ukraine and $11.9 \%$ from Russia, and in the legalization category $66 \%$ are from El Salvador and $23 \%$ from Guatemala.

\subsection{Migration and Stratification: Visa Depression}

Table 13 reports conditional logit estimates of the visa depression equation with countryof-birth fixed effects. As expected from the overall percentages, the pooled versions (not shown) indicate that women are statistically significantly more likely to experience visa depression than men (with prob values of .003 in the full sample and .005 in the subsample). Visa category and the adjustment variable are statistically significant in the men's full-sample equation (beyond the .004 level and the .000 level, respectively) but neither is significant in the women's equations (and only adjustee reaches significance in the men's subsample equation).

- Table 13 about here - 
The question whether having an employer or a relative in the United States - perhaps a special kind of relative - confers protection against depression or instead operates to promote stress receives some hints from the statistically significant results for men and the point estimates for women. Among immigrants married to (and sponsored by) U.S. citizens, those married to foreign-born U.S. citizens appear to gain more protection against depression than those married to native-born U.S. citizens; this advantage is particularly visible in the women's subsample equation, where wives of native-born U.S. citizens have the second-highest probability of visa depression, while wives of foreign-born U.S. citizens rank tenth. Young men (with a child-ofU.S.-citizen visa) also appear to benefit from having a U.S. citizen parent, but young women with a U.S. citizen parent have the highest probability of visa depression in the full sample and the second-highest in the subsample. These results provide further hints of the gender-specific character of social capital and of the degrees of social capital (Curran, Garip, Chung, and Tangchonlatip 2005).

As expected, diversity lottery immigrants of both sexes and both principals and spouses appear to have moderately low probability of visa depression, as do refugees/asylees/parolees and their spouses, except for RAP principal women (full sample). Employment-based immigrant men have some of the highest probabilities of visa depression -- with principals and spouses ranking second and third, respectively, in the full sample - while wives of employment principals rank $9^{\text {th }}$ and $13^{\text {th }}$ in the full sample and subsample, respectively.

As noted, the adjustee variable is statistically significant and positive in the men's equations but negative and not reliably estimated in the women's equations. To test whether the effect is of adjusting per se or of adjusting from illegality, the equations include a variable for adjusting from illegality. Though not reaching statistical significance, the coefficient in the men's equation is negative, indicating that adjustees who are adjusting from illegality have a lower probability of visa depression than adjustees who are adjusting from a valid nonimmigrant visa. Moreover, like the adjustee variable, the variable for adjusting from illegality it hints at diametrically opposite patterns by gender. 
Overall, then, the coveted employment visas confer no protection from depression on principals, but do appear to protect their wives. Refugees are a highly select set of survivors, and it is likely that the hardships of the visa process pale next to the hardships that made them refugees - and the earlier process by which they acquired the initial refugee or asylee status. Diversity immigrants -- winners of a lottery -- may be basking in the glow of fortune, not to mention the expedited handling of their visas, given, as noted, legal requirements to admit to LPR status within the fiscal year. And not all U.S. citizen sponsors of spouses are the same. The foreign-born among them, whose spouses' immigration cases have greater probability of lost documents and longer duration, appear to do more to prevent or mitigate depression among their spouses, with the discrepancy larger among cases involving U.S. citizen husbands and immigrant wives than among cases involving U.S. citizen wives and immigrant husbands.

Among personal characteristics, age matters for women. The probability of depression increases with age until the late thirties, and then declines.

Schooling appears not to protect against depression; the coefficients do not reach significance, although their signs are uniformly positive. Having experienced harm increases the probability of depression, statistically significantly so for men in the full sample. Thus, refugees who suffered harm have both the protection attached to refugees and the risk attached to harm.

Turning to the effect of having documents lost during the visa process, the subsample equations indicate that having documents lost significantly increases the probability of visa depression for both men and women.

Thus, adjustees would seem to endure a "triple whammy." First, they are more likely to have documents lost. Second, if they have documents lost, processing time is lengthened by about a year (perhaps because the documents are more difficult to replace in the United States than in the origin country). Third, holding constant lost documents, adjustee men have a higher probability of becoming depressed during the visa process.

These results suggest that the hardships of the visa process are more difficult to endure if they occur at the same time that immigrants are trying to adjust to life in a new country. The 
"comforts of home" would seem to mitigate visa stress.

Finally, as with lost documents, the longitudinal nature of the New Immigrant Survey will make it possible to gauge the long-term consequences of having experienced visa depression, both with respect to health and with respect to the degree of attachment to the United States. ${ }^{29}$

\section{PRESENTATION OF SELF:}

\section{GENDER, STATUS, AND DECLARING ONESELF THE PRINCIPAL}

As discussed above, the immigrant principal is the individual who qualifies for the immigrant visa (section 2.2). In many visa categories - obviously excepting spouse principals (spouses of U.S. citizens and of LPRs) and unmarried children of U.S. citizens and of LPRs but also excepting parents of U.S. citizens - immigrant visas are also made available to the spouse of the principal. Being a principal appears to confer a certain social status. Anecdotal evidence suggests that immigrants who are actually spouses of principals may like to be thought of as principals. After all, being a principal announces to the world that one has qualified for a coveted immigrant visa and, moreover, except for spouses sponsored by U.S. citizens and LPRs, that one is not indebted to one's husband or wife or to one's in-laws for the immigrant visa. Thus, in a Goffman (1959) sense, declaring oneself the principal is a perfect ingredient in the presentation of self.

A notable possible exception to this status interpretation of being a principal pertains to diversity visas, which are awarded by lottery; it is thought to be quite common for married couples (in which both spouses satisfy the schooling or experience requirement) to submit two separate applications, with each spouse as principal, and fortune picks the winner. Thus, there being no special merit in winning a diversity visa - beyond the favor of the gods - the phenomenon of declaring oneself the principal may be muted in diversity visas, unless luck is

29 Recent medical research suggests that depression increases the risk of type 2 diabetes, net of other risk factors (Carnethon et al. 2007). Because the NIS includes information not only on visa depression but also on depression not linked to the visa process, it will be possible to assess the particular effects, if any, of visa depression on diabetes and other health conditions. 
thought to signal other good qualities or even the promise of further luck.

Meanwhile, as we have seen, the reality of applying for an immigrant visa is, for most applicants, a test of enduring adversity and disrespect. Moreover, social status may decline in the United States (Bean and Stevens 2003:28). The stage is set for the right salve. In the world of immigration, declaring oneself the principal - what we may call the "me-principal" assertion -provides a perfect mix. Perhaps a little lie, but a harmless one and one with no apparent repercussions.

Concomitantly, however, there may be persons of such modesty and self-effacement - or obsequiousness -- that they are loath to declare themselves the principal, generally avoiding the subject or even misrepresenting the part they played in their family's immigration. Moreover, depression may intensify the self-effacement and lack of assertiveness.

Alongside these mechanisms for protecting the self, there is, of course, the effect of knowledge. Some new immigrants may know more about the visa process than others.

Finally, the immigrant may think that in a just world (s)he would (or would not) be the principal, and attempt to redress the injustice by reporting the just situation rather than the actual situation. As Blanche Dubois puts it in Tennessee Williams' A Streetcar Named Desire, “I don't tell truths. I tell what ought to be truth."

\subsection{Empirical Setup and NIS Data for Analyzing the Me-Principal Assertion}

The objective of this analysis is to assess the determinants of declaring oneself the principal. Accordingly, we divide the sample into two subsamples, the first consisting of principals and the second of nonprincipals (in the NIS data, all the Adult Sample main-sampled nonprincipals are accompanying spouses). Using sampling weights, $88.6 \%$ of the sample are principals (Table 3).

The equation specification includes the immigrant's age, schooling, and visa characteristics, two childhood variables - childhood religion and parental relative income at age 16 -- as well as visa depression. Interpretation of the estimates differs across subsample. In the subsample of principals, positive coefficients indicate having more information and/or 
overcoming modesty to assert one's true principalhood. In the subsample of nonprincipals, positive coefficients indicate having incorrect information and/or using the me-principal salve. For example, if schooling increases the likelihood of having correct information or promotes telling the truth, then the schooling coefficient should be positive in the principals equation and negative in the nonprincipals equation.

The NIS-2003-1 (again, building on the oral tradition) asked all main sampled respondents (except the 321 who were overseas - see section 2.4 and Appendix Table A.1), "Did you obtain legal permanent residence because you yourself qualified for an immigrant visa, or because you are the accompanying spouse or child of another immigrant? That is, were you the 'principal' immigrant or accompanying the principal immigrant?' Among the true principals, only 78.9 percent responded in the affirmative, while among the nonprincipals, 26.5 percent said yes. Looking at the gender breakdown, men were more likely to declare themselves the principal, whether or not they were $-83.0 \%$ of male principals versus $75.6 \%$ of female principals and $33.3 \%$ of male nonprincipals versus $22.2 \%$ of female nonprincipals.

\subsection{Migration and Stratification: the Me-Principal Assertion}

Table 14 reports binary logit estimates of the me-principal equation, separately for principals and nonprincipals and by gender. As expected from the overall gender percentages, specifications pooled by sex (not shown) indicate that men are statistically significantly more likely to declare themselves the principal, among both principals and nonprincipals (significant beyond the .000 level among principals and beyond the .05 level in the smaller nonprincipals subsample), suggesting a certain male sense of entitlement and/or greater need of a status boost. This male propensity to claim principal status is net of all the other characteristics included in the equation -- net of visa, origin area, and visa depression.

- Table 14 about here -

Visa depression inhibits the me-principal assertion, among both men and women and both principals and nonprincipals, attaining statistical significance in the men nonprincipals equation. Thus, if declaring oneself the principal helps to repair the self, then immigrants who 
have endured visa depression cannot help themselves even in this way. It would seem that visa depression reduces the drive to assert oneself the principal, even among principals.

The two age variables are jointly highly statistically significant in both the sex-specific principals equations and borderline in the men's nonprincipals equation. In these three equations, the parabolas open downward, with peaks at 57 and 30 years among male principals and nonprincipals, respectively, and 79 among female principals. Thus, if, among principals, advancing age attenuates false modesty or increases knowledge, then women are on an unambiguously upward trajectory, while men hit a bound in their late fifties. Among nonprincipals, however, appropriating principal status is a young man's game, peaking early before age thirty - and diminishing thereafter.

Visa class is highly statistically significant in all equations. Among principals of both sexes, the top three categories correctly identifying their principal status are employment and diversity principals and spouses of native-born citizens. These three categories are also associated with some of the highest levels of schooling and English fluency (Table 4). Spouses of U.S. citizens and employment principals must be sufficiently fluent in English to have attracted a sponsor; and, while many employment and all diversity principals have a schooling requirement (albeit one that can be waived given occupational credentials), spouses of nativeborn U.S. citizens reflect Americans' penchant for assortative mating in schooling (Jasso, Massey, Rosenzweig, and Smith 2000).

Meanwhile, the visa classes associated with the lowest probability of correctly identifying principal status are spouses of LPRs, children (age 18-21) of U.S. citizens, husbands of foreignborn U.S. citizens, and mothers of U.S. citizens. Whether these cases reflect lack of information or insufficient understanding of the term "principal" and its translation into the 94 non-English languages used in the New Immigrant Survey, one can only speculate. But it is interesting that they are all family immigrants, that most of the sponsors are foreign-born, and that while some are youthful (those with the child of U.S. citizen visa), others may be quite old (mothers of U.S. citizens). 
Of course, the false modesty and self-effacement mechanism may also be operating; the spouses are all spouses of foreign-born persons, and the mothers and children are for the most part mothers and children of foreign-born persons. These results strongly complement the gender result in the pooled equations, and introduce an element of what may be called the immigration status hierarchy, with low-status persons -- dependent for their new visa on the higher-status naturalized U.S. citizens and previous immigrants -- displaying a reluctance to express their principalhood and making obeisance, as it were, to their status superiors.

The adjustee and adjusting-from-illegality variables are jointly statistically significant in both the sex-specific principals' equations and both the men's equations, thus resembling the age variables. Among principals, the two lowest probabilities of asserting principal status are among the formerly illegal EWI/WI immigrants and the set with a UU/UN code. In contrast, among male nonprincipals, the EWI immigrants are most likely to say they are principals. At first blush, these results appear to be at odds with each other. However, both responses have a powerful element in common. The EWI immigrants have lived for years in the shadows, and as a survival strategy have learned to dissemble and to conceal. Here we find principals reluctant to reveal their principal status and nonprincipals appropriating it. These may be vestigial behaviors, as the formerly illegal emerge from the shadows and start to shed the habits of illegality.

Childhood religion does not reach statistical significance. However, it is interesting that the highest probability of the me-principal assertion among women nonprincipals is found among Jewish and Muslim women; the lowest probabilities are found among Hindu and other-religion women. The Muslim effect is provocative, as it may signal a mechanism for coping with gender inequality.

The coefficients for parental relative family income, though not statistically significant, hint at an interesting pattern. Among principals of both sexes, those from average socioeconomic backgrounds have the highest probability of correctly identifying that they are principals. Among male nonprincipals, the richest are most likely to erroneously claim that they are the principal. 
Finally, schooling does not reach significance in any equation. We also tested for a direct effect of having documents lost, but did not find any. Lost documents, of course, operate through visa depression. The origin area fixed effects are statistically significant in three of the four sexspecific equations and borderline (prob value of .0521) in the men's nonprincipals equation.

More broadly, the gender difference in making the me-principal assertion raises the question whether a similar mechanism may be operating in social surveys - men systematically overstating, women systematically understating, their schooling and earnings -- contributing to the observed gender gap. Either the male or female component of such a mechanism would have far-reaching consequences, as discussed by Ruel and Hauser (2007). It is not often the case that survey data permit comparison of a respondent's real and reported characteristics. The NIS may thus be useful in assessing the broader conjecture.

\section{RACE-ETHNIC COMPOSITION OF NEW IMMIGRANTS} AND THE NEW BLACK IMMIGRATION FROM AFRICA

\subsection{Immigration and the American Race/Ethnic Structure}

A perennial theme in immigration research and policy involves the effects of immigration on the racial and ethnic composition of the United States (Alba and Nee 2003; Bean and Stevens 2003; Jasso and Rosenzweig 1990, 2006; Smith and Edmonston 1997). Indeed, the history of U.S. immigration law can be written from a race-ethnic perspective, with critical junctures - such as the first quantitative restrictions in 1921 and, later, the removal of quotas and racial bars -intimately tied to visions of the ideal racial and ethnic composition of the country.

In the 1970s, as it was becoming clear that the family reunification provisions of the 1965 Immigration Act engendered increased flows of relatives of previous immigrants, a new concern arose in policymaking circles. For persons in countries without a foothold in the immigration stream, there would be little possibility of immigrating to the United States. For example, documents of the U.S. Select Commission on Immigration and Refugee Policy, whose final report was issued in 1981, convey a sense of urgency about opening a new channel for 
"independent" immigration, and the oral tradition suggests that at least part of the concern involved the small numbers of black immigrants from Africa. According to the Staff Report of the Select Commission (1981:455-456),

[I]ndependent immigration would be used by nationals of many African and European countries, as well as by those of some of the currently more prominent countries of immigration. This new channel might, therefore, be expected to open immigration to new or renewed source of immigrants, while both it and the familyreunification category would continue to build on the more recent bases of immigration.

A number of procedures for selecting immigrants in the envisioned open immigration channel were discussed, including an ill-fated point system (Jasso 1988). Eventually, however, the United States established the Diversity Visa Program, making available new visas for blacks and others from Africa. Note that there was no scarcity of black immigrants from the Caribbean; the dearth was of black immigrants from Africa.

However, assessing the race-ethnic composition of cohorts of new legal immigrants - and the success of the diversity lottery program - has not been possible given that the U.S. stopped collecting data on the race and ethnicity of new immigrants in 1961. The New Immigrant Survey, as noted earlier, includes the standard two questions on race and Hispanic origin, and thus enables for the first time since 1961 description of the race-ethnic composition of an immigrant cohort. $^{30}$

30

The Bureau of Immigration began collecting data on "race or people" in 1899. According to the Dillingham Commission Report (U.S. Immigration Commission 1911), "This departure was necessitated by the fact that among immigrants from southern and eastern European countries, as well as from Canada and other sources of immigration, the country of birth does not afford a satisfactory clue to the actual racial or ethnical status of such immigrants" (Vol 3, p. 44). Further, the Dillingham Commission prepared a Dictionary of Races or Peoples (Volume 5), including designations such as "English", "Scandinavian", "African (black)", "French", "Mexican", "Hebrew", "Italian, North", and "Italian, South". Subsequently, the race classification was updated to eight categories - white, Negro, Chinese, East Indian, Filipino, Japanese, Korean, and Pacific Islander. As discussed above, P.L. 87-301 (26 September 1961) 
We focus first on the race-ethnic composition of the cohort and next on black immigrants.

\subsection{Special NIS Data for Race-Ethnic Analysis}

The two standard survey questions on race and Hispanic origin described earlier will receive special attention in this section because of uncertainty surrounding the approximately $7.6 \%$ of respondents who did not answer the race question and who may affect the estimated proportion black. A third piece of data is introduced here, both for its own intrinsic interest as well as to deepen understanding of nonresponse to the race question - the respondent's skin color as coded by the interviewer.

Skin color appears prominently in many discussions of immigration, such as Alba and Nee (2003), Bean and Stevens (2003), and Jensen, Cohen, Toribio, DeJong, and Rodriguez (2006), as well as in more general discussions of the American stratification structure, for example, Anderson (1999), Feagin (1991), Gans (2005), Lacy (2007), and Massey and Denton (1992). The New Immigrant Survey measured respondent skin color on an 11-point scale, ranging from zero to 10 , with zero representing albinism (the total absence of color) and 10 representing the darkest possible skin. The ten shades of skin color corresponding to the points 1 to 10 on the NIS Skin Color Scale are depicted in a chart, with each point represented by a hand, of identical form, but differing in color. The NIS Skin Color Scale is for use by interviewers, who "memorize" the scale, so that respondents never see the chart. [A copy of the Scale appears in the appendix.]

Skin color assessments are available for 4,652 main sampled immigrants $(54.3 \%)$ in the Adult Sample, as follows. First, skin color was not assessed among the 321 overseas respondents (section 2.4 and Appendix Table A.1), although they were asked the Hispanic origin and race questions. Second, skin color was assessed among non-overseas respondents who were interviewed in person. Third, skin color was assessed among non-overseas respondents who had

eliminated the requirement that visa applicants report their race, and thus the Annual Report of the Immigration and Naturalization Service for 1961 was the last to include a tabulation of new immigrants classified by race (Table 10). 
met the interviewer even if the interview was conducted (or completed) by telephone. The data indicate that $29 \%$ (27\% weighted) of the skin color ratings were made for respondents interviewed in person. Respondents interviewed by telephone tend to fall into two main groups, those who requested an interview language in which a fluent interviewer or interpreter was not available on site, and those who requested a telephone interview (for their convenience or for privacy, etc.).

Interviewers may have systematically seen respondents of differing skin color (given the link between skin color and interview language), or, alternatively, they may perceive skin color differently. Thus, although the data provide interviewer ID codes and it is straightforward to control for threshold effects by incorporating interviewer fixed effects in estimation, it is not clear whether the color scale should be corrected for interviewer effects. Further work on this question is warranted, including calibration and physical measurements in future rounds of the NIS. Moreover, analysts can test for the possibility that skin color perception differs with duration of exposure by including a binary variable for the mode of the interview.

An additional point is worth noting. A few months after the start of fieldwork NIS survey managers became concerned that interviewers were using too many "zeroes," which were to be reserved for albinism, and issued a memorandum to all staff on this matter; accordingly, analysts can test for effects of the memorandum by including a binary variable for whether the interview took place before or after the date of the memorandum.

In the work reported below, we distinguish between the "raw" interviewer ratings and "corrected" ratings obtained by regressing the raw rating on the date and mode binary variables and the interviewer fixed effects.

In this section we also use the behavioral measure of English fluency shown in Table 4. This binary measure is coded " 1 " if the respondent chose to be interviewed in English and, further, did not use any other language during the interview. This is a stringent measure, one that 
indicates sufficient fluency in English to sustain a long and elaborate interview. ${ }^{31}$

We also introduce childhood language and origin-country official language in this section. The New Immigrant Survey asked the main sampled adult respondents (except the 321 overseas respondents) the question, "What languages did you speak in your home with your parents when you were age 10?" We coded the responses into six categories. The categories and their proportions among the main sampled immigrants are: English only, 6.99\%; Spanish only, 35\%; English and Spanish, 1.34\%; English and a language other than Spanish, 5.46\%; Spanish and a language other than English, 1.01\%; English, Spanish, and another language, .20\%; and other, $49.7 \%$. Data are missing for $.32 \%$.

We constructed a binary variable indicating whether English is an official or dominant language of the country of birth. Approximately $25.4 \%$ of the sample come from a country where English is an official or dominant language.

\subsection{Race, Hispanic Origin, and Skin Color in the 2003 Immigrant Cohort}

Table 15 reports the race-ethnic composition for the immigrant cohort, together with the corresponding figures for the U.S. population in 2003. The racial composition of the two populations differs in two main ways: First, the proportion white among new immigrants is dramatically lower than in the U.S. population as a whole $-48 \%$ versus $81 \%$. Second, the proportion Asian among new immigrants is, again, dramatically higher than in the total U.S. population $-29 \%$ versus $4.1 \%$. The proportion black in the immigrant cohort is $11.2 \%$, or about $1.5 \%$ less than the proportion black in the resident population, but, given that a nontrivial proportion of new immigrants did not report their race $-7.6 \%$ - the true proportion black in the immigrant cohort may be the same or even higher than among residents. ${ }^{32}$

- Table 15 about here -

31 Some respondents initially chose one language and then went to another language; such respondents are not coded " 1 " on this measure.

32 In 1961, the last year for which the Annual Reports of the Immigration and Naturalization Service provided information on race, the proportion black was 3.04 percent (Table 10). 
With respect to Hispanic origin, the figures in Table 15 are no surprise. The proportion of new immigrants reporting Hispanic origin is almost 3 times as large as among the total population $-38.1 \%$ versus $13.7 \%$. Among respondents reporting themselves as Hispanic, $75 \%$ report themselves as white - substantially more than the $50 \%$ in the general population (Alba and Nee 2003:9). Further, and more to our purpose in this section, 14.8\% of the self-reported Hispanics did not report their race.

Nonresponders to the NIS race question included a large majority who reported themselves as Hispanic (74\%). A closer look at the source data indicate that the top four origin countries of race nonresponders, which together comprise two-thirds of the nonresponders -Mexico (40.3\%), El Salvador (13.1\%), Dominican Republic (7.92\%), and Guatemala (5.28\%) are countries whose immigrants overwhelmingly report themselves as Hispanic (over 97\% in every case). Within these four countries, the proportion who did not respond to the race question hovered around $16-17 \%$ in three of them (Mexico, El Salvador, and Guatemala), but registered a larger 26.5\% for the Dominican Republic, suggesting that these two subsets may differ in pertinent ways. A natural question is whether the nonresponders resemble the responders. Among those who did report a race, while the proportion black did not reach even half of one percent for Mexico, El Salvador, and Guatemala, for the Dominican Republic the figures are $6.85 \%$ black alone and $12.3 \%$ black and another race, for a total of 19.1 percent. Thus, if nonresponders resemble responders, then some of the nonresponders in the Dominican Republic are black, thereby increasing the overall proportion black.

We next examine the interviewer-coded skin color by nonresponse on the race question. In all four countries, average skin color is darker among nonresponders than among responders; however, the magnitude of the discrepancy is small in all cases except that of the Dominican Republic, where the difference is over one unit on the 11-point scale.

These results suggest, first, that the proportion black among the new immigrants may indeed be higher than our estimate (11.2\%) - and perhaps even higher than the proportion black in the U.S. population (12.7\%), and, second, that among black immigrants, the relative size of the 
subset born in the Americas may be larger than our estimate below (47.2\%).

These results also suggest that some immigrants who see themselves as Hispanic are reluctant to assign themselves one (or more) of the five races - though at $15 \%$ substantially fewer than the $40 \%$ who chose the "some other race" option provided in the 2000 Census (Tienda and Mitchell 2006) - and that, consistent with Waters (1990, 1999), Hispanic immigrants from the Dominican Republic are especially reluctant to do so, as are those of darker skin color. As Tienda and Mitchell (2006:44) suggest, some Hispanics may not find any of the five official races a good fit.

It is also interesting that few respondents from Latin America choose both white and American Indian races, notwithstanding the history and explicit ideology of mestizaje (Villarreal 2010). On the other hand, the question wording may inhibit selection of the American Indian response option: "A person having origins in any of the original peoples of North, Central, or South America, and who maintains tribal affiliation or community attachment." The first clause would be satisfied by much larger numbers than the second clause. It is interesting to speculate how changes in the wording of the race question - to highlight ancestry rather than identity or political affiliation - would affect response. 33

Table 16 reports average skin color for the race and Hispanic origin groups. Raw figures are based directly on the interviewer assessments. Corrected figures are based on regressions including the interviewer fixed-effects and the date and interview mode dummies. The raw and corrected estimates differ not only in magnitude but also in the relative orderings, although in both estimates the white group is the lightest and the black group the darkest. As already noted, average skin color is darker for groups that did not report a race - contrast the three subsets which did not report race (bottom rows in the top panel) with the entire relevant groups (bottom panel). For example, average skin color among all persons who reported that they are not of

33 In the era when race mattered for immigration and naturalization a major concern had been how to define "white". Smith (2002) describes, for example, an INS circular in 1937 stipulating that for purposes of immigration and naturalization Mexicans were considered white. 
Hispanic origin is lighter than among the subset who reported that they are not of Hispanic origin but did not report a race (4.11 versus 4.49 in the raw score and 4.21 versus 4.53 in the corrected score). The effect of skin color on the propensity to assign oneself one (or more) of the five races clearly warrants further research.

- Table 16 about here -

\subsection{Black Immigrants}

An important theme in recent American history is the increasing diversity within the black population. At first the critical dimension of diversity appeared to be foreign birth, with most foreign-born blacks originating in Caribbean countries such as Jamaica and Haiti. Thus, there seemed to be "two kinds" of blacks in the United States, those whose ancestors had been forcibly brought to the United States as slaves and those who freely immigrated. But soon another dimension emerged -- the origin continent of black immigrants.

Though the history of the Diversity Visa Program is yet to be written, a lively oral tradition suggests that at least some of the impetus for the diversity lottery program came from policymakers holding dear the vision of an American people drawn from every corner of the globe and noticing the dearth of immigrants from Africa. Whatever its roots, there is little doubt that the Diversity Visa Program has substantially increased the flow of immigrants from Africa. In the period 2001-2009, the proportion Africa-born of all diversity-visa admissions to legal permanent residence ranged from $35.2 \%$ in 2005 to $50.4 \%$ in 2009 (U.S. INS and U.S. DHS, Yearbook of Immigration Statistics, 2001-2009). ${ }^{34}$

The growing view is that there are "three kinds" of blacks in the United States today: (1) descendants of slaves (who also, importantly, endured the Jim Crow era - 1876-1965); (2) immigrants from the Americas and their descendants; and (3) voluntary immigrants from Africa and their descendants. Scholarly interest is increasing in understanding heterogeneity among blacks in the United States (Corra 2005; Elo, Mehta, and Huang 2011; Massey, Mooney, Torres,

34 Official government figures on LPRs do not provide information on race. For information about black diversity-based LPRs, we rely on NIS data. 
and Charles 2007; Portes and Rumbaut 1990).

A priori one would expect that new immigrants from Africa would be more highly selfselected and thus more highly skilled than new immigrants from the Americas. There are at least three mechanisms driving this conjecture, the first two related to the costs of migration, the third to U.S. visa allocation policy (described in section 2 above). The first mechanism pertains to the fact that Africa is more distant, and thus the costs of migration are higher. The second pertains to the fact that the African flow is a flow of pioneer immigrants, for whom the costs are higher than for Caribbean immigrants whose co-nationals have already established a beachhead and with whom they are already embedded in networks. The third mechanism highlights visa requirements - diversity visas and (most of the) visas for skilled immigrants have a schooling requirement, so that pioneer immigrants are likely to be more highly schooled than family reunification immigrants. The available data support this conjecture: Black foreign-born from Africa are indeed more skilled and earn more than black foreign-born from the Americas (Massey et al. 2007; Portes and Rumbaut 1990).

The New Immigrant Survey can shed light on the new black immigration, and in this section we provide the first quantitative description of a representative sample of a recent cohort of new legal immigrants. Future work should undertake systematic comparisons with the nativeborn, a task beyond the scope of the present paper.

Among the main sampled adult immigrants, $11.6 \%$ reported that they are black, inclusive of mixed-race origin (a total of 1,107 immigrants). Within this set, those reporting nonHispanic origin constitute $10.8 \%$ of the sample, while blacks of Hispanic origin are about $.77 \%$ of the sample. Over half of the black immigrants -- 51.4\% -- come from African countries, 47.2\% from the Americas, and $1.45 \%$ from the rest of the world. ${ }^{35}$

35 We refer to black immigrants born in the Western Hemisphere but outside the United States collectively as born in the "Americas". In this paper there is little danger of confusing them with U.S.-born blacks, given that the sample is a sample of immigrants (and this section focuses on the immigrants only, ignoring their possibly U.S.-born spouses). Nonetheless, it would be useful to find another term with less potential for confusion. Note that "Caribbean" is not a good term, as the Americas-born contingent of black immigrants includes immigrants born 
Among the 1,107 black immigrants, 1,079 cases reported only a black race and 28 reported two or more races. Because the mixed-race immigrants are too few for reliable analysis, we eliminate them from the analyses in this section. Among the black-only immigrants, $52.7 \%$ are from Africa, $45.8 \%$ from the Americas, and 1.5\% from the rest of the world.

The black-only immigrants from outside Africa and the Americas number only 14, and thus, for the rest of this section, analysis is restricted to the Africa and Americas immigrants. The final sample of immigrants who reported being black only and who come from Africa or the Western Hemisphere totals 1,065. In this final black sample, 53.5\% are from Africa and 46.5\% from the Americas.

The two top African origin countries are Nigeria (13\%) and Ethiopia (11.3\%), and the two top Western Hemisphere origin countries are Haiti (17.8\%) and Jamaica (14.5\%).

Table 17 reports the main characteristics of the black-only immigrants, separately by origin area. As expected, the two immigration streams differ in important ways. The Americas stream is more established, and hence the proportion of immigrants with family visas is substantially larger - approximately $56.5 \%$ versus $15.9 \%$, not counting spouses of U.S. citizens, and $87.6 \%$ versus $40.4 \%$, including spouses. Indeed, the Americas stream is so well-established and robust that the two top countries, Haiti and Jamaica, are not even eligible for diversity visas, and neither is the Dominican Republic; the proportion of Americas-born blacks with lottery visas is a negligible tenth of one percent. In contrast, $40 \%$ of the Africa-born blacks achieved LPR with diversity visas, consistent with one of the original driving ideas behind the lottery program. Moreover, the proportion with employment visas is negligible in both streams $(1 \%$ among the Africa-born and 1.7\% among the Americas-born). Finally, the proportion with refugee/asylee/parolee visas is almost twice as large among the Africa-born, reflecting their origin-country experiences - over three times as many Africa-born as Americas-born suffered harm before coming to the United States.

in many non-Caribbean countries of the Western Hemisphere, such as Canada (in North America), El Salvador (in Central America), and Peru (in South America). 
- Table 17 about here -

Table 18 reports previous illegal experience in the black sample, paralleling the estimates for the whole sample in Table 6. The proportion with previous illegal experience is larger among the Americas-born than among the Africa-born (5.18\% versus 3.04\% in the lower-bound estimate and $40.9 \%$ versus $15.7 \%$ in the largest estimate obtained when all components from the administrative record as well as the survey measures are included (section 2).

- Table 18 about here -

Almost every characteristic listed in Tables 17 and 18 merits sustained scrutiny. In this paper, however, we focus on two important indicators of skill and of potential for social and economic incorporation (Alba and Nee 2003; Bean and Stevens 2003; Jasso and Rosenzweig 1990, 2006; Portes and Rumbaut 2006) -- schooling and English fluency, the latter manifested in choosing to be interviewed in English and completing the entire interview exclusively in English. The Africa-born immigrants have completed on average two more years of schooling than the Americas-born, even though the Americas-born are older by almost four years, on average. The Africa-born were interviewed in English at a rate over ten percentage points larger than the Americas-born, mirroring the larger percentage born in a country where English is an official or dominant language, although a substantially larger fraction of the Americas-born spoke English as a child (over nine times as many Americas-born blacks as Africa-born blacks spoke English only at age 10, and about twice as many spoke at least some English at age 10). Below we test for differences in schooling and English fluency between the Africa-born and the Americas-born in multivariate models.

Finally, both the raw and corrected skin color scores indicate that the Africa-born are darker, on average, than the Americas-born, although the magnitude of the differential does not reach even one unit on the skin-color scale (.65 on the raw scale and .27 on the corrected scale). If, across other immigrant cohorts, the Africa-born blacks indeed are darker - and also more accomplished than the Americas-born blacks -- then the usual skin color correlations would be overturned. Such patterns could be monumental for many aspects of the future of the United 
States. They could lay siege to stereotypes linking skin color to educational attainment and productivity, possibly even hastening racial integration.

\subsection{The Determinants of Schooling and English Fluency among Black Immigrants}

Table 19 reports OLS estimates of the schooling equation and binary logit estimates of the English fluency equation. In the pooled equations (not shown), women have less schooling than men (with statistical significance beyond .003) and they are less likely to be fluent in English (with statistical significance beyond .023). The big story, however, pertains to the different streams of black immigrants from Africa and from the Americas.

- Table 19 about here -

Table 19 confirms that, net of age, and the visa, adjustee, and previous illegal experience variables, black immigrants born in Africa have statistically significantly higher educational attainment than those born in the Americas - on average, 2.4 years more among men and 1.3 years more among women. Similarly, the Africa-born have a statistically significantly higher probability of being fluent in English than the Americas-born. This is net of coming from a country in which English is an official language and net of knowledge of English in childhood, which have their own substantial and highly statistically significant effects.

Thus, the Africa-born immigrants appear to be more intensely positively self-selected than the Americas-born, consistent with the recency of the immigration streams and the longer distance to the United States.

\subsection{Black Immigration and the Attack on American Apartheid}

The infusion of highly accomplished black immigrants threatens the very foundation of the racial stereotypes and racial hierarchies christened "American Apartheid" by Massey and Denton (1992). Such flows of highly accomplished black immigrants would erode "whites' assumptions about the social meanings attached to skin color" (Alba and Nee 2003:291). Among new immigrants, it is clearly the case that black immigrants from Africa have higher schooling and black immigrants from both Africa and the Americas have higher English fluency than the rest of the cohort. Average schooling completed is 11.9 years in the rest of the cohort, relative to 
13.1 among the Africa-born and 11.2 among the Americas-born (Table 17). The proportion interviewed exclusively in English is 37.5\% among nonblacks, versus $75.9 \%$ among Africa-born blacks and 65\% among Americas-born blacks (Table 17). If black immigrants are compared to nonHispanic white immigrants, they lose top rank in schooling (nonHispanic whites average 14.1 years of schooling) but retain it in English fluency (57.2\% of nonHispanic whites were interviewed exclusively in English).

Thus, racial differences are attenuated among immigrants, and infusions of immigrants may, depending on relative numbers and schooling averages, overturn the racial hierarchy in the United States.

Meanwhile, it is illuminating to also consider the association between skin color and the schooling and language outcomes. Black immigrants are darker than all other immigrants (Table 16), and thus it can be said that among immigrants, the darkest ones are among the most accomplished. What about the contrast between the two streams of immigrants? The evidence is not conclusive. As shown in Table 17, average skin color is indeed darker among the Africaborn; however, the discrepancy is small in the corrected measure. If future rounds of the NIS obtain physical measurements of skin color or use calibration procedures, it will be possible to definitively contrast the skin color of the Africa-born and the Americas-born. If even within the set of black immigrants, the darker are the more accomplished, the foundation for a stratification system based on skin color would be shattered. ${ }^{36}$

It is widely thought -- building on Goffman's (1963) analysis of stigma -- that an entrenched and persistent "black stigma" (Feagin 1991) or "racial stigma" (Loury 2003) operates to eclipse the accomplishments of U.S. blacks, leaving visible only the negative stereotypes and images of a less productive minority of the U.S. black population. Note that black immigrants,

36 The possibility of overturning the associations of race and color with skills can be traced to the Diversity Visa Program and thus has a precarious foundation, for almost every year the United States considers legislation which would eliminate the lottery program. In the NIS 2003 cohort, which is the only data source with information on the race of new legal immigrants, the category of diversity principals has the highest percentage black $-33 \%$. 
especially those from Africa, could join accomplished native U.S. blacks to achieve a surpassing critical mass that would, in Gans' (1999:381) evocative words, “disturb white America's long association of poverty with blackness," generating new and positive stereotypes and images and bringing to life the brightest of Gans' (1999:381) scenarios for the future of race in America.

Interestingly, and perhaps ironically, it is immigration, which has sometimes been blamed for the lack of more rapid progress among American blacks, that may prove to be the avenging angel that obliterates the color line - which dominated the twentieth century, as predicted by DuBois (1903) - and catapults the American black population onto the overworld. Indeed, in such a future there would no longer be white Americans or black Americans but only Americans with a variety of ancestral histories.

Finally, it is illuminating to consider that the current President of the United States exemplifies the variety of ancestral histories - with a white American mother and a black African father - and has been joyously embraced by both white and black Americans. Further, with every passing generation, the within-individual variety of ancestral histories increases.

\section{SKIN COLOR AND SPOUSE SELECTION}

\section{AMONG U.S. CITIZEN SPONSORS OF IMMIGRANT SPOUSES}

Two icons with roots in the American Midwest illuminate this discussion - Marion Robert Morrison (1907-1979), better known as John Wayne, and Stanley Ann Dunham (19421995), better known as the mother of the $44^{\text {th }}$ President of the United States, but an accomplished anthropologist in her own right. Between them they had three wives - one born in the United States to parents from Spain, the others born in Mexico and Peru - and two husbands - born in Kenya and Indonesia. ${ }^{37}$

\subsection{Spouse Choice by Sponsor Gender and Nativity}

As we have seen and as discussed in the literature (Alba and Nee 2003; Bean and Stevens

37 Even their first names are evocative of profound questions in social stratification. 
2003; Jasso and Rosenzweig 1990), immigration is increasing diversity in the U.S. population by introducing substantial contingents of Asian and Hispanic immigrants. Moreover, as discussed above, immigration threatens to overturn racial and skin color associations with skill by introducing accomplished black immigrants from Africa. We turn now to assess skin color and diversity in a more intimate arena, namely, within the married couples formed by U.S. citizen sponsors and their immigrant spouses. Note the crucial distinction between population diversity and within-couple diversity. Within-couple diversity would reflect the diminishing importance of skin color in spouse selection and thus in the broader society as well (Qian and Lichter 2007). 38

As noted in section 2, approximately a third of adults granted legal permanent residence every year are admitted as the spouses of U.S. citizens. In the NIS-2003, that figure is $34.1 \%$ (1,427 immigrants); approximately $16.2 \%$ are sponsored by native-born U.S. citizens and $17.9 \%$ by previous immigrants who have naturalized (Table 4). Within the set of spouses of U.S. citizens in the NIS-2003, a majority are sponsored by naturalized citizens ( $52.6 \%$ versus $47.4 \%$ ), and, similarly, a majority are sponsored by men (62.9\% versus $37.1 \%)$. The breakdown by sponsor gender-nativity is: NB men, $28.3 \%$; NB women, $19.2 \%$; FB men, $34.7 \%$; and $\mathrm{FB}$ women, $17.9 \%{ }^{39}$

By far the favorite place where U.S. citizens find mates is Mexico -- $24.1 \%$ and $24 \%$ in the sets sponsored by native-born and foreign-born, respectively. The second-place countries are the Philippines for native-born U.S. citizens (4.62\%) and India for foreign-born U.S. citizens $(6.05 \%)$. Patterns of spouse selection tend to differ for the naturalized and the native-born who

38

It should also be noted that immigration of adopted children of U.S. citizens is increasing within-family racial diversity and thus reducing social distance between the races. For example, in FY 2009, 46.9\% of adopted child immigrants were from Asia and $21.3 \%$ from Africa (U.S. DHS, 2009 Yearbook, Table 12).

39 The nativity differential in sponsorship is itself an interesting topic of study, but outside the scope of this paper. There appears to be a downward trend in the proportion nativeborn among the U.S. citizen sponsors of spouses, from 80 percent in 1985 (Jasso and Rosenzweig 1989, 1990) to 55 percent in 1996 (Jasso and Rosenzweig 2006) to 47 percent in 2003. 
sponsor spouses, and thus only two countries are in the top five in both sets (Mexico and the Philippines). For example, countries with a substantial U.S. military presence tend to provide spouses for native-born U.S. citizens (Jasso and Rosenzweig 1989:876-880, 1990:166-171; Bean and Stevens 2003:197-198).

A majority of the Mexico-born contingent of spouses are women sponsored by U.S. citizen men (55.3\%). While there are roughly equal proportions of Mexico-born immigrant men sponsored by native-born and foreign-born U.S. citizens $-22.7 \%$ and $21.9 \%$, respectively - the nativity breakdown differs among the U.S. citizen male sponsors of Mexico-born immigrant women $-30.5 \%$ foreign-born versus $24.8 \%$ native-born.

The question thus arises whether there is a skin color difference between the sponsors and their immigrant spouses and whether such a difference varies by sponsor nativity and gender. In the analyses that follow we distinguish between four kinds of married couples, formed by eight kinds of persons. The four types of married couples are formed by gender and nativity: (1) native-born U.S. citizen women and their immigrant husbands; (2) native-born U.S. citizen men and their immigrant wives; (3) foreign-born U.S. citizen women and their immigrant husbands; and (4) foreign-born U.S. citizen men and their immigrant wives.

Here our focus is on skin-color diversity, but we note that future research on these four types of married couples may prove useful in assessing patterns of immigrant incorporation, building on the insights that marital sponsorship provides a superior immigrant screening mechanism because spouses screen for long-term economic success rather than for a specific job (Jasso and Rosenzweig 1995) and that intermarriage by nativity is "the litmus test of assimilation" (Alba and Nee 2003:90) and promotes "quicker social integration" (Bean and Stevens 2003:176).

\subsection{Special NIS Data for Studying Marriage and Diversity}

To examine skin color patterns in these couples we use the skin color scale introduced in Section 6 and we construct two new variables to measure marital skin color difference. The first measure, applicable to spouses sponsored by U.S. citizens and LPRs, is defined as the 
immigrant's skin color minus the sponsor's skin color. This measure equals zero if both spouses have identical scores on the skin color scale; it is positive if the immigrant is darker than the sponsor, and negative if the immigrant is lighter than the sponsor. The second measure, applicable to all married couples, is defined as the husband's skin color minus the wife's skin color. This measure equals zero if both spouses have identical scores on the skin color scale; it is positive if the husband is darker than the wife, and negative if the husband is lighter than the wife. The second measure enables direct examination of the longstanding insight that within all human groups or populations, men are slightly darker than women (van den Berghe and Frost 1986; Jablonski 2004; Jablonski and Chaplin 2000).

The NIS data include 536 spouse-of-U.S.-citizen couples with skin color scores for both spouses. The breakdown by sponsor gender-nativity is: NB men, 24.3\%; NB women, 19.4\%; FB men, 36.3\%; and FB women, 19.9\%. Within this set, approximately 96\% (514 couples) were interviewed by the same interviewer. Thus, under the assumption that interviewer effects, if any, are mainly threshold effects, we use the raw scores as the underlying measure for the new skincolor difference variable. ${ }^{40}$

\subsection{Skin-Color Patterns Among Married Couples Formed by}

\section{U.S. Citizen Sponsors and Their Immigrant Spouses}

To begin, we examine the eight skin-color distributions among gender-nativity subsets of sponsors and their immigrant spouses. For each of the eight pairs formed by these eight distributions (such as the pair formed by native-born U.S. citizen sponsor women and foreignborn U.S. citizen sponsor women), as well as for each of the four pairs formed by the pooled distributions (such as the pair formed by all foreign-born sponsors and all native-born sponsors), we use the Kolmogorov-Smirnov test to test the hypothesis that both distributions in the pair are drawn from the same underlying distribution. Proceeding in this way, we establish that sponsor

40 Of the 1,427 immigrant spouses, skin color was assessed in 803 (see Section 6.2); of the sponsor-spouses residing in the household who agreed to be interviewed, skin color was assessed in 604. 
skin color differs by nativity but not by gender, while immigrant skin color differs by gender but not by sponsor nativity. These results (not shown) are strong and hold in all comparisons. For example, the result that sponsor skin color differs by nativity emerges in three tests: (1) between all native-born sponsors and all foreign-born sponsors $(\mathrm{K}-\mathrm{S}=.249, p=.000)$; (2) between male native-born sponsors and male foreign-born sponsors $(\mathrm{K}-\mathrm{S}=.285, p=.000)$; and (3) between female native-born sponsors and female foreign-born sponsors $(\mathrm{K}-\mathrm{S}=.234, p=.003)$.

Table 20 reports the means and standard deviations of skin color in the eight personal skin-color distributions. As expected from the Kolmogorov-Smirnov tests, which also provide directional information, foreign-born sponsors are darker than native-born sponsors, by approximately one point on the skin color scale, on average (3.92 versus 2.93 among men and 3.95 versus 3.04 among women). However, within nativity subset, male and female sponsors have similar skin color, on average (2.93 and 3.04 among the native-born and 3.92 and 3.95 among the foreign-born).

- Table 20 about here -

Meanwhile, again as expected from the Kolmogorov-Smirnov tests, female immigrants are lighter than male immigrants, on average (3.58 versus 4.60 among those married to nativeborn sponsors and 3.65 versus 4.22 among those married to foreign-born sponsors). However, within gender subset, immigrants married to native-born and foreign-born sponsors have similar skin color, on average (4.60 and 4.22 among males and 3.58 and 3.65 among females).

Figure 4 provides visual representation of these patterns, presenting the quantile functions for the eight distributions, grouped, as in Table 20, by the sponsor's gender and nativity characteristics. The sponsor distributions are represented by a connected line, and the immigrant distributions by an unconnected line. For any percentage rank, the higher the observation the darker the person. As just discussed, the sponsor distributions are very similar within nativity (in panels $\mathrm{A}$ and $\mathrm{B}$ for native-born and in panels $\mathrm{C}$ and $\mathrm{D}$ for foreign-born), while the immigrant distributions are very similar within gender (in panels $\mathrm{A}$ and $\mathrm{C}$ for men and in panels $\mathrm{B}$ and $\mathrm{D}$ for women). 
- Figure 4 about here -

The more striking feature in Table 20 and Figure 4, however, pertains to skin-color difference and, in particular, the skin-color difference in couples with a native-born female sponsor (panel A). As reported in Table 20, the average skin-color difference is positive in three subsets of the couples (the exception being couples with a foreign-born male sponsor), but the magnitude of the skin-color difference is larger by far in the subset with a native-born female sponsor. Thus, native-born American women appear to be marrying spouses who are on average darker by a point-and-a-half on the skin-color scale.

For a closer look, we report in Table 21 the proportions of sponsors in each of the four married-couple sets who are marrying someone lighter, marrying someone of the same skin color, and marrying someone darker. As shown, the proportion marrying darker lines up exactly as the average skin-color difference, led by native-born U.S. citizen women (64.3\%), followed by native-born U.S. citizen men (44.8\%) and foreign-born U.S. citizen women (36.7\%), and ending with foreign-born U.S. citizen men (15.6\%). The proportion marrying lighter lines up in exactly the opposite way.

- Table 21 about here -

Recall now that in groups around the world men are a little darker than women (van den Berghe and Frost 1986; Jablonski 2004; Jablonski and Chaplin 2000). Accordingly, it is no surprise that husbands are darker than wives in three of the four subsets. What is worthy of note is that the magnitude of the difference is larger when the sponsor is a native-born U.S. woman. Further, what is also worthy of note is that native-born U.S. citizen husbands are lighter than their wives. Thus, there is an unambiguous nativity effect in skin color difference between husbands and wives.

As an initial attempt to quantify the nativity effect, we take the difference-in-differences (DD). Among women sponsors, the DD is 1.3 (1.57 minus .269); among men sponsors, the DD is -.918 (.651 minus -.267). Thus, the net amount by which native-born women marry darker is 1.3 units on the skin color scale, and the net amount by which native-born men marry lighter is 
.92 on the scale.

From a stratification perspective, it would appear that native-born U.S. citizens, and especially women, are leading the charge against colorism in this most intimate of spheres. They are pushing the boundaries of skin-color difference within marriage.

\subsection{Multivariate Results on Marriage and Skin-Color Diversity}

To examine the robustness of the patterns just discussed, we estimate regressions of skincolor difference on sponsor characteristics, including age, race, and Hispanic origin, and on the immigrant's birth area, separately by gender, and also both in the full sample and the subsample in which both spouses had the same interviewer. As shown in Table 22, multivariate analysis supports the early results. Native-born U.S. citizen women marry darker than foreign-born U.S. citizen women, and native-born U.S. citizen men similarly marry darker than foreign-born U.S. citizen men.

\section{- Table 22 about here -}

Sponsor's age and age-squared are jointly statistically significant only in the women's equations, and they indicate that the propensity to marry darker increases until about age 38 and subsequently declines. This result is consistent with an interpretation in which reaching out across the color line peaked for native-born U.S. citizen women born in 1965 - at the height of the civil rights movement - suggesting integrationist parental influences during the formative years.

The race-ethnicity regressors are jointly statistically significant, with nonHispanic whites marrying darkest. Immigrant birth area is also statistically significant. Skin-color difference is greatest when the immigrant hails from the Philippines, Africa, and Colombia (among female sponsors) and from the Dominican Republic, Oceania, and Haiti (among male sponsors).

\subsection{Spouse-of-U.S.-Citizen Couples Contrasted with Other Married Couples}

Within-couple diversity is clearly not trivial among couples involving a native-born U.S. citizen sponsor of a spouse, especially if the sponsor is female. But how different are these couples from the other couples in the 2003 immigrant cohort? To address this question, Table 23 
reports the skin-color difference measured as husband's skin color minus wife's skin color, for all the visa classes except those designated for unmarried persons (children of U.S. citizens, family first preference for unmarried sons and daughters of U.S. citizens, and the subset of family second preference for unmarried sons and daughters of LPRs).

- Table 23 about here -

If respondents marry within their ancestral group, all the skin color differences in Table 23 would be positive - that is, husbands would be darker than their wives. The averages in Table 23 would cluster around some small positive number. Of course, it is possible that this "natural" gender difference in skin color may differ across ancestral group, such that the skin color difference between husbands and wives would be larger in some ancestral groups than in others. To the extent that visa categories differ in their origin-country composition, the natural skin color difference would vary across visa categories. Moreover, our ability to discern this natural skin color difference depends on interviewer behavior. That is, it depends on interviewers coding the skin color they see and not mentally adjusting for the sex difference and assigning husbands and wives with similar origins the same skin color score.

Skin color differences larger than the natural difference indicate that husbands are darker than expected (or, equivalently, wives lighter), and skin color differences smaller than the natural difference indicate that husbands are lighter than expected (or, equivalently, wives darker). Even if the natural difference is unknown, negative magnitudes indicate that husbands are lighter than expected (or, equivalently, wives darker). As shown, the two extreme skin color differences in Table 23 remain those involving native-born U.S. citizen sponsors of spouses, namely, 1.566 among women sponsors and -.651 among men sponsors. There are three other negative differences, among marriages involving women legalization principals and wives of employment and refugee/asylee/parolee principals. These skin color data can thus be used to explore variation in the gender difference in skin color across ancestral groupings, using NIS information on country of birth, religion, and language - and, of course, to distinguish the natural difference from skin color difference induced by intermarriage across ancestral groupings. 
The information in Table 23 can also be used as a springboard to explore the characteristics of the missing spouses - that is, spouses who refused to be interviewed - of main sampled immigrants in the subset of visa categories in which visas are available for accompanying spouses of principals. To see this, recall that the main sampled immigrants include both immigrants who received visas as principals and immigrants who received visas as accompanying spouses (Table 3). Accordingly, for each of the visa categories which permit accompanying spouses, NIS data have information based on two subsets: (1) sampled-immigrant principal and spouse, and (2) sampled-immigrant spouse and spouse-principal. Average skin color difference should be the same in both subsets. Under the assumption that the decision by main sampled immigrants to participate is unrelated to skin color, any discrepancy in average skin color difference across the two subsets indicates missing spouses with the missingness related to skin color. Note that the converse does not hold. If the two subsets have equal average skin color difference, they could still have missing spouses, but in this case, the missing spouses would be complementary with respect to skin color.

To illustrate, consider immigrant couples in which the main sampled immigrant is a married son of a U.S. citizen (that is, a male obtaining LPR as a principal in the married-child-ofU.S.-citizen visa category); his wife agreed to be interviewed, and both spouses received a skin color score. As shown in Table 23, in such couples the average skin color difference is .315 . Under the assumption that the decision to participate in the survey is unrelated to skin color among both sons and daughters-in-law drawn as main sampled immigrants, these couples' skin color difference should be the same, except for sampling fluctuation, as that among couples in which the main sampled immigrant is the daughter-in-law of a U.S. citizen (that is, the wife of a principal in the married-child-of-U.S.-citizen visa category). And, indeed, average skin color difference is almost the same - viz., .273 for the second subset.

These subsets of couples can be visually discerned as they occupy "diagonals" on Table 23. To continue the illustration, consider now immigrant couples in which the main sampled immigrant is the married daughter of a U.S. citizen (that is, a female obtaining LPR as a principal 
in the married-child-of-U.S.-citizen visa category). The skin color difference in such couples is .363. However, the skin color difference in the second subset - couples in which the main sampled immigrant is the son-in-law of a U.S. citizen (that is, husband of a principal in the visa category) - is .0527 . The discrepancy between .363 and .0527 suggests that one or both of the two subsets has missing spouses. If the true natural skin color difference in this visa category is .363 , then the observed skin color difference of .0527 in the subset with the husband main sampled immigrant is too low, indicating that the missing wives are lighter skinned. But if the true natural skin color difference is .0527 , then the observed skin color difference of .363 in the subset with the wife main sampled immigrant is too high, indicating that the missing husbands are lighter skinned.

It is outside the scope of this paper to analyze the skin color of the missing spouses, but it is evident both that NIS data can shed light and that this information can be used to shed light on other behavioral patterns observed in the data.

As a final way of assessing contributors to skin color diversity among married couples, we obtain the absolute skin-color differences, ignoring any directionality by sponsor or by marital partner. These figures (not shown) indicate that the three largest average absolute differences are among native-born citizens who sponsor spouses (2.014 and 1.28, among female and male sponsors, respectively) and legalization principals (1.279). The potentially exemplary character of native-born U.S. citizen women, who are marrying darker, remains unchallenged. It is noteworthy that the current American President's native-born white mother was in the vanguard, marrying a black from Africa.

Of course, much further research is warranted, including a deeper look at spouse selection among both native-born and foreign-born U.S. citizens, relations between the spouses, effects on gender inequality, and, as future rounds of the NIS accumulate, the unfolding of marital cohesiveness and disruption. 


\section{ENGLISH SKILL AMONG YOUNG CHILDREN \\ AND THEIR IMMIGRANT PARENTS}

\subsection{Learning a New Language}

Perhaps no single characteristic is as emblematic of both the life chances of immigrants and their children and the reactions of natives as English fluency (Alba and Nee 2003; Bean and Stevens 2003; Jasso and Rosenzweig 1990; Portes and Rumbaut 2006; Rumbaut, Massey, and Bean 2006). Yet for adults, learning English can be difficult, especially if first encountered after adolescence, if there is little time left after work, and if there are few English-class options. Moreover, immigrants who have spent time as illegals may experience even more difficulty learning English, given that perhaps the safest way to avoid detection may be to blend in with conationals.

Meanwhile, however, the children of immigrants quickly find English in their environment. Even when parents know no English or, even if they know English, decide to use only their first language at home - so that the children can master the origin language, while hopefully also mastering English in school - their children, once they are in school, face an environment rich in English resources. Mass media, labels on food at the grocery store, toy boxes at the toy store, signs and billboards - all envelop young children in English. Not surprisingly, the evidence points in the direction of fairly rapid acquisition of English among the second generation (Alba and Nee 2003; Bean and Stevens 2003; Portes and Rumbaut 2006; Rumbaut, Massey, and Bean 2006). ${ }^{41}$

In general, there are four distinct sets of children whose life chances are affected by international migration. The four sets, formed by crossclassifying children's country of birth and country of residence, are: (1) foreign-born children residing with their foreign-born parents in the destination country; (2) native-born children of foreign-born parents in the destination country; (3) foreign-born children whose parents are in the destination country but who are left

41 On the parental decision to speak only the origin language at home and enroll their children in English-only schools, see Rimer (2009). 
behind in the origin country; and (4) native-born children whose parents are in the destination country and send the children to be raised in the origin country. The NIS enables a close look at all four sets.

In this section, we use NIS data to examine the influences which militate for and against achieving fluency in English among parents and two sets of children - foreign-born and nativeborn residing with their parents in the United States. Influences to explore include the origincountry and childhood environment as well as situational factors captured by visa category and previous illegal experience. $^{42}$

Among children, two potentially important factors are whether the child was born in the United States and, if not, the age at entry. With few exceptions - notably children of foreign diplomats -- children born in the United States acquire U.S. citizenship at birth and enjoy the full set of rights of native-born U.S. citizens - including the constitutional right to run for the Presidency. Foreign-born children of immigrants, including those brought in as infants or toddlers -- sometimes called the 1.5 generation -- have no claim on a life in the United States unless they acquire legal status as the minor children accompanying their parents or are sponsored for LPR by their parents. If their parents do not obtain legal status, the children are deportable. One may speculate that both the children themselves and their parents are more likely to invest, and to invest more heavily, in the U.S.-specific capital - including English language skill - of native-born children, who have every claim on a full American life. Of course, given the pervasiveness of English in the environment, such a nativity premium may be small (though possibly larger for other skills and behaviors, such as reading about American history and visiting the country's foundational monuments).

Another factor potentially influencing children's English fluency is the presence of native-born persons in the immediate environment. If the child's immigrant parent is the spouse

42 The other two sets of children figure prominently in other analyses. For example, Jasso and Rosenzweig (2010) explore the interconnections between remittances to children in the origin country and sponsoring them for LPR. 
of a native-born U.S. citizen (see Table 4), the household includes a native-born adult. This adult (married to the child's immigrant parent) may in fact be the child's own biological parent; or this adult may be the child's step-parent. Under both scenarios, the household may include nativeborn children who are the immigrant child's siblings. In the scenario with the step-parent, the household may also include native-born half-siblings and step-siblings. A natural question to ask is whether these scenarios have different effects on the child's English fluency. A priori one may speculate that if the child is the biological child of the native-born U.S. citizen sponsor, the child may have more English in the environment. However, a countervailing speculation is that parents may seek to diversify their children's language portfolio and discourage English at home, analogously to diversifying the family citizenship portfolio, as has been empirically found (Jasso and Rosenzweig 1990).

\subsection{Special NIS Data for Studying English Fluency}

\section{Among Immigrant Parents and Their Young Children}

The New Immigrant Survey, besides interviewing the main sampled immigrants in the Adult Sample and their spouses (Table 1), also interviewed up to two randomly selected children age 8-12 residing in the household. A total of 1,072 children were thus interviewed in the Adult Sample. These children include biological, step, and adopted children. This section focuses on interviewed biological children of the main sampled immigrant, of whom there are 1,014 . These are children of 887 main sampled immigrants.

Children were given the same broad choice of interview language as their parents, and the data provide information on whether English, if chosen, proved to be the only language used by the child during the interview. Accordingly, we define for the children the same behavioral measure of English fluency used in Section 6 for adults. The children are coded " 1 " if the entire interview was completed solely in English.

The NIS also obtained information on the children's first language, asking, "What was the first language you learned to speak when you were a child?" We coded the responses into three categories. These and their proportions among the biological children are: English, 16.5\%; 
Spanish, 48.2\%; and other, $35.1 \%$. $^{43}$

To characterize the child's nativity and age at entry we combine nativity and age at entry to classify children into three categories: (1) born in the United States; (2) born abroad, entered before age four; and (3) born abroad, entered at age four or older. The first two categories represent an initial crude attempt to distinguish between native-born children of immigrants and those brought in as infants or toddlers, as discussed above. The proportions in these categories among the biological children are: born in the United States, 45.1 percent; entered before age four, 6.41 percent; entered at four or older, 43.1 percent; missing, 5.4 percent.

To represent more sharply the environment associated with the spouse-of-NB-citizen visa category, we replace it by two binary variables, indicating whether the immigrant parent's spouse is or is not the biological parent of the focal child. The proportion with a native-born parent is 71.2 percent. $^{44}$

\subsection{Parental Origin Country, Previous Illegal Experience, and English Fluency among Parents and Children}

We begin by looking at the class-of-admission and origin-country distributions of the children's parents. By far the largest visa classes of the entire cohort are the two spouse-of-U.S. citizen categories (16.2\% and $17.9 \%$ for NB and FB sponsors, respectively), followed by parent of U.S. citizen $(11.9 \%)$, and legalization (7.98\%). In contrast, among the parents of young children age $8-12$, the largest visa category is that of legalization (at $22.1 \%$ almost three times as

43 The sampling weights used in this section for quantities defined on the set of children, besides adjusting for the visa category sampling stratification design (as in previous sections), also adjust for the design feature that no more than two children would be interviewed per household.

44 Three data matters: First, children whose immigrant parent is not currently married to their own biological other parent may also have a native-born U.S. citizen parent, but that parent is not in the household. Second, we do not create a global variable for a native-born parent (across all parental visa categories) because all but one of the biological children whose immigrant parent is currently married to a NB citizen who is the child's biological parent are in families in which the sampled immigrant is the spouse of a NB U.S. citizen. Third, data on whether the child is the biological child of the immigrant parent's current spouse is missing in three cases involving spouse-of-NB-citizen immigrants, two of which appear to be children of the NB sponsor; including them increases the proportion with a native-born parent to $76.6 \%$. 
large as among the cohort as a whole), followed by spouse of FB citizen (11.7\%), spouse of NB citizen (7.34\%), and spouse of LPR (7.02\%). As would be expected, the parent-of-U.S.-citizen category is not among the top categories. Among the children, the figures are similar, except that spouse of NB citizen falls to fifth place (6.95\%), spouse of LPR ascends to third place (7.75\%), and refugee/asylee/parolee principal rises to fourth place (7.21\%). These early numbers hint at the intensity of parental previous illegal experience in these children's histories.

Turning to parental origin country, recall from Section 2.3 that the top five birth countries for the adult immigrants are Mexico (17.5\%), India (7.30\%), El Salvador (6.11\%), Philippines $(5.47 \%)$, and China (5.27\%). The origin-country distribution of the children's parents is likely to differ from that among all adult immigrants, given that country-specific immigrant streams may differ in age. For example, while only $2.69 \%$ of those born in El Salvador immigrated as parents of U.S. citizens, $23.3 \%$ of those born in China did so.

Indeed, the parental origin-country distribution among the biological children replaces China with Guatemala in the top five, alters the ordering, and yields substantially larger proportions from Mexico and El Salvador: Mexico (25\%), El Salvador (13.9\%), Guatemala (6.58\%), India (5.19\%), and Philippines (4.79\%). In sixth through tenth place are: Vietnam (3.71\%), Dominican Republic (3.04\%), Cuba (2.51\%), China (1.95\%), and Ukraine (1.83\%). ${ }^{45}$

The top three parental origin countries are the same three countries with the highest previous illegal experience among the adult immigrants, with El Salvador in first place, followed by Guatemala and Mexico (Section 2.4). Among the children, the estimated proportions with parental previous illegal experience range from the lower-bound estimate of $28.6 \%$ (counting immigrants with either a legalization immigrant visa or an EWI/WI nonimmigrant code) to $48.9 \%$ (including all the information on the immigrant record) to $52.3 \%$ (adding as well the survey measures). Among children whose immigrant parent is from one of the top three

45 These percentages are calculated on the set of children, not the set of parents. The figures change slightly when calculated on the parents of co-resident biological children age 812. For example, the proportions of parents born in Mexico, El Salvador, and Guatemala are, respectively, $24.5 \%, 14.34 \%$, and $5.98 \%$. 
countries, the estimated ranges of parental previous illegal experience are: Mexico (36-87.491.5\%), El Salvador (86.5-94.9-95.6\%), and Guatemala (88.5-92-97.4\%). Again, the figures change only slightly if calculated on the set of parents; for example, the three overall proportions, starting with the lower bound, are 28.6, 49.2, and 52.6\%. Thus, immigrants with co-resident children aged 8-12 are more likely to have previous illegal experience than the adult immigrants as a whole, for whom the three corresponding figures are 11.4, 35.7, and 39.6\% (Table 6). And over half the children aged 8-12 have parents with illegal experience.

The proportion fluent in English among the 887 immigrant parents is estimated at $26.0 \%$ (substantially less than among all the main sampled immigrants, for whom it is $41.2 \%$ ), and it varies greatly across birth country, visa class, and previous illegal experience. Among the top ten parental origin countries, it ranges from lows of $2.25 \%$ and $4.66 \%$ (Vietnam and Ukraine, respectively) to highs of 55.5\% and 69.0\% (India and Philippines, respectively); the proportions for Mexico, El Salvador, and Guatemala are 6.55\%, 10.1\%, and 11.3\%, respectively. By visa class, parental English fluency ranges from lows of 9.31\% and 13.4\% among legalization principals and spouses of LPRs, respectively, to highs of $59.6 \%$ and $63.9 \%$ among employment principals and spouses, respectively. And English fluency differs across immigrant parents with and without illegal experience. Among new arrivals and adjustees with a valid visa code, who additionally have no history of illegal experience as measured by the survey questions, the estimated proportions fluent are $34.1 \%$ and $55.6 \%$, respectively, while among adjustees with a legalization visa or an EWI nonimmigrant code, the proportion is $8.55 \%$, and among all adjustees with previous illegal experience, the proportion fluent is $13.4 \%$.

The situation is quite different among the children. The proportion who completed the interview exclusively in English is $68 \%$ - more than twice as high as among their immigrant parents $(26.0 \%)$. With respect to parental origin country, the proportion fluent in English ranges from lows of $21.7 \%$ (Vietnam) and $23.0 \%$ (China) to highs of $87.2 \%$ (India) and 96.2\% (Philippines). For the top three parental birth countries, the estimates are 67.2\% (Mexico), $70.1 \%$ (E1 Salvador), and 71.7\% (Guatemala) - dramatically larger than the $6.55 \%-11.3 \%$ among 
their parents. Across parental visa class, the proportions of children fluent in English range from $37.6 \%$ and $41.5 \%$ (sibling principals and spouses, respectively) to $84.6 \%$ and $80.4 \%$

(employment principals and spouses). Across parental illegal experience, the children of adjustees are almost indistinguishable from each other regardless of their parent's illegal experience - with proportions fluent that range from $71.5 \%$ among children with an EWI parent to $81.2 \%$ among children of a valid-visa parent with no illegal experience on the survey measures - while the children of new-arrival parents with no illegal experience register a proportion fluent of $55.3 \%$.

Among immigrants with no estimated previous illegal experience, both adjustees and their children have greater English fluency than new arrivals and their children, by 20-25 percentage points. However, among adjustees with illegal experience, the parents have very low English fluency while their children's English fluency rivals that of the children of adjustees with no illegal experience.

Taken together, these patterns suggest two potentially important dynamics, first, a leveling across generation - with children far more similar to each other than are their parents and, second, a kind of compensation for parental illegal experience - with children of previous illegals achieving great English fluency, possibly in response to the hardships their parents endure or to practice translating and interpreting for their parents (Valdés 2003).

\subsection{Multivariate Analysis of English Fluency Attainment among Parents and Children}

Table 24 reports binary logit estimates of the determinants of English fluency among the biological children aged 8-12 interviewed in the NIS and their immigrant parent. One equation is estimated for the parent and two for the children, one of which parallels closely the parent equation while the other adds parent's English fluency as a regressor. All three equations include the binary variable indicating whether English is an official or dominant language of the parent's country of birth. The parent's equation includes the set of visa categories which, as in previous sections, distinguish between principals and spouses (see Tables 1, 3, 4, etc.), who may differ in knowledge of English. The children's equations, however, group together principals and spouses 
from the same visa category, given that the child's environment includes both parents. As well, the children's equations replace the category for spouse of native-born citizen with the two categories described above distinguishing between the subsets in which the immigrant parent's spouse is or is not the child's biological parent. The origin area dummies are for the top ten parental countries (Section 8.3). The children's equations also include the new variable characterizing the child's nativity/entry. Finally, the children's equations include a correction for heteroskedasticity due to the clustering of children within family.

- Table 24 about here -

The first result is that children do not reproduce the adult gender effect. While immigrant mothers (and immigrant women in general) are statistically significantly less likely to be fluent in English than immigrant fathers (and immigrant men in general), there is no statistically discernible gender effect among the children. Indeed, the point estimates indicate a greater English fluency among girls.

The estimates for parental visa category and the adjustee and illegal experience variables echo some of the results in the previous section and introduce others. Among the parents, the top four visa categories associated with English fluency are the two employment categories, the category for adult married children of U.S. citizens, and the category for spouses of NB citizens. Among the children, those in the top visa category have an immigrant parent who attained LPR as the parent of a U.S. citizen - that is, children who have siblings or half-siblings who are U.S. citizens. The second top visa category includes children whose immigrant parent is married to a native-born U.S. citizen who is not the biological parent of the focal child - children, that is, who may have half-siblings or step-siblings who are U.S. citizens. These results, together with the rather low probability of English fluency among children whose biological parent is a native-born citizen, suggest three possible dynamics: (1) parents may seek to diversity their children's linguistic portfolio, as noted above; (2) children learn from their environment -- learning from a native-born adult in the household who is not their biological parent; and (3) siblings, halfsiblings, and step-siblings may play an important role in promoting English fluency among 
children. $^{46}$

The adjustee and previous illegal experience variables are jointly statistically significant, highly so in the children's equations. Other things the same, adjustees are more likely to be fluent in English, as one would expect given their longer time in the United States. However, parental previous illegal experience operates in opposite ways for parents and children, echoing the raw proportions discussed in the previous section. While parents are less likely to be fluent in English if they have previous illegal experience, children do best precisely when their parents have illegal experience. This effect strongly suggests that children of illegal immigrants are transcending their origins, whether the mechanism involves compensating for the hardships endured by their parents and/or becoming "gifted interpreters" for their parents, to use Valdés' (2003) evocative phrase.

Note that there is a highly statistically significant positive effect of parental English fluency on child fluency (in the children's second equation). Thus, even when one of the parents is fluent in English, the child still does better when that parent is legalizing from an illegal status or has been illegal in the past, suggesting a keenness to achieve and/or the presence in the household of other relatives (including the other parent) for whom to translate and interpret.

The children are not only learning from their environment, but also they are learning more and more with each passing year, as indicated by the statistically significant age effect. There is no age effect, however, for their parents (with or without a square term).

Of course, origin country and childhood language matter, for both parents and children. The binary variable for English an official/dominant language has a highly statistically significant positive effect on parents - exactly as in the equation for black immigrants. In the children's

46 In the children's regressions in Table 24, the three children of spouses of NB citizens with missing data on whether they are the biological child of the sponsor are included in the "Not biological child" category. If the two of these children who appear to have a U.S. citizen parent are recoded, all results remain qualitatively the same. The only coefficients which change perceptibly are the two coefficients for the biological child regressors. Though their rank ordering remains the same, the distance between them is attenuated. In specification (1) the two coefficients change from -.086 and .937 to .00649 and .856 , and in specification (2), they change from .0383 and .956 to .137 and .865 . 
equations, however, the effect, though positive, reaches statistical significance only in the first equation. Moreover, the magnitude declines in the second equation - which includes the binary variable for parental English fluency - indicating that the origin-country linguistic environment is important for the parent but not directly for the children.

As for parental origin country, the birth areas most conducive to English fluency, net of the English official/dominant language variable, are India and the Philippines, for children, and El Salvador and Guatemala for the parents. Four of the bottom five countries for both parents and children, albeit in different order, are Ukraine, China, Korea, and Vietnam. Also in the bottom five are Guatemala children and Dominican Republic for parents.

Net of parental origin country and whether English is an official or dominant language there, children are least likely to be fluent in English if their first language was Spanish; parents are least likely to be fluent in English if their languages at age 10 included Spanish, whether alone or in combination with English or another language. Thus, Spanish continues to exert downward pressure on English fluency (consistent with it lasting longer than other immigrant languages, as found by Rumbaut, Massey, and Bean 2006).

The nativity/entry variables indicate that, as expected, children born in the United States or brought to the United States under the age of four are more likely to be fluent in English than children brought in at older ages (or children with missing information on nativity and entry). The results also support an estimate of the nativity premium - small but positive. Further research is warranted to explore more deeply the nativity premium.

These results add to the accumulating evidence that immigrant children and children of immigrants quickly adopt English (Alba and Nee 2003; Bean and Stevens 2003; Portes and Rumbaut 2006; Rumbaut, Massey, and Bean 2003). Moreover, they signal the possibility that children may overachieve to overcome parental disadvantages (Bean and Stevens 2003), with children of previously illegal parents potentially outperforming children of parents who never lapsed into illegality.

Information obtained during the NIS second round should prove illuminating. Whether 
parents (and the other adults) improve their English, whether children continue on this achieving course, whether determinants and correlates shift their patterns - these will be possible to assess. It will also be important to track the children's early occupational experiences and their effects on educational and socioeconomic outcomes (Mortimer 2003). As well, further research is warranted on the subset of children whose immigrant parents are spouses of U.S. citizens (complementing the work here), exploring not only family language dynamics and whether there are specific patterns involving child's gender and parent's gender but also exploring step-siblings - sponsor's children from previous unions -- and the part they play in socializing and integrating the newcomer children. It is possible that step-siblings may join adoptive parents, native-born U.S. citizen women, and black immigrants from Africa as special protagonists in eradicating inequalities of various kinds.

\section{CONCLUDING NOTE}

Stratification is embedded in migration, and, increasingly and around the world, migration is embedded in stratification. One day soon it will be impossible to understand one without the other. This paper has used a unique new data set, the New Immigrant Survey, to explore the connections between migration and stratification in six dimensions that exemplify the parts played by government, private citizens, and immigrants and their children in the unfolding of the immigrants' and their children's life chances and the impacts on the stratification structure of the United States.

The paper made several methodological and substantive contributions. Methodologically, the paper provides basic information about the U.S. immigration context, necessary for understanding the immigrants' lives and the rich new detail in the NIS; uses a new skin color scale to understand not only skin color among new immigrants but also marital diversity in skin color and nonresponse to the standard race question used in U.S. surveys; uses whole-distribution graphical tools whose usefulness is increasingly appreciated; conducts Kolmogorov-Smirnov tests on the skin color distributions; and explores difference-in-differences procedures for 
inferring the skin color of missing (noninterviewed) spouses.

Substantively, the paper provides a range of new results with potentially important implications for both science and policy. First, starting with an examination of lost documents in immigration offices, we found that documents are more likely to be lost in offices of the INS/USCIS in the United States than in consular or embassy posts overseas, and that the characteristics of immigrants and their sponsors affect the probability of lost documents - for example, in the immigration of spouses of U.S. citizens, both stateside and abroad, documents are more likely to be lost if the U.S. citizen sponsor is foreign-born than if the sponsor is nativeborn. Second, lost documents increase the probability that the immigrant experienced depression as a result of the visa application process; adjustee immigrants are more likely to experience visa depression; and only certain kinds of kin protect against visa depression. Third, men are more likely than women to declare that they are the principal applicant in the case, whether or not they are, raising questions about gender entitlement and the possibility of gender effects in reported schooling and earnings in survey data. Fourth, immigration is increasing diversity in the U.S. population - by introducing substantial contingents of Asian and Hispanic immigrants - and threatens to overturn racial and skin color associations with skill - by introducing accomplished black immigrants from Africa. Fifth, native-born U.S. citizen sponsors of spouses are marrying spouses who are darker than themselves, and this is most pronounced among female sponsors, suggesting that they are in the vanguard of increasing marital diversity in skin color. Sixth, young children are dramatically more likely than their immigrant parents to be fluent in English; there is a nativity premium, such that children born in the United States are more likely to be fluent in English than children brought before age four; and children of previously illegal immigrants are especially more likely to be fluent in English, suggesting that they may be compensating for the hardships they have seen their parents endure and/or that they have obtained practice translating for their parents or other family members.

Much more will be learned about these processes and their longer-term effects, as further analyses are carried out on the first and second round data and new information is collected in 
subsequent rounds of the NIS. It will be possible to assess whether lost documents and visa depression engender diminished attachment to the United States, visible in emigration, naturalization, and voting, and whether visa depression affects subsequent health outcomes. As well, it will be possible to observe whether and how new legal immigrants shed the habits of their former life, in some cases shedding the habits of illegality, in others the habits of elitism and gender entitlement. And it will be possible to gauge whether the auspicious signs of highly accomplished black immigrants and of marital diversity in skin color develop into social forces. As well, it will be possible to see whether other aspects of immigration, beyond those analyzed here, contribute to intensifying or attenuating the stratification structure of the United States.

Immigration research and NIS data are as Shakespeare imagined Cleopatra: they make hungry where most they satisfy. 


\section{REFERENCES}

Abbott, Andrew. 2004. Methods of Discovery: Heuristics for the Social Sciences. New York, NY: W. W. Norton.

Akresh, Ilana Redstone, and Reanne Frank. 2008. "Health Selection Among New Immigrants." American Journal of Public Health 98:2058-2064.

Alba, Richard, and Victor Nee. 2003. Remaking the American Mainstream: Assimilation and Contemporary Immigration. Cambridge, MA: Harvard University Press.

Anderson, Elijah. 1999. "The Social Situation of the Black Executive: Black and White Identities in the Corporate World.” Pp. 3-29 in Michele Lamont (ed.), The Cultural Territories of Race: Black and White Boundaries. Chicago: University of Chicago Press.

Bean, Frank D., and Gillian Stevens. 2003. America's Newcomers and the Dynamics of Diversity. New York, NY: Russell Sage.

van den Berghe, Pierre L., and Peter Frost. 1986. "Skin Color Preference, Sexual Dimorphism and Sexual Selection: A Case of Gene-Culture Coevolution?" Ethnic and Racial Studies 9:87-113.

Carnethon, Mercedes R., Mary L. Biggs, Joshua I. Barzilay, Nicholas L. Smith, Viola Vaccarino, Alain G. Bertoni, Alice Arnold, and David Siscovick. 2007. "Longitudinal Association Between Depressive Symptoms and Incident Type 2 Diabetes Mellitus in Older Adults.” Archives of Internal Medicine 167:802-807.

Corra, Mamadi. 2005. "Race, Gender, and Immigrant Status: Assessing Differences in Earnings Among Persons of African Origin.” Paper presented at the annual meeting of the American Sociological Association, Philadelphia, PA.

Curran, Sara, Filiz Garip, Chang Y. Chung, and Kanehana Tangchonlatip. 2005. "Gendered Migrant Social Capital: Evidence from Thailand.” Social Forces 84:225-255.

Davis, James A. 2004. "Did Growing Up in the 1960s Leave a Permanent Mark on Attitudes and Values?" Public Opinion Quarterly 68:161-183.

Donato, Katharine M., Donna Gabaccia, Jennifer Holdaway, Martin Manalansan, IV, and Patricia 
R. Pessar. 2006. "A Glass Half Full? Gender in Migration Studies.” International Migration Review 40:3-26.

DuBois, W. E. B. 1903. The Souls of Black Folk: Essays and Sketches. Gloucester, MA: Peter Smith.

Elo, Irma T., Neil K. Mehta, and Cheng Huang. 2011. "Disability Among Native-born and Foreign-born Blacks in the United States.” Demography 48:241-265.

Feagin, Joe. 1991. "The Continuing Significance of Race: Antiblack Discrimination in Public Places.” American Sociological Review 56:101-116.

Fernández-Kelly, Patricia. 1995. “Divided Fates: Immigrant Children in a Restructured Economy.” International Migration Review 28:662-689.

Gans, Herbert J. 1999. The Possibility of a New Racial Hierarchy in the Twenty-First Century United States.” Pp. 371-390 in Michele Lamont (ed.), The Cultural Territories of Race: Black and White Boundaries. Chicago, IL: University of Chicago Press. . 2005. "Race as Class." Contexts 4:17-21. . 2007. "Acculturation, Assimilation and Mobility." Ethnic and Racial Studies 30:152164.

Goffman, Erving. 1959. The Presentation of Self in Everyday Life. New York: Doubleday Anchor.

- 1963. Stigma: Notes on the Management of a Spoiled Identity. Englewood Cliffs, NJ: Prentice-Hall.

Hersch, Joni. 2007. "Profiling the New Immigrant Worker: The Effects of Skin Color and Height." Vanderbilt Law and Economics Research Paper No. 07-02.

Jablonski, Nina. 2004. "The Evolution of Human Skin and Skin Color.” Annual Review of Anthropology 33:585-623.

Jablonski, Nina, and George Chaplin. 2000. "The Evolution of Human Skin Coloration.” Journal of Human Evolution 39:57-106.

Jasso, Guillermina. 1988. "Whom Shall We Welcome? Elite Judgments of the Criteria for the 
Selection of Immigrants." American Sociological Review 53:919-932.

Jasso, Guillermina. 2003. “Migration, Human Development, and the Lifecourse.” Pp. 331-364

in Jeylan T. Mortimer and Michael Shanahan (eds.), Handbook of the Lifecourse. New

York: Kluwer.

Jasso, Guillermina. 2008. "New Immigrant Survey.” Pp. 499-500 in William A. Darity Jr. (ed.), International Encyclopedia of the Social Sciences, Second Edition, Volume 5. Detroit: Macmillan Reference USA.

Jasso, Guillermina. 2009. "Ethnicity and the Immigration of Highly Skilled Workers to the United States.” International Journal of Manpower 30:26-42.

Jasso, Guillermina. 2010. "What Do We Expect from Our Government Representatives on Immigration? Three Things: Information, Integrity, Inventiveness.” Pp. 107-133 in Beryl

A. Radin and Joshua M. Chanin (eds.), What Do We Expect from Our Government?

Lanham, MD: Lexington Books.

Jasso, Guillermina, Douglas S. Massey, Mark R. Rosenzweig, and James P. Smith. 2000.

"Assortative Mating among Married New Legal Immigrants to the United States:

Evidence from the New Immigrant Survey Pilot." International Migration Review 34:443-459.

Jasso, Guillermina, Douglas S. Massey, Mark R. Rosenzweig, and James P. Smith. 2005. "Immigration, Health, and New York City: Early Results Based on the U.S. NewImmigrant Cohort of 2003.” Economic Policy Review 11:127-151.

Jasso, Guillermina, Douglas S. Massey, Mark R. Rosenzweig, and James P. Smith. 2008.

"From Illegal to Legal: Estimating Previous Illegal Experience among New Legal Immigrants to the United States.” International Migration Review 42:803-843.

Jasso, Guillermina, Douglas S. Massey, Mark R. Rosenzweig, and James P. Smith. In press.

"The U.S. New Immigrant Survey: Overview and Preliminary Results Based on the NewImmigrant Cohorts of 1996 and 2003.” Pp. 29-46 in Beverley Morgan and Ben Nicholson (eds.), Immigration Research and Statistics Service Workshop on Longitudinal 
Surveys and Cross-Cultural Survey Design: Workshop Proceedings. London, UK: Crown Publishing.

Jasso, Guillermina, and Mark R. Rosenzweig. 1990. The New Chosen People: Immigrants in the United States. A volume in "The Population of the United States in the 1980s: A Census Monograph Series." New York: Russell Sage.

Jasso, Guillermina, and Mark R. Rosenzweig. 1995. "Do Immigrants Screened for Skills Do Better Than Family-Reunification Immigrants?" International Migration Review 29:85111.

Jasso, Guillermina, and Mark R. Rosenzweig. 2006. "Characteristics of Immigrants to the United States: 1820-2003.” Pp. 328-358 in Reed Ueda (ed.), A Companion to American Immigration. A volume in the series, Blackwell Companions to American History. Malden, MA: Blackwell Publishing. and _ 2010. "Remit or Reunify? US Immigrant Parents, Remittances, and the Sponsorship of Children.” Presented at the Research Conference on Remittances and Immigration, Federal Reserve Bank of Atlanta, Atlanta, GA, November 2010.

Jasso, Guillermina, Vivek Wadhwa, Ben Rissing, Gary Gereffi, and Richard Freeman. 2010. "How Many Highly Skilled Foreign-Born Are Waiting in Line for U.S. Legal Permanent Residence?” International Migration Review 44:477-498.

Jensen, Leif, Jeffrey H. Cohen, Almeida Jacqueline Toribio, Gordon F. DeJong, and Leila Rodriguez. 2006. "Ethnic Identities, Language, and Economic Outcomes Among Dominicans in a New Destination.” Social Science Quarterly 87:1088-1099.

Kao, Grace. 2004. "Social Capital and Its Relevance to Minority and Immigrant Populations." Sociology of Education 77:172-175. , and Lindsay Taggart Rutherford. 2007. "Does Social Capital Still Matter? Immigrant Minority Disadvantage in Social Capital and Its Effects on Academic Achievement.” Sociological Perspectives 50:27-52.

Lacy, Karyn R. 2007. Blue-Chip Black: Race, Class, and Status in the New Black Middle Class. 
Berkeley: University of California Press.

Lee, Jennifer, and Frank D. Bean. 2007. "Redrawing the Color Line?" City and Community 6:49-62.

Levine, Daniel B., Kenneth Hill, and Robert Warren (eds.). Immigration Statistics: A Story of Neglect. Washington, DC: National Academies Press.

Loury, Glenn C. 2003. "Racial Stigma: Toward a New Paradigm for Discrimination Theory." American Economic Review 93:2:334-337.

Massey, Douglas S. 2003. Beyond Smoke and Mirrors: Mexican Immigration in an Era of Economic Integration. New York, NY: Russell Sage. , Joaquin Arango, Graeme Hugo, Ali Kouaouci, Adela Pellegrino, and J. Edward Taylor. 1993. "Theories of International Migration: A Review and Appraisal." Population and Development Review 19:431-466. , and Nancy A. Denton. 1992. American Apartheid: Segregation and the Making of the Underclass.” Cambridge: Harvard University Press. , Margarita Mooney, Kimberly C. Torres, and Camille Z. Charles. 2007. "Black Immigrants and Black Natives Attending Selective Colleges and Universities in the United States.” American Journal of Education 113:243-271. , Rafael Alarcón, Jorge Durand, and Humberto González. 1987. Return to Aztlan: The

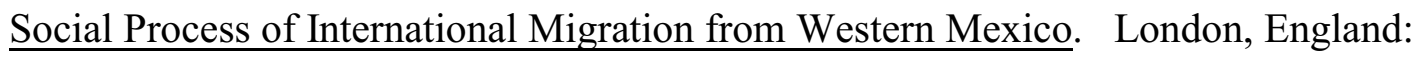
University of California Press.

Mincer, Jacob. 1978. "Family Migration Decisions.” Journal of Political Economy 86:749-773. Mortimer, Jeylan T. 2003. Working and Growing Up in America. Cambridge, MA: Harvard University Press.

Ogbu, John. 1974. The Next Generation: An Ethnography of Education in an Urban Neighborhood. New York: Academic.

Portes, Alejandro. 1979. "Illegal Immigration and the International System, Lessons from Recent Legal Immigrants to the United States. Social Problems 26:425-438. 
. 1998. "Social Capital: Its Origins and Applications in Modern Sociology." Annual Review of Sociology 24:1-24.

and Rubén G. Rumbaut. 2001. Legacies: The Story of the Immigrant Second

Generation. Berkeley, CA: University of California Press. and . 1990. Immigrant America: A Portrait. Berkeley, CA: University of

California Press. and . 2006. Immigrant America: A Portrait. Third edition. Revised, expanded, and updated. Berkeley, CA: University of California Press. and Min Zhou. 1993. "The New Second Generation: Segmented Assimilation and Its Variants." The Annals of the American Academy of Political and Social Science 530:7496.

Powers, Mary G., Ellen Percy Kraly, and William Seltzer. 2004. "IRCA: Lessons of the Last Legalization Program.” www.migrationinformation.org . , and William Seltzer. 1998. “Occupational Status and Mobility among Undocumented Immigrants by Gender." International Migration Review 32:21-55.

Qian, Zhenchao, and Daniel T. Lichter. 2007. "Social Boundaries and Marital Assimilation." American Sociological Review 72:68-94.

Rimer, Sara. 2009. "Immigrants See Charter Schools as a Haven.” New York Times, 10 January 2009.

Rossi, Peter H. 1955. Why Families Move: A Study in the Social Psychology of Urban Residential Mobility. Glencoe, IL: Free Press.

Ruel, Erin, and Robert M. Hauser. 2007. “Gender, Education, and Wealth: A Prospective Study." Unpublished paper.

Rumbaut, Rubén G., Douglas S. Massey, and Frank D. Bean. 2006. “Linguistic Life Expectancies: Immigrant Language Retention in Southern California.” Population and Development Review 32:447-460.

Sharkey, Joe. 2006. "Memo Pad." The New York Times, December 16, 2006. 
Simmons, Roberta G., and Dale A. Blyth. 1987. Moving into Adolescence: The Impact of Pubertal Change and School Context. New York: Aldine.

Smith, James P., and Barry Edmonston (eds.). 1997. The New Americans: Economic, Demographic, and Fiscal Effects of Immigration. Report of the National Research Council. Washington, DC: National Academy Press.

Smith, Marian. 1998. ““Any Woman Who Is Now or May Hereafter Be Married ...’ Women and Naturalization, ca. 1802-1940." U.S. National Archives and Records Administration, Summer 1998, Vol. 30, No. 2. (Available at www.archives.gov) . 2002. "Race, Nationality, and Reality: INS Administration of Racial Provisions in U.S. Immigration and Nationality Law Since 1898.” U.S. National Archives and Records Administration, Summer 2002, Vol. 34, No. 2. (Available at www.archives.gov)

Telles, Edward E. 2004. Race in Another America: The Significance of Skin Color in Brazil.

Princeton, NJ: Princeton University Press.

Tienda, Marta, and Faith Mitchell (Eds.). 2006. Multiple Origins, Uncertain Destinies:

Hispanics and the American Future. Washington, DC: National Academies Press.

Thomas, William I., and Florian Znaniecki. 1927. The Polish Peasant in Europe and America.

Two volumes. New York: Knopf.

USCIS Ombudsman. 2007. Annual Report to Congress June 2007.

U.S. Commissioner General of Immigration. 1898-1932. Annual Reports. Washington, DC:

Government Printing Office.

U.S. Department of Homeland Security. Various issues. Annual Flow Report - U.S. Legal Permanent Residents. Posted online.

U.S. Department of Homeland Security. 2002-2009. Yearbook of Immigration Statistics.

Washington, DC: Government Printing Office.

U.S. Department of State. Various issues. Visa Bulletin. Posted online.

U.S. Immigration Commission. 1911. Reports of the Immigration Commission. 42 Volumes. Washington, DC: U.S. Government Printing Office. Also known as the Dillingham 


\section{Commission Report.}

U.S. Immigration and Naturalization Service. 1943-1978. Annual Report of the Immigration and Naturalization Service. Washington, DC: U.S. Government Printing Office. . 1979-2001. Statistical Yearbook of the Immigration and Naturalization Service.

Washington, DC: Government Printing Office.

Valdés, Guadalupe. 2003. Expanding Definitions of Giftedness: Young Interpreters of Immigrant Background. Erlbaum.

Villarreal, Andrés. 2010. "Stratification by Skin Color in Contemporary Mexico." American Sociological Review 75:652-678.

Waldinger, Roger. 2001. Strangers at the Gates: New Immigrants in Urban America. Berkeley, CA: University of California Press.

Warren, Robert. 2003. "Estimates of the Unauthorized Immigrant Population Residing in the United States: 1990 to 2000.” Available on the DHS website.

. Unpubl. "Detailed Methodology for Annual Estimates of the Unauthorized Immigrant Population Residing in the United States: 1990-2000.

Waters, Mary C. 1990. Ethnic Options: Choosing Identities in America. Berkeley, CA: University of California Press. . 1999. Black Identities: West Indian Immigrant Dreams and American Realities. New York and Cambridge: Russell Sage Foundation and Harvard University Press.

Weber, Max. 1892. Die Verhältnisse der Landarbeiter im ostelbischen Deutschland. Tübingen: Mohr Siebeck.

. 1922. Wirtschaft und Gesellschaft. Grundriß der Verstehenden Soziologie. Leipzig: Duncker \& Humblot.

Welch, Sara J. 2007. "When a Visa Becomes a Headache.” The New York Times, February 6, 2007.

Zelditch, Morris, Jr. 1968. "Status, Social." Pp. 250-257 in David L. Sills (ed.), International Encyclopedia of the Social Sciences, Volume 15. New York: Macmillan. 
Table 1. Links Among Immigrant Visa Characteristics

\begin{tabular}{||l|c|c|c|c|c||}
\hline $\begin{array}{c}\text { Immigrant Class of } \\
\text { Admission }\end{array}$ & $\begin{array}{c}\text { Numerica } \\
\text { lly } \\
\text { Limited }\end{array}$ & $\begin{array}{c}\text { Requires } \\
\text { Sponsor }\end{array}$ & $\begin{array}{c}\text { Provides } \\
\text { Visa for } \\
\text { Spouse }\end{array}$ & $\begin{array}{c}\text { New } \\
\text { Arrival } \\
\text { or } \\
\text { Adjustee }\end{array}$ & $\begin{array}{c}\text { Previous } \\
\text { Illegal } \\
\text { Experienc } \\
\text { e }\end{array}$ \\
\hline \hline $\begin{array}{l}\text { Immediate relative of U.S. } \\
\text { citizen }\end{array}$ & No & Almost all & No & Both & Possible \\
\hline Family preference & Yes & Almost all & Some & Both & Possible \\
\hline Employment preference & Yes & Almost all & Yes & Both & Possible \\
\hline Diversity & Yes & No & Yes & Both & Possible \\
\hline Humanitarian & Some & No & Some & $\begin{array}{c}\text { Mostly } \\
\text { Adjustee }\end{array}$ & Possible \\
\hline Legalization & Some & No & Some & $\begin{array}{c}\text { Mostly } \\
\text { Adjustee }\end{array}$ & Yes \\
\hline
\end{tabular}

Notes: In the process for obtaining LPR, the term "sponsor" is used in two senses, to designate both (1) the person who provides eligibility for a family-based or employment-based visa and "petitions for" the immigrant, submitting a special form (such as I-130 or I-140); and (2) a person who signs an affidavit of support (I-864) for the immigration applicant. In this paper, the term "sponsor" pertains exclusively to the first kind of sponsor, who may be called the visa sponsor. For further details, see the Glossaries on the DHS and DOS websites. Given the intricacies of U.S. immigration law, there is considerable variation, as indicated in the table. For example, some humanitarian and legalization LPR visas have been available to new arrivals, notably for Amerasians related to U.S. soldiers and for dependents of IRCA legalization immigrants. The NIS-2003 sample does not include any respondents with those visas; thus, in the NIS, all immigrants with humanitarian and legalization visas are adjustees. 
Table 2. Processing Venue for New Immigrants in 2003

\begin{tabular}{||l|c|c|c||}
\hline \multicolumn{1}{|c|}{ Immigrant Class of Admission } & $\begin{array}{c}\text { State } \\
\text { Only }\end{array}$ & $\begin{array}{c}\text { INS/CIS } \\
\text { Only }\end{array}$ & $\begin{array}{c}\text { Both } \\
\text { State \& US/CIS }\end{array}$ \\
\hline \hline Immediate relative of U.S. citizen & & & \\
\hline New arrival & & & $\mathrm{X}$ \\
\hline Adjustee & & & $\mathrm{X}$ \\
\hline Family preference & & & $\mathrm{X}$ \\
\hline Employment preference & & $\mathrm{X}$ & \\
\hline New arrival & & & \\
\hline Adjustee & & $\mathrm{X}$ & \\
\hline Diversity & & $\mathrm{X}$ & \\
\hline New arrival & $\mathrm{X}$ & & \\
\hline Adjustee & & & $\mathrm{X}$ \\
\hline Humanitarian & & & \\
\hline Legalization & & & \\
\hline
\end{tabular}

Notes: The table depicts venue of LPR visa processing. However, all new arrivals are inspected at the U.S. port of entry by an official of the Customs and Border Protection unit of DHS. Also, see note on humanitarian and legalization immigrants in Table 1. 
Table 3. Immigration Characteristics of Main Sampled Immigrants and Their Spouses Interviewed in the NIS-2003 Adult Sample

\begin{tabular}{|c|c|c|c|}
\hline $\begin{array}{l}\text { Immigration } \\
\text { Characteristic }\end{array}$ & Main Adult & Spouse & Total \\
\hline Principal & $\begin{array}{c}7,615 \\
(88.6 \%)\end{array}$ & $\begin{array}{c}714 \\
(15.3 \%)\end{array}$ & 8,329 \\
\hline Nonprincipal & $\begin{array}{c}958 \\
(11.4 \%)\end{array}$ & NA & 958 \\
\hline $\begin{array}{l}\text { Native-born U.S. citizen sponsor of } \\
\text { spouse }\end{array}$ & NA & $\begin{array}{c}522 \\
(22.3 \%)\end{array}$ & 522 \\
\hline Other native-born U.S. citizen & NA & $\begin{array}{c}39 \\
(.58 \%)\end{array}$ & 39 \\
\hline $\begin{array}{l}\text { Foreign-born U.S. citizen sponsor } \\
\text { of spouse }\end{array}$ & NA & $\begin{array}{c}566 \\
(24.7 \%)\end{array}$ & 566 \\
\hline Other foreign-born U.S. citizen & NA & $\begin{array}{c}43 \\
(.72 \%)\end{array}$ & 43 \\
\hline $\begin{array}{l}\text { Previous immigrant LPR sponsor of } \\
\text { spouse }\end{array}$ & NA & $\begin{array}{c}133 \\
(2.84 \%)\end{array}$ & 133 \\
\hline $\begin{array}{l}\text { Foreign-born spouse of principal } \\
\text { who can have accompanying spouse }\end{array}$ & NA & $\begin{array}{c}1,610 \\
(18.3 \%)\end{array}$ & 1,610 \\
\hline $\begin{array}{l}\text { Foreign-born spouse of principal } \\
\text { who cannot have accompanying } \\
\text { spouse }\end{array}$ & NA & $\begin{array}{c}707 \\
(15.3 \%)\end{array}$ & 707 \\
\hline Total & 8,573 & 4,334 & 12,907 \\
\hline
\end{tabular}

Notes: Percentages in Main Adult and Spouse columns are based on design weights for main sampled immigrants. The principal is the person who qualifies for the immigrant visa; in some visa categories, visas are also available for the accompanying spouses of principals. Spouses who are principals $(n=714)$ are married to nonprincipal main sampled immigrants $(n=958)$; in the NIS all nonprincipal main sampled immigrants are accompanying spouses of principals. Foreign-born spouses of principals who can have accompanying spouses may be accompanying spouses, contemporaneous legal immigrants (e.g., both with employment principal visas), previous immigrants, or unauthorized immigrants. Foreign-born spouses of principals who cannot have accompanying spouses may be contemporaneous legal immigrants (e.g., with visas as parents of U.S. citizens), previous immigrants, or unauthorized immigrants. Spouses of overseas Main Adult respondents were not interviewed; the overseas respondents were 268 principals and 53 nonprincipals (see section 2.4). Thus, for example, the 714 Spouse principals are married to persons from among the 905 non-overseas subset of the 958 Main Adult nonprincipals. 
Table 4. Basic Characteristics of New Legal Immigrants Aged 18+: NIS-2003 Cohort

\begin{tabular}{|c|c|c|c|c|c|c|}
\hline \multirow{2}{*}{ Immigrant Class of Admission } & \multirow{2}{*}{$\begin{array}{l}\text { Percent } \\
\text { Female }\end{array}$} & \multicolumn{2}{|c|}{$\overline{\text { Age }}$} & \multicolumn{2}{|c|}{ PSchooling } & \% Adjust \\
\hline & & Men & Women & Men & Women & Men \\
\hline Spouse of NB U.S. citizen $(16.2 \%)$ & 59.6 & 31.6 & 32.1 & 13.0 & 13.8 & 84.2 \\
\hline Spouse of FB U.S. citizen (17.9\%) & 66.0 & 34.2 & 33.1 & 12.3 & 12.5 & 79.3 \\
\hline Parent of U.S. citizen $(11.9 \%)$ & 66.2 & 65.5 & 62.7 & 8.75 & 6.93 & 25.3 \\
\hline Minor child of U.S. citizen $(3.38 \%)$ & 41.9 & 20.2 & 20.2 & 11.5 & 11.9 & 46.1 \\
\hline Adult single child of U.S. citizen $(3.28 \%)$ & 54.3 & 31.6 & 34.8 & 12.3 & 12.3 & 31.8 \\
\hline Adult married child of U.S. citizen $(1.72 \%)$ & 57.7 & 40.6 & 39.9 & 13.2 & 12.4 & 20.4 \\
\hline Spouse of adult child of U.S. citizen (1.51\%) & 48.1 & 42.4 & 37.4 & 12.9 & 11.2 & 8.92 \\
\hline Sibling of U.S. citizen $(3.94 \%)$ & 51.4 & 48.5 & 48.2 & 11.8 & 11.1 & 8.97 \\
\hline Spouse of sibling $(2.49 \%)$ & 52.8 & 50.3 & 46.2 & 13.0 & 10.8 & 3.98 \\
\hline Spouse of LPR (2.44\%) & 83.5 & 43.2 & 40.2 & 8.65 & 7.76 & 47.7 \\
\hline Child of LPR $(2.81 \%)$ & 49.2 & 34.3 & 35.0 & 11.0 & 11.1 & 23.5 \\
\hline Employment principal $(6.02 \%)$ & 32.8 & 37.3 & 36.8 & 15.7 & 15.2 & 78.9 \\
\hline Employment spouse $(3.63 \%)$ & 77.1 & 40.4 & 35.3 & 14.7 & 15.2 & 56.5 \\
\hline Diversity principal $(5.53 \%)$ & 41.1 & 32.3 & 32.8 & 14.5 & 14.5 & 8.45 \\
\hline Diversity spouse $(2.58 \%)$ & 48.7 & 37.7 & 34.5 & 14.6 & 13.1 & 5.17 \\
\hline Refugee/asylee/parolee principal (5.35\%) & 42.8 & 40.7 & 38.3 & 12.8 & 11.8 & 100 \\
\hline Refugee/asylee/parolee spouse $(1.22 \%)$ & 74.8 & 45.3 & 43.0 & 13.3 & 10.9 & 100 \\
\hline Legalization $(7.98 \%)$ & 49.8 & 38.7 & 37.9 & 9.03 & 8.43 & 100 \\
\hline Other $(.05 \%)$ & --- & --- & --- & --- & --- & --- \\
\hline All immigrants & 56.5 & 38.7 & 39.1 & 12.3 & 11.6 & 57.9 \\
\hline
\end{tabular}

Notes: Sample size is 8,573. Estimates based on weighted data. The measure of English fluency requires that the interview was conducted entirely in English. 
Table 5. Top Ten Countries of Birth, with Percentage, by Gender: NIS-2003 Cohort

\begin{tabular}{ccc}
\hline \hline Men & Women & All \\
& & \\
\hline Mexico & Mexico & Mexico \\
16.1 & 18.7 & 17.5 \\
India & India & India \\
7.24 & 7.34 & 7.30 \\
El Salvador & Philippines & El Salvador \\
6.88 & 6.45 & 6.11 \\
China & China & Philippines \\
4.90 & 5.55 & 5.47 \\
Philippines & El Salvador & China \\
4.20 & 5.52 & 5.27 \\
Guatemala & Vietnam & Vietnam \\
2.77 & 3.59 & 3.08 \\
Vietnam & Colombia & Guatemala \\
2.41 & 2.36 & 2.43 \\
& & Dominican Republic \\
Dominican Republic & Dominican Republic & 2.27 \\
Cuba & 2.34 & Colombia \\
2.13 & Guatemala & 2.08 \\
Haiti & 2.16 & Haiti \\
1.98 & 2.09 & 2.04 \\
\hline & &
\end{tabular}

Notes: Country of birth constructed from two data series, in the government immigrant record and collected in the survey, with additional information from both the administrative record and the survey used to resolve discrepancies. Percentages based on weighted data. 
Table 6. Previous Illegal Experience, by Information Source: NIS-2003 Cohort

\begin{tabular}{lccc}
\hline \hline Source of Information & Men & Women & All \\
\hline Immigrant legalization visa & 9.23 & 7.02 & 7.98 \\
Nonimmigrant code EWI/WI & 4.14 & 3.47 & 3.76 \\
Nonimmigrant code UU/UN & 13.4 & 11.7 & 12.4 \\
Nonimmigrant code missing & 15.0 & 14.0 & 14.4 \\
Nonimmigrant Warren measure & 4.96 & 5.23 & 5.12 \\
Survey measures & 24.5 & 19.3 & 21.6 \\
Total based on legalization visa or & 12.9 & 10.3 & 11.4 \\
EWI/WI code & 37.5 & 34.4 & 35.7 \\
Total based on record alone & 41.3 & 38.2 & 39.6 \\
Total including survey measures & & & \\
\hline
\end{tabular}

Notes: The information based on immigrant and nonimmigrant visa is from the official administrative immigrant record. The four components based on nonimmigrant visas are mutually exclusive. The Warren measure refers to having a nonimmigrant tourist visa (B2) and reporting the most recent entry six years or more earlier. The two other components - the immigrant legalization visa and the survey measures - may be combined with any of the other codes, so that, for example, a given respondent may be included in both the legalization visa figure, one of the nonimmigrant visa figures, and the survey measures. Thus, the total estimate is less than the sum of the components. The total estimate may be an underestimate, as it may miss new-arrival immigrants who were already living in the United States illegally and do not report it in the survey measures, as well as persons who had been working without authorization. 
Table 7. Parental Location in the Origin Country's Stratification Structure: NIS-2003 Cohort

\begin{tabular}{lccc}
\hline \hline Family Income at Age 16 & Men & Women & All \\
\hline Far below average & 10.1 & 9.83 & 9.93 \\
Below average & 19.5 & 18.2 & 18.8 \\
Average & 51.7 & 54.2 & 53.1 \\
Above average & 15.0 & 14.1 & 14.5 \\
Far above average & 3.66 & 3.64 & 3.65 \\
Number of respondents & 4,077 & 4,374 & 8.451 \\
\hline
\end{tabular}

Notes: Percentages based on weighted data. 
Table 8. Documents Lost During the Visa Process, by Processing Venue and Gender: NIS-2003 Cohort

\begin{tabular}{lcccccc}
\hline \hline \multirow{2}{*}{ Processing Venue } & \multicolumn{2}{c}{ Men } & \multicolumn{2}{c}{ Women } & \multicolumn{2}{c}{ All } \\
& $\begin{array}{c}\text { Percent in } \\
\text { Sample }\end{array}$ & $\begin{array}{c}\text { Percent } \\
\text { Lost Docs }\end{array}$ & $\begin{array}{c}\text { Percent in } \\
\text { Sample }\end{array}$ & $\begin{array}{c}\text { Percent } \\
\text { Lost Docs }\end{array}$ & $\begin{array}{c}\text { Percent in } \\
\text { Sample }\end{array}$ & $\begin{array}{c}\text { Percent } \\
\text { Lost Docs }\end{array}$ \\
\hline State only & 7.54 & 4.37 & 4.28 & 2.36 & 5.70 & 3.52 \\
INS/CIS only & 58.4 & 14.7 & 52.4 & 12.5 & 55.0 & 13.5 \\
Both State and INS/CIS & 34.1 & 9.54 & 43.3 & 9.11 & 39.3 & 9.27 \\
Total lost documents & NA & 12.2 & NA & 10.6 & NA & 11.3 \\
Number of observations & 1853 & NA & 1930 & NA & 3783 & NA \\
\hline
\end{tabular}

Notes: NA = not applicable. See Table 2 for definition of processing venue. Percentages based on data weighted to adjust for sampling stratification. 
Table 9. Immigrant Principals Whose Documents Were Lost During the Visa Process: By Origin Country, Visa Category, and Sex: NIS-2003 Cohort

\begin{tabular}{|c|c|c|c|}
\hline \multicolumn{2}{|c|}{ New Arrivals } & \multicolumn{2}{|c|}{ Adjustees } \\
\hline Men & Women & Men & Women \\
\hline \multicolumn{4}{|c|}{ A. Percent Documents Lost in Top Ten Immigration Countries } \\
\hline $\begin{array}{c}\text { Dominican Republic } \\
12.4\end{array}$ & $\begin{array}{c}\text { Dominican Republic } \\
11.0\end{array}$ & $\begin{array}{l}\text { China } \\
16.3\end{array}$ & $\begin{array}{c}\text { Mexico } \\
14.2\end{array}$ \\
\hline $\begin{array}{l}\text { Mexico } \\
10.0\end{array}$ & $\begin{array}{l}\text { Philippines } \\
9.54\end{array}$ & $\begin{array}{l}\text { Mexico } \\
15.5\end{array}$ & $\begin{array}{c}\text { Guatemala } \\
10.5\end{array}$ \\
\hline $\begin{array}{c}\text { Vietnam } \\
9.14\end{array}$ & $\begin{array}{l}\text { Haiti } \\
8.64\end{array}$ & $\begin{array}{c}\text { Cuba } \\
15.4\end{array}$ & $\begin{array}{c}\text { India } \\
9.78\end{array}$ \\
\hline $\begin{array}{l}\text { China } \\
4.97\end{array}$ & $\begin{array}{l}\text { Vietnam } \\
6.11\end{array}$ & $\begin{array}{c}\text { Philippines } \\
11.4\end{array}$ & $\begin{array}{c}\text { El Salvador } \\
9.24\end{array}$ \\
\hline $\begin{array}{l}\text { Philippines } \\
3.99\end{array}$ & $\begin{array}{l}\text { India } \\
4.84\end{array}$ & $\begin{array}{l}\text { India } \\
10.2\end{array}$ & $\begin{array}{l}\text { Cuba } \\
8.79\end{array}$ \\
\hline $\begin{array}{l}\text { India } \\
2.56\end{array}$ & $\begin{array}{l}\text { Mexico } \\
3.06\end{array}$ & $\begin{array}{c}\text { El Salvador } \\
8.31\end{array}$ & $\begin{array}{c}\text { Philippines } \\
3.47\end{array}$ \\
\hline --- & $\begin{array}{l}\text { China } \\
1.66\end{array}$ & $\begin{array}{c}\text { Guatemala } \\
3.74\end{array}$ & $\begin{array}{c}\text { China } \\
.897\end{array}$ \\
\hline
\end{tabular}

B. Visa Categories with Five Highest Rates of Lost Documents

\begin{tabular}{|c|c|c|c|}
\hline $\begin{array}{c}\text { Married Child of Cit } \\
\qquad 13.9\end{array}$ & $\begin{array}{c}\text { Spouse of LPR } \\
15.4\end{array}$ & $\begin{array}{c}\text { Spouse of FB Cit } \\
20.1\end{array}$ & $\begin{array}{c}\text { Single Child of Cit } \\
25.7\end{array}$ \\
\hline $\begin{array}{l}\text { Single Child of Cit } \\
\qquad 11.5\end{array}$ & $\begin{array}{c}\text { Employment } \\
14.8\end{array}$ & $\begin{array}{c}\text { Child of US Cit } \\
16.7\end{array}$ & $\begin{array}{l}\text { Diversity } \\
21.8\end{array}$ \\
\hline $\begin{array}{c}\text { Spouse of FB Cit } \\
10.9\end{array}$ & $\begin{array}{c}\text { Spouse of NB Cit } \\
13.8\end{array}$ & $\begin{array}{c}\text { Spouse of NB Cit } \\
16.0\end{array}$ & $\begin{array}{c}\text { Employment } \\
19.1\end{array}$ \\
\hline $\begin{array}{c}\text { Sibling of US Cit } \\
9.34\end{array}$ & $\begin{array}{c}\text { Spouse of FB Cit } \\
11.0\end{array}$ & $\begin{array}{c}\text { Ref/Asy/Par } \\
14.3\end{array}$ & $\begin{array}{c}\text { Spouse of FB Cit } \\
15.2\end{array}$ \\
\hline $\begin{array}{c}\text { Employment } \\
9.18\end{array}$ & $\begin{array}{c}\text { Child of LPR } \\
8.14\end{array}$ & $\begin{array}{c}\text { Employment } \\
13.9\end{array}$ & $\begin{array}{c}\text { Spouse of NB Cit } \\
12.0\end{array}$ \\
\hline \multicolumn{4}{|c|}{ C. Overall Proportion with Documents Lost - All Principals } \\
\hline $\begin{array}{l}7.99 \\
(822)\end{array}$ & $\begin{array}{l}7.25 \\
(937)\end{array}$ & $\begin{array}{c}14.7 \\
(1031)\end{array}$ & $\begin{array}{l}12.9 \\
(993)\end{array}$ \\
\hline \multicolumn{2}{|c|}{$\begin{array}{c}7.56 \\
(1759)\end{array}$} & \multicolumn{2}{|c|}{$\begin{array}{c}13.7 \\
(2024)\end{array}$} \\
\hline
\end{tabular}

Notes: The question on documents lost during the visa process was asked of half the main sampled immigrants, randomly chosen. Each principal represents a case in the visa process. New arrivals are processed by consular offices of the State Department overseas; adjustees are processed in the United States by offices of the Immigration and Naturalization Service (until March 2003) and the U.S. Citizenship and Immigration Services (starting in March 2003). Proportions are based on weighted data, in cells with at least 20 observations. Overall proportions with documents lost appear in panel $\mathrm{C}$, with the number of observations in parentheses under the overall proportions. 
Table 10. Logit Estimates of Venue and Adjustee Effects on Documents Lost During the Visa Process, by Sex: NIS-2003 Cohort

\begin{tabular}{|c|c|c|c|c|c|c|}
\hline \multirow{2}{*}{ Regressor } & \multicolumn{3}{|c|}{ Men } & \multicolumn{3}{|c|}{ Women } \\
\hline & (1) & (2) & (3) & (1) & (2) & (3) \\
\hline \multicolumn{7}{|c|}{ A. Which processing venue has the higher probability of lost documents? } \\
\hline INS/CIS only & 1.301 & 1.150 & 1.480 & 1.906 & 1.707 & 1.309 \\
\hline Both State and INS/CIS & .905 & .865 & 1.096 & 1.584 & 1.523 & 1.150 \\
\hline Joint test $\operatorname{chi}^{2}(2 \mathrm{df})$ & $21.52 * * *$ & $13.73 * * *$ & $14.95 * * *$ & $19.05^{* * *}$ & $12.72 * *$ & $6.42 *$ \\
\hline Illegal experience & NS & $\begin{array}{c}.277 \\
(1.46) \\
\end{array}$ & $\begin{array}{c}.302 \\
(1.43) \\
\end{array}$ & NS & $\begin{array}{c}.303 \\
(1.50) \\
\end{array}$ & $\begin{array}{l}.571 * * \\
(2.74) \\
\end{array}$ \\
\hline \multicolumn{7}{|c|}{ B. Do new arrivals or adjustees face the higher probability of lost documents? } \\
\hline Adjustee & $\begin{array}{c}.550 \\
(2.59)^{* *}\end{array}$ & $\begin{array}{l}.319 \\
(1.36)\end{array}$ & $\begin{array}{l}.307 \\
(1.18)\end{array}$ & $\begin{array}{c}.645 \\
(3.10)^{* *}\end{array}$ & $\begin{array}{c}.471 \\
(2.05)^{*}\end{array}$ & $\begin{array}{c}.517 \\
(2.17)^{*}\end{array}$ \\
\hline Spouse of NB citizen & .754 & .750 & .950 & .275 & -.410 & -.313 \\
\hline Spouse of FB citizen & 1.115 & 1.122 & 1.500 & .525 & -.144 & .227 \\
\hline Parent of US citizen & .433 & .453 & .735 & -.340 & -1.018 & -.777 \\
\hline Child of US citizen & .774 & .790 & .853 & .625 & -.0669 & -.0585 \\
\hline $\begin{array}{l}\text { Adult single child of } \\
\text { U.S. citizen }\end{array}$ & 1.075 & 1.088 & 1.175 & .522 & -.166 & .00255 \\
\hline Married child of US cit & 1.280 & 1.311 & 1.217 & --- & -.692 & -.581 \\
\hline Sibling of US cit & .855 & .890 & 1.358 & -.513 & -1.186 & -.653 \\
\hline Spouse of LPR & --- & --- & --- & .264 & -.480 & -.174 \\
\hline Child of LPR & .666 & .702 & .812 & .694 & --- & --- \\
\hline Employment & .710 & .891 & 1.250 & .818 & .195 & .278 \\
\hline Diversity & -.0575 & .0228 & .0175 & -.440 & -1.093 & -.420 \\
\hline Refugee/asylee/parolee & .666 & .749 & .811 & .00162 & -.629 & -.249 \\
\hline Legalization & .103 & -.0107 & .657 & -.102 & -.887 & -.334 \\
\hline Joint test chi $^{2}(12 \mathrm{df})$ & 19.20 & 20.56 & 15.42 & $29.82 * *$ & $31.47 * *$ & 16.86 \\
\hline Illegal experience & NS & $\begin{array}{l}.431 * \\
(2.15) \\
\end{array}$ & $\begin{array}{l}.360 \\
(1.55) \\
\end{array}$ & NS & $\begin{array}{c}.309 \\
(1.54) \\
\end{array}$ & $\begin{array}{c}.408 \\
(1.78) \\
\end{array}$ \\
\hline Number of observations & 1853 & 1853 & 1597 & 1930 & 1930 & 1692 \\
\hline
\end{tabular}

Notes: NS = not in specification. Specifications (1) and (2) are binary logit, with robust standard errors. Specifications (3) are fixed effects logit, with fixed effects for the full set of countries. Absolute values of asymptotic $t$-ratio appear in parentheses under parameter estimates for numeric and binary variables. Joint tests reported for multiple-category categorical variables.

$(* p<.05, * * p<.01, * * * p<.001$; two-tailed tests for single coefficients, one-tailed for joint tests) 
Table 11. Average Years of Immigrant Visa Processing Time, by Visa Characteristics and Sex: NIS-2003 Cohort

\begin{tabular}{lccccccc}
\hline \hline \multirow{2}{*}{ Immigrant Class of Admission } & \multicolumn{3}{c}{ New Arrival } & \multicolumn{2}{c}{ Adju } \\
& \multicolumn{2}{c}{ Principal } & \multicolumn{2}{c}{ Spouse } & \multicolumn{2}{c}{ Principal } \\
& Men & Women & Men & Women & Men & Women \\
\hline Spouse of NB U.S. citizen & 1.23 & 1.11 & NA & NA & 2.39 & 2.15 \\
Spouse of FB U.S. citizen & 1.88 & 1.88 & NA & NA & 3.60 & 2.78 \\
Parent of U.S. citizen & 2.65 & 2.38 & NA & NA & 2.54 & 2.58 \\
Minor child of U.S. citizen & 2.80 & 3.74 & NA & NA & 4.78 & 4.59 \\
Adult single child of U.S. citizen & 6.96 & 6.41 & NA & NA & 8.17 & 9.06 \\
Adult married child of U.S. citizen & 7.71 & 8.19 & 6.45 & 6.69 & 8.93 & 8.84 \\
Sibling of U.S. citizen & 13.2 & 13.7 & 12.4 & 12.7 & 10.39 & 13.8 \\
Spouse of LPR & 6.34 & 7.70 & NA & NA & 7.73 & 8.54 \\
Child of LPR & 9.09 & 8.85 & NA & NA & 11.5 & 11.3 \\
Employment & 2.67 & 2.25 & 2.50 & 3.76 & 4.04 & 4.73 \\
Diversity & 2.01 & 2.27 & 2.32 & 2.29 & 2.15 & 2.04 \\
Refugee/asylee/parolee & NA & NA & NA & NA & 5.82 & 5.45 \\
Legalization & NA & NA & NA & NA & 7.08 & 5.95 \\
Other & --- & --- & --- & --- & --- & -- \\
$\quad$ All immigrants & 4.58 & 4.18 & 6.48 & 6.59 & 4.89 & 3.90 \\
\hline
\end{tabular}

Notes: Sample size is 8,573. Estimates based on weighted data. Combinations which either do not arise in immigration law or do not appear in the sample are denoted NA. The mark "- - " indicates cells with observations fewer than 20 . 
Table 12. OLS Estimates of Effects of Lost Documents and Visa Characteristics on Duration of Visa Process, by Sex: NIS-2003 Cohort

\begin{tabular}{|c|c|c|c|c|}
\hline \multirow{2}{*}{ Regressor } & \multicolumn{2}{|c|}{ New Arrivals } & \multicolumn{2}{|c|}{ Adjustees } \\
\hline & Men & Women & Men & Women \\
\hline Documents lost & $\begin{array}{c}0.572 \\
(1.42)\end{array}$ & $\begin{array}{l}-0.0180 \\
(.05)\end{array}$ & $\begin{array}{c}1.017 \\
(2.89)^{* *}\end{array}$ & $\begin{array}{c}0.899 \\
(3.07)^{* *}\end{array}$ \\
\hline Spouse of NB citizen & -8.428 & -8.104 & 1.035 & .398 \\
\hline Spouse of FB citizen & -8.073 & -7.255 & 1.829 & 1.090 \\
\hline Parent of U.S. citizen & -6.855 & -6.819 & .622 & .919 \\
\hline Child of U.S. citizen & -6.905 & -6.287 & 3.613 & 2.705 \\
\hline Adult single child of U.S. citizen & -2.337 & -2.480 & 5.733 & 6.244 \\
\hline Adult married child of U.S. citizen & -2.263 & -.990 & 7.377 & 5.910 \\
\hline Spouse of adult child of U.S. cit & -2.831 & -.945 & 1.185 & 8.233 \\
\hline Sibling of U.S. citizen & 3.315 & 4.774 & 9.280 & 13.289 \\
\hline Spouse of sibling of U.S. citizen & 2.564 & 3.131 & 13.351 & 11.542 \\
\hline Spouse of LPR & -3.776 & -1.563 & 6.178 & 6.575 \\
\hline Child of LPR & --- & --- & 8.310 & 10.166 \\
\hline Employment principal & -7.227 & -6.670 & 2.729 & 2.989 \\
\hline Spouse of employment principal & -7.213 & -5.738 & 2.656 & 1.893 \\
\hline Diversity principal & -7.972 & -6.789 & .683 & .175 \\
\hline Spouse of diversity principal & -6.709 & -6.937 & --- & --- \\
\hline Refugee/asylee/parolee principal & NA & NA & 4.099 & 3.626 \\
\hline $\begin{array}{l}\text { Spouse of refugee/ asylee/parolee } \\
\text { principal }\end{array}$ & NA & NA & 5.027 & 5.582 \\
\hline Legalization principal & NA & NA & 4.716 & 4.025 \\
\hline Joint test $\mathrm{F}$ & $\begin{array}{c}81.1 * * * \\
(14,898 \mathrm{df})\end{array}$ & $\begin{array}{c}51.2 * * * \\
(14,983 \mathrm{df})\end{array}$ & $\begin{array}{c}26.75^{* * *} \\
(17,2004 \mathrm{df})\end{array}$ & $\begin{array}{c}79.15 * * * \\
(17,1043 \mathrm{df})\end{array}$ \\
\hline Adjustee, EWI/WI & NA & NA & .521 & 1.810 \\
\hline Adjustee, UU/UN & NA & NA & 1.038 & .718 \\
\hline Adjustee, no code & NA & NA & .868 & .789 \\
\hline Adjustee, Warren overstay & NA & NA & .444 & 1.193 \\
\hline Joint test $\mathrm{F}$ & NA & NA & $\begin{array}{c}3.10^{*} \\
(4,1004 \mathrm{df})\end{array}$ & $\begin{array}{c}6.01 * * * \\
(4,1043 \mathrm{df})\end{array}$ \\
\hline
\end{tabular}




\begin{tabular}{lcccc} 
Constant & 9.761 & 9.103 & 1.052 & 1.116 \\
& $(23.41)^{* * *}$ & $(16.68)^{* * *}$ & $(2.02)^{*}$ & $(1.53)$ \\
$R$-squared & .593 & .591 & .240 & .367 \\
Observations & 914 & 999 & 1027 & 1066 \\
\hline
\end{tabular}

Notes: The visa process lasts from the date of filing the first application to the date of admission to legal permanent residence. NA $=$ not applicable. Absolute values of asymptotic $t$-ratio appear in parentheses under parameter estimates for numeric variables. Joint tests reported for multiple-category categorical variables.

$(* p<.05, * * p<.01, * * * p<.001 ;$ two-tailed tests for single coefficients, one-tailed for joint tests) 
Table 13. Logit Estimates of Depression Due to the Visa Process, by Sex: NIS-2003 Cohort

\begin{tabular}{|c|c|c|c|c|}
\hline \multirow{2}{*}{ Regressor } & \multicolumn{2}{|c|}{ Full Sample } & \multicolumn{2}{|c|}{$\begin{array}{l}\text { Subsample with Data on } \\
\text { Lost Documents }\end{array}$} \\
\hline & Men & Women & Men & Women \\
\hline Age & 0.0324 & 0.0513 & 0.0224 & 0.0692 \\
\hline Age squared & -0.000446 & -0.000668 & -0.000279 & -0.000834 \\
\hline Joint test chi $^{2}(2 \mathrm{df})$ & 2.92 & $8.85^{*}$ & 0.47 & 5.67 \\
\hline Schooling & $\begin{array}{l}0.00594 \\
(0.42)\end{array}$ & $\begin{array}{c}0.0167 \\
(1.39)\end{array}$ & $\begin{array}{c}0.0404 \\
(1.92)\end{array}$ & $\begin{array}{c}0.0268 \\
(1.55)\end{array}$ \\
\hline Spouse of NB citizen & -0.115 & 0.232 & -0.271 & 0.158 \\
\hline Spouse of FB citizen & -0.288 & -0.216 & -0.807 & -0.193 \\
\hline Parent of U.S. citizen & -0.213 & -0.0108 & -0.694 & -0.0714 \\
\hline Child of U.S. citizen & -0.345 & 0.344 & -0.227 & 0.155 \\
\hline Sibling of U.S. citizen & -0.0375 & -0.381 & 0.278 & -0.384 \\
\hline Spouse of sibling of U.S. citizen & -0.0919 & -0.118 & 0.0189 & -0.862 \\
\hline Employment principal & 0.0765 & 0.0445 & -0.183 & -0.0215 \\
\hline Spouse of employment principal & 0.0609 & -0.195 & -0.226 & -0.643 \\
\hline Diversity principal & -0.352 & -0.428 & -0.716 & -0.253 \\
\hline Spouse of diversity principal & -0.713 & -0.519 & -1.578 & -0.528 \\
\hline Refugee/asylee/parolee principal & -1.149 & 0.104 & -1.203 & -0.243 \\
\hline $\begin{array}{l}\text { Spouse of refugee/ asylee/parolee } \\
\text { principal }\end{array}$ & -0.586 & -0.273 & -2.007 & -0.277 \\
\hline Legalization principal & 0.536 & -0.00346 & 0.284 & -0.497 \\
\hline Joint test chi $^{2}(13 \mathrm{df})$ & $30.54 * *$ & 17.03 & 20.68 & 11.42 \\
\hline Adjustee & $\begin{array}{c}0.591 \\
(3.75)^{* * *}\end{array}$ & $\begin{array}{l}-0.0358 \\
(0.26)\end{array}$ & $\begin{array}{l}0.459 \\
(2.01)^{*}\end{array}$ & $\begin{array}{l}-0.0259 \\
(0.13)\end{array}$ \\
\hline Adjusting from illegality & $\begin{array}{l}-0.173 \\
(1.11)\end{array}$ & $\begin{array}{c}0.00821 \\
(0.06)\end{array}$ & $\begin{array}{l}-0.190 \\
(0.82)\end{array}$ & $\begin{array}{l}0.122 \\
(0.61)\end{array}$ \\
\hline Experienced harm & $\begin{array}{c}0.409 \\
(2.34)^{* *}\end{array}$ & $\begin{array}{l}0.238 \\
(1.23)\end{array}$ & $\begin{array}{l}0.403 \\
(1.43)\end{array}$ & $\begin{array}{l}0.292 \\
(0.99)\end{array}$ \\
\hline Documents lost & NA & NA & $\begin{array}{c}0.770 \\
(4.15)^{* * *}\end{array}$ & $\begin{array}{l}0.468 \\
(2.60)^{* *}\end{array}$ \\
\hline Log likelihood & -1504.27 & -1703.95 & -657.86 & -800.53 \\
\hline
\end{tabular}


Notes: NA = not applicable. Specifications include full set of country fixed effects. Absolute values of asymptotic $t$-ratio appear in parentheses under parameter estimates for numeric and binary variables. Joint tests reported for multiple-category categorical variables.

$\left(* p<.05,{ }^{*} p<.01,{ }^{* * *} p<.001\right.$; two-tailed tests for single coefficients, one-tailed for joint tests) 
Table 14. Declaring Oneself the Principal: Logit Estimates, Separately for Principals and Nonprincipals and by Sex, NIS-2003 Cohort

\begin{tabular}{|c|c|c|c|c|}
\hline \multirow{2}{*}{ Regressor } & \multicolumn{2}{|c|}{ Principals } & \multicolumn{2}{|c|}{ Accompanying Spouses } \\
\hline & Men & Women & Men & Women \\
\hline Age & 0.124 & 0.509 & 0.0696 & -0.0351 \\
\hline Age squared & -.00109 & -.000323 & -0.00117 & 0.000655 \\
\hline Joint test $\operatorname{chi}^{2}(2 \mathrm{df})$ & $27.98 * * *$ & $20.09 * * *$ & 5.58 & 2.55 \\
\hline Hispanic, no race & 0.304 & -0.106 & -0.0763 & --- \\
\hline Hispanic white & 0.294 & 0.181 & 1.774 & 0.814 \\
\hline NonHispanic Asian & 0.243 & 0.392 & -0.414 & 1.283 \\
\hline NonHispanic black & 0.105 & 0.268 & 2.410 & 1.373 \\
\hline NonHispanic white & -0.332 & -0.163 & 1.301 & 0.930 \\
\hline Joint test chi $^{2}$ & $\begin{array}{c}6.56 \\
(5 \mathrm{df})\end{array}$ & $\begin{array}{c}9.34 \\
(5 \mathrm{df})\end{array}$ & $\begin{array}{l}10.79 \\
(5 \mathrm{df})\end{array}$ & $\begin{array}{c}2.98 \\
(4 \mathrm{df})\end{array}$ \\
\hline Catholic & 0.0973 & -0.189 & -0.0879 & -0.459 \\
\hline Orthodox Christian & 0.476 & 0.134 & 0.143 & 0.0227 \\
\hline Protestant & 0.201 & -0.283 & -0.00645 & -0.330 \\
\hline Muslim & 0.444 & -0.162 & -0.212 & 0.305 \\
\hline Jewish & 0.151 & 0.0654 & -1.461 & 0.949 \\
\hline Buddhist & 0.1599 & 0.253 & -0.345 & 0.103 \\
\hline Hindu & -0.135 & -0.336 & 0.731 & -1.476 \\
\hline Other religion & -0.572 & -0.911 & 0.345 & -1.728 \\
\hline Childhood religion missing & -0.0806 & -0.0592 & 1.071 & 0.172 \\
\hline Joint test $\operatorname{chi}^{2}$ (9 df) & 5.87 & 9.18 & 5.44 & 9.50 \\
\hline Family income below average & -0.407 & -0.0586 & 1.014 & -0.864 \\
\hline Family income average & -0.217 & 0.225 & .966 & -0.802 \\
\hline Family income above average & -0.600 & 0.191 & .379 & -0.597 \\
\hline Family income far above average & -0.449 & -0.0260 & 2.131 & -1.801 \\
\hline Joint test chi $^{2}$ (4 df) & 8.17 & 6.84 & 4.421 & 3.40 \\
\hline Schooling & $\begin{array}{l}0.0216 \\
(0.133)\end{array}$ & $\begin{array}{c}-0.00103 \\
(0.08)\end{array}$ & $\begin{array}{c}-0.00977 \\
(0.22)\end{array}$ & $\begin{array}{c}-0.000549 \\
(0.02)\end{array}$ \\
\hline Visa depression & $\begin{array}{l}-0.248 \\
(1.61)\end{array}$ & $\begin{array}{l}-0.192 \\
(1.75)\end{array}$ & $\begin{array}{l}-1.156 \\
(2.56)^{* *}\end{array}$ & $\begin{array}{l}-0.621 \\
(1.61)\end{array}$ \\
\hline
\end{tabular}




\begin{tabular}{|c|c|c|c|c|}
\hline Spouse of FB citizen & -0.446 & -0.121 & NA & NA \\
\hline Parent of U.S. citizen & -0.359 & -0.404 & NA & NA \\
\hline Child of U.S. citizen & -0.492 & -0.405 & NA & NA \\
\hline $\begin{array}{l}\text { Adult unmarried child of U.S. } \\
\text { citizen }\end{array}$ & -0.164 & 0.0646 & NA & NA \\
\hline Sibling of U.S. citizen & -0.156 & 0.819 & 0.129 & -0.444 \\
\hline Spouse of LPR & -0.958 & -0.292 & NA & NA \\
\hline Child of LPR & -0.422 & -0.0214 & NA & NA \\
\hline Employment & 2.380 & 2.298 & -2.279 & 0.223 \\
\hline Diversity & 2.820 & 2.287 & -0.628 & 1.525 \\
\hline Refugee/asylee/parolee & 0.327 & 0.358 & -2.653 & 1.820 \\
\hline Legalization & -0.0856 & -0.0902 & --- & --- \\
\hline Joint test chi $^{2}$ & $\begin{array}{l}157.01 * * * \\
(12 \mathrm{df})\end{array}$ & $\begin{array}{l}180.64^{* * *} \\
(12 \mathrm{df})\end{array}$ & $\begin{array}{c}10.89^{*} \\
(4 \mathrm{df})\end{array}$ & $\begin{array}{c}20.24 * * * \\
(4 \mathrm{df})\end{array}$ \\
\hline Adjustee, nonimm visa & 0.309 & 0.0506 & 2.051 & -0.584 \\
\hline Adjustee, EWI/WI & -0.342 & -0.667 & 3.475 & -0.277 \\
\hline Adjustee, UU/UN & -0.232 & -0.549 & --- & 0.434 \\
\hline Adjustee, no code & 0.327 & -0.0671 & 1.499 & -0.325 \\
\hline Adjustee, Warren overstay & 0.248 & 0.0391 & 2.779 & 0.929 \\
\hline Joint test chi ${ }^{2}$ & $\begin{array}{c}12.43^{*} \\
(5 \mathrm{df})\end{array}$ & $\begin{array}{c}20.04^{* *} \\
(5 \mathrm{df})\end{array}$ & $\begin{array}{c}10.01 * \\
(4 \mathrm{df})\end{array}$ & $\begin{array}{l}4.61 \\
(5 \mathrm{df})\end{array}$ \\
\hline Number of observations & 3566 & 3577 & 333 & 537 \\
\hline
\end{tabular}

Notes: NA $=$ not applicable. Specifications also include origin-area fixed effects. Absolute values of asymptotic $t$-ratio appear in parentheses under parameter estimates for numeric and binary variables. Joint tests reported for multiple-category categorical variables.

(* $p<.05,{ }^{* *} p<.01,{ }^{* * *} p<.001$; two-tailed tests for single coefficients, one-tailed for joint tests) 
Table 15. Percentage Distribution of Race and Hispanic Origin: U.S. Resident Population in 2003 and NIS-2003 Cohort

\begin{tabular}{|c|c|c|c|}
\hline \multirow{2}{*}{ Race and Hispanic Origin } & \multirow{2}{*}{$\begin{array}{l}\text { U.S. Resident } \\
\text { Population in } \\
2003\end{array}$} & \multicolumn{2}{|c|}{ NIS-2003 } \\
\hline & & Race & Race-Hispanic \\
\hline White & 80.5 & 48.1 & \\
\hline White, Hispanic & & & 28.5 \\
\hline White, not Hispanic & & & 19.5 \\
\hline White, no Hispanic information & & & .12 \\
\hline Black & 12.7 & 11.2 & \\
\hline Black, Hispanic & & & .56 \\
\hline Black, not Hispanic & & & 10.6 \\
\hline Black, no Hispanic information & & & .04 \\
\hline American Indian & .959 & 2.51 & \\
\hline American Indian, Hispanic & & & .46 \\
\hline American Indian, not Hispanic & & & 2.05 \\
\hline Asian & 4.10 & 28.6 & \\
\hline Asian, Hispanic & & & .41 \\
\hline Asian, not Hispanic & & & 28.2 \\
\hline Asian, no Hispanic information & & & .05 \\
\hline Pacific & .171 & .77 & \\
\hline Pacific, Hispanic & & & .18 \\
\hline Pacific, not Hispanic & & & .59 \\
\hline Two or more races & 1.48 & 1.15 & \\
\hline Mixed-race, Hispanic & & & .83 \\
\hline Mixed-race, not Hispanic & & & .32 \\
\hline No race & --- & 7.60 & \\
\hline No race, Hispanic & & & 5.63 \\
\hline No race, not Hispanic & & & 1.61 \\
\hline No race, no Hispanic information & & & .36 \\
\hline Hispanic origin & 13.7 & & \\
\hline Not Hispanic origin & 86.3 & & \\
\hline No information on Hispanic origin & --- & & \\
\hline
\end{tabular}


Table 16. Average Skin Color, as Reported by Interviewer, Raw and Corrected for Interviewer, Timing, and Mode Effects: NIS-2003 Cohort

\begin{tabular}{|c|c|c|c|c|}
\hline \multirow{2}{*}{ Race and Hispanic Origin } & \multicolumn{2}{|c|}{ Race } & \multicolumn{2}{|c|}{ Race-Hispanic } \\
\hline & Raw & Corrected & Raw & Corrected \\
\hline White & 3.56 & 2.92 & & \\
\hline White, Hispanic & & & 4.09 & 3.39 \\
\hline White, not Hispanic & & & 2.56 & 2.44 \\
\hline White, no Hispanic information & & & --- & --- \\
\hline Black & 7.13 & 7.84 & & \\
\hline Black, Hispanic & & & 7.68 & 7.58 \\
\hline Black, not Hispanic & & & 7.10 & 7.80 \\
\hline Black, no Hispanic information & & & --- & --- \\
\hline American Indian & 4.56 & 4.20 & & \\
\hline American Indian, Hispanic & & & 4.58 & 4.29 \\
\hline American Indian, not Hispanic & & & 4.46 & 4.70 \\
\hline Asian & 3.92 & 4.21 & & \\
\hline Asian, Hispanic & & & --- & --- \\
\hline Asian, not Hispanic & & & 3.92 & 4.15 \\
\hline Asian, no Hispanic information & & & --- & --- \\
\hline Pacific & 4.97 & 4.53 & & \\
\hline Pacific, Hispanic & & & --- & --- \\
\hline Pacific, not Hispanic & & & 4.71 & 4.43 \\
\hline Two or more races & 4.27 & 4.67 & & \\
\hline Mixed-race, Hispanic & & & 5.01 & 4.90 \\
\hline Mixed-race, not Hispanic & & & --- & --- \\
\hline No race & 4.78 & 4.47 & & \\
\hline No race, Hispanic & & & 4.80 & 4.55 \\
\hline No race, not Hispanic & & & 4.49 & 4.53 \\
\hline \multirow[t]{2}{*}{ No race, no Hispanic info. } & & & --- & --- \\
\hline & \multicolumn{2}{|c|}{ Raw } & \multicolumn{2}{|c|}{ Corrected } \\
\hline Hispanic origin & \multicolumn{2}{|c|}{4.27} & \multicolumn{2}{|c|}{3.61} \\
\hline Not Hispanic origin & \multicolumn{2}{|c|}{4.11} & \multicolumn{2}{|c|}{4.21} \\
\hline No information on Hispanic origin & \multicolumn{2}{|c|}{5.37} & \multicolumn{2}{|c|}{4.82} \\
\hline
\end{tabular}


Notes: Skin color is measured by the interviewer on an 11-point scale. Corrected skin-color averages are obtained from regressions that include, besides the race-Hispanic categories, interviewer fixed-effects and binary variables for whether the interview took place after the date of a memo to interviewers concerning the coding of skin color and for whether the interview was conducted in person. Average skin color not shown for cells with fewer than 20 cases. 
Table 17. Characteristics of Black Immigrants from Africa and the Americas: NIS-2003 Cohort

\begin{tabular}{|c|c|c|}
\hline Characteristic & Born in Africa & Born in the Americas \\
\hline Percent female & 50.4 & 54.1 \\
\hline Average age at admission to LPR (years) & 35.7 & 39.3 \\
\hline Spouse of native-born U.S. citizen (\%) & 12.5 & 10.8 \\
\hline Spouse of foreign-born U.S. citizen (\%) & 12.0 & 20.3 \\
\hline Parent of U.S. citizen (\%) & 8.53 & 12.7 \\
\hline Minor child of U.S. citizen (\%) & 3.30 & 9.31 \\
\hline Employment principal (\%) & 1.01 & 1.72 \\
\hline Diversity principal (\%) & 29.8 & 0.11 \\
\hline Spouse of diversity principal (\%) & 10.0 & .34 \\
\hline Refugee/asylee/parolee principal (\%) & 14.0 & 7.25 \\
\hline Other family visa (\%) & 4.09 & 34.5 \\
\hline Other visa $(\%)$ & 4.91 & 3.02 \\
\hline Adjustee (\%) & 43.4 & 48.3 \\
\hline Documents lost during visa process (\%) & 11.3 & 12.3 \\
\hline Duration of visa process (years) & 3.13 & 5.33 \\
\hline English an official language (\%) & 59.7 & 53.0 \\
\hline Spoke English only at age $10(\%)$ & 4.82 & 47.1 \\
\hline Spoke English (only/some) at age 10 (\%) & 24.0 & 51.8 \\
\hline Suffered harm outside the U.S. (\%) & 14.0 & 3.51 \\
\hline Average schooling (years) & 13.1 & 11.2 \\
\hline Own home $(\%)$ & 16.9 & 18.1 \\
\hline Own home, new arrivals (\%) & 4.23 & 7.91 \\
\hline Own home, adjustees (\%) & 32.8 & 29.0 \\
\hline Intend to stay in United States (\%) & 77.9 & 71.4 \\
\hline Interviewed in English only (\%) & 75.9 & 65.0 \\
\hline Average skin color (raw) & 7.46 & 6.81 \\
\hline Average skin color (corrected) & 7.37 & 7.10 \\
\hline Percent in black-only sample & 53.5 & 46.5 \\
\hline Sample size & 688 & 377 \\
\hline
\end{tabular}

Notes: Sample restricted to immigrants who reported only black race. Lost documents calculated on principals only. 
Table 18. Previous Illegal Experience, by Information Source: NIS-2003 Cohort

\begin{tabular}{lcc}
\hline \hline Source of Information & Born in Africa & Born in the Americas \\
\hline Immigrant legalization visa & 1.18 & .66 \\
Nonimmigrant code EWI/WI & 1.86 & 4.52 \\
Nonimmigrant code UU/UN & .60 & 1.61 \\
Nonimmigrant code missing & 7.79 & 13.3 \\
Nonimmigrant Warren measure & 2.11 & 16.4 \\
Survey measures & 4.16 & 13.4 \\
Total based on leg visa or EWI code & 3.04 & 5.18 \\
Total based on record alone & 12.4 & 35.8 \\
Total including survey measures & 15.7 & 40.9 \\
\hline
\end{tabular}

Notes: The information based on immigrant and nonimmigrant visa is from the official administrative immigrant record. The four components based on nonimmigrant visas are mutually exclusive. The Warren measure refers to having a nonimmigrant tourist visa (B2) and reporting the most recent entry six years or more earlier. The two other components - the immigrant legalization visa and the survey measures - may be combined with any of the other codes, so that, for example, a given respondent may be included in both the legalization visa figure, one of the nonimmigrant visa figures, and the survey measures. Thus, the total estimate is less than the sum of the components. The total estimate may be an underestimate, as it may miss new-arrival immigrants who were already living in the United States illegally and do not report it in the survey measures, as well as persons who had been working without authorization. 
Table 19. Determinants of Schooling (OLS Estimates) and English Fluency (Logit Estimates), Black Immigrants from Africa and the Americas: NIS-2003 Cohort

\begin{tabular}{|c|c|c|c|c|}
\hline \multirow{2}{*}{ Regressor } & \multicolumn{2}{|c|}{ Years of Schooling } & \multicolumn{2}{|c|}{ Fluency in English } \\
\hline & Men & Women & Men & Women \\
\hline Age & 0.509 & .310 & .0450 & .00738 \\
\hline Age squared & -0.00625 & -.00428 & -.000848 & -.000263 \\
\hline Joint test $\mathrm{F}$ & $\begin{array}{l}27.6^{* * *} \\
(2,547)\end{array}$ & $\begin{array}{l}14.3 * * * \\
(2,481)\end{array}$ & NA & NA \\
\hline Joint test $\operatorname{chi}^{2}(2 \mathrm{df})$ & NA & NA & $\begin{array}{c}3.74 \\
(2 \mathrm{df}) .\end{array}$ & $\begin{array}{c}.93 \\
(2 \mathrm{df})\end{array}$ \\
\hline Spouse of NB citizen & .395 & 1.411 & -.00385 & -.540 \\
\hline Spouse of FB citizen & .599 & 1.190 & -2.301 & -.516 \\
\hline Parent of U.S. citizen & .0205 & -.712 & -1.441 & -1.978 \\
\hline Child of U.S. citizen & 2.128 & 2.098 & -1.583 & -1.071 \\
\hline Employment principal & 1.751 & 2.750 & .189 & --- \\
\hline Diversity principal & .825 & 2.378 & -1.393 & -1.051 \\
\hline Spouse of diversity prin. & 1.676 & .556 & -1.154 & -1.248 \\
\hline Refugee principal & -.914 & -2.272 & -1.964 & -.938 \\
\hline Other family visa & .0739 & 2.510 & -1.180 & -1.249 \\
\hline Joint test $\mathrm{F}$ & $\begin{array}{c}2.87 * * \\
(9,547)\end{array}$ & $\begin{array}{l}5.23 * * * \\
(9,481)\end{array}$ & NA & NA \\
\hline Joint test $\mathrm{chi}^{2}$ & NA & NA & $\begin{array}{c}9.35 \\
(9 \mathrm{df})\end{array}$ & $\begin{array}{c}7.29 \\
(8 \mathrm{df})\end{array}$ \\
\hline Adjustee & $\begin{array}{c}1.233 \\
(2.26)^{*}\end{array}$ & $\begin{array}{c}1.453 \\
(2.22)^{*}\end{array}$ & $\begin{array}{c}2.202 \\
(4.13)^{* * *}\end{array}$ & $\begin{array}{l}1.030 \\
(1.68)\end{array}$ \\
\hline Previous illegal experience & $\begin{array}{l}-.181 \\
(.44)\end{array}$ & $\begin{array}{l}.390 \\
(.67)\end{array}$ & $\begin{array}{l}-.431 \\
(.72)\end{array}$ & $\begin{array}{l}.151 \\
(.29)\end{array}$ \\
\hline Born in Africa & $\begin{array}{c}2.406 \\
(4.53)^{* * *}\end{array}$ & $\begin{array}{c}1.346 \\
(2.33)^{*}\end{array}$ & $\begin{array}{c}1.005 \\
(2.06)^{*}\end{array}$ & $\begin{array}{c}1.019 \\
(2.49)^{*}\end{array}$ \\
\hline English an official language & NA & NA & $\begin{array}{c}3.276 \\
(7.33)^{* * *}\end{array}$ & $\begin{array}{c}3.340 \\
(8.00)^{* * *}\end{array}$ \\
\hline Spoke English only at age 10 & NA & NA & 2.082 & 2.394 \\
\hline Spoke some English at age 10 & NA & NA & .884 & 1.125 \\
\hline Joint test $\operatorname{chi}^{2}(2 \mathrm{df})$ & NA & NA & $\begin{array}{c}14.6^{* * *} \\
(2 \mathrm{df})\end{array}$ & $\begin{array}{c}25.5^{* * * *} \\
(2 \mathrm{df})\end{array}$ \\
\hline
\end{tabular}




\begin{tabular}{lcccc} 
Constant & 1.350 & 4.532 & -.640 & -.758 \\
& $(.73)$ & $(2.20)^{*}$ & $(.32)$ & $(.56)$ \\
$R$-squared & .298 & .330 & $\mathrm{NA}$ & $\mathrm{NA}$ \\
Log pseudolikelihood & $\mathrm{NA}$ & $\mathrm{NA}$ & -199.76 & -173.10 \\
Observations & 562 & 496 & 563 & 501 \\
\hline
\end{tabular}

Notes: $\mathrm{NA}=$ not applicable. Absolute values of asymptotic $t$-ratio appear in parentheses under parameter estimates for numeric and binary variables. Joint tests reported for multiple-category categorical variables.

$(* p<.05, * * p<.01, * * * p<.001$; two-tailed tests for single coefficients, one-tailed for joint tests) 
Table 20. Summary Characteristics of Spouses' Skin Color and Skin-Color Difference in Marriages Formed by U.S. Citizen Sponsors and Their Immigrant Spouses:

NIS-2003 Cohort

\begin{tabular}{lcccc}
\hline \hline \multicolumn{1}{c}{ Sponsor Characteristics } & Husbands & Wives & $\begin{array}{c}\text { Skin- } \\
\text { Color } \\
\text { Difference }\end{array}$ & N \\
\hline Sponsor male native-born & 2.93 & 3.58 & .651 & 133 \\
Sponsor male foreign-born & $(2.17)$ & $(2.09)$ & $(1.91)$ & 193 \\
Sponsor female native-born & 3.92 & 3.65 & -.267 & 106 \\
& $(1.93)$ & $(1.90)$ & $(1.39)$ & 1.57 \\
Sponsor female foreign-born & 4.60 & 3.04 & $(2.34)$ & 104 \\
\hline
\end{tabular}

Notes: Skin color is measured by the interviewer on an 11-point scale. Skin-color difference is defined as the immigrant's skin color minus the sponsor's skin color. Estimates based on weighted data. Standard deviations in parentheses beneath arithmetic means. The average skincolor difference across all four sets of spouse-of-U.S.-citizen couples is .419 and the standard deviation is 1.92 . 
Table 21. Proportions Marrying Lighter, Like, and Darker among U.S. Citizen Sponsors of Immigrant Spouses: NIS-2003 Cohort

\begin{tabular}{lcccc}
\hline \hline \multicolumn{1}{c}{ Sponsor Characteristics } & $\begin{array}{c}\text { Percent } \\
\text { Marrying } \\
\text { Lighter }\end{array}$ & $\begin{array}{c}\text { Percent } \\
\text { Marrying } \\
\text { Like }\end{array}$ & $\begin{array}{c}\text { Percent } \\
\text { Marrying } \\
\text { Darker }\end{array}$ & N \\
\hline Sponsor male native-born & 14.8 & 40.4 & 44.8 & 133 \\
Sponsor male foreign-born & 29.2 & 55.2 & 15.6 & 193 \\
Sponsor female native-born & 13.7 & 22.1 & 64.3 & 106 \\
Sponsor female foreign-born & 23.8 & 39.6 & 36.7 & 104 \\
\multicolumn{1}{c}{ All sponsors } & 21.6 & 42.0 & 36.4 & 536 \\
\hline
\end{tabular}

Notes: Skin color is measured by the interviewer on an 11-point scale. Skin-color difference is defined as the immigrant's skin color minus the sponsor's skin color. Estimates based on weighted data. 
Table 22. Skin-Color Difference Between U.S. Citizen Sponsors and Their Immigrant Spouses: NIS-2003 Cohort

\begin{tabular}{|c|c|c|c|c|}
\hline \multirow[t]{2}{*}{ Regressor } & \multicolumn{2}{|c|}{$\begin{array}{c}\text { Sample of Married } \\
\text { Couples Formed by U.S. } \\
\text { Citizen and Sponsored } \\
\text { Spouse }\end{array}$} & \multicolumn{2}{|c|}{$\begin{array}{l}\text { Subsample in Which } \\
\text { Both Spouses Had the } \\
\text { Same Interviewer }\end{array}$} \\
\hline & $\begin{array}{c}\text { Male } \\
\text { Sponsors }\end{array}$ & $\begin{array}{c}\text { Female } \\
\text { Sponsors }\end{array}$ & $\begin{array}{c}\text { Male } \\
\text { Sponsors }\end{array}$ & $\begin{array}{c}\text { Female } \\
\text { Sponsors }\end{array}$ \\
\hline \multicolumn{5}{|c|}{ Sponsor's age, sex, nativity, and race-ethnic group } \\
\hline Age & -0.0284 & 0.281 & -0.0359 & 0.242 \\
\hline Age squared & 0.000365 & -0.00369 & 0.000438 & -0.00322 \\
\hline Joint test $\mathrm{F}$ & $\begin{array}{c}.25 \\
(2,296 \mathrm{df})\end{array}$ & $\begin{array}{c}8.39 * * * \\
(2,180 \mathrm{df})\end{array}$ & $(2,281 \mathrm{df})$ & $\begin{array}{c}5.89 * * \\
(2,173 \mathrm{df})\end{array}$ \\
\hline Native-born female & NA & $\begin{array}{c}0.800 \\
(2.97)^{* *}\end{array}$ & NA & $\begin{array}{c}0.773 \\
(2.90)^{* *}\end{array}$ \\
\hline Foreign-born female & NA & NA & NA & NA \\
\hline Native-born male & $\begin{array}{c}0.504 \\
(2.25)^{*}\end{array}$ & NA & $\begin{array}{c}0.447 \\
(1.98)^{*}\end{array}$ & NA \\
\hline Joint test $\mathrm{F}$ & NA & NA & NA & NA \\
\hline Hispanic, no race & -0.0473 & -0.962 & -0.0353 & -0.891 \\
\hline Hispanic white & -0.0288 & -0.531 & 0.129 & -0.282 \\
\hline NonHispanic Asian & -0.280 & -0.262 & -0.269 & -0.387 \\
\hline NonHispanic black & -0.793 & -1.169 & -0.626 & -0.927 \\
\hline NonHispanic white & 1.170 & 1.152 & 1.183 & 1.257 \\
\hline Joint test $\mathrm{F}$ & $\begin{array}{c}4.29 * * * \\
(5,296 \mathrm{df})\end{array}$ & $\begin{array}{c}5.09 * * * \\
(5,180 \mathrm{df})\end{array}$ & $\begin{array}{c}3.94^{* *} \\
(5,281 \mathrm{df})\end{array}$ & $\begin{array}{c}5.14 * * * \\
(5,173 \mathrm{df})\end{array}$ \\
\hline \multicolumn{5}{|l|}{ Immigrant's birth area } \\
\hline Africa & 1.153 & 3.206 & 1.428 & 3.033 \\
\hline China & 1.619 & 1.430 & 1.604 & 1.699 \\
\hline India & 1.838 & 2.268 & 1.819 & 2.419 \\
\hline Philippines & 0.797 & 4.624 & 0.745 & 3.513 \\
\hline Vietnam & 1.369 & 1.968 & 1.475 & 2.211 \\
\hline Other Asia & 1.100 & 1.713 & 1.092 & 1.882 \\
\hline Oceania & 2.359 & 1.984 & 2.384 & 2.097 \\
\hline
\end{tabular}




\begin{tabular}{lcccc} 
Dominican Republic & 3.797 & 2.108 & 3.685 & 2.012 \\
El Salvador & 0.662 & 2.237 & 0.350 & 2.177 \\
Guatemala & 1.557 & 1.540 & 1.405 & 1.524 \\
Haiti & 2.215 & 2.572 & 2.050 & 2.441 \\
Mexico & 1.002 & 2.533 & 0.840 & 2.499 \\
Other North/Central Am. & 0.733 & 2.256 & 0.705 & 2.151 \\
Colombia & 1.204 & 3.059 & 1.089 & 2.836 \\
Other South America & 1.679 & 1.532 & 1.393 & 1.686 \\
Joint test F & $3.18 * * *$ & $4.54 * * *$ & $2.91 * * *$ & $4.35 * * *$ \\
& $(15,296 \mathrm{df})$ & $(15,180 \mathrm{df})$ & $(15,281 \mathrm{df})$ & $(15,173 \mathrm{df})$ \\
Constant & -0.987 & -6.479 & -0.808 & -5.818 \\
& $(0.82)$ & $(3.54)^{* * *}$ & $(0.68)$ & $(3.18)^{* *}$ \\
R-squared & 0.248 & 0.318 & 0.252 & 0.310 \\
Observations & 320 & 204 & 305 & 197 \\
\hline
\end{tabular}

Notes: Skin color is measured by the interviewer on an 11-point scale. NA $=$ not applicable. Robust standard errors; absolute values of asymptotic $t$-ratio appear in parentheses under parameter estimates for numeric and binary variables. Joint tests reported for multiple-category categorical variables.

$(* p<.05, * * p<.01, * * * p<.001$; two-tailed tests for single coefficients, one-tailed for joint tests) 
Table 23. Skin-Color Difference Among Married Couples, by Sampled Immigrant's Visa Class and Sex: NIS-2003 Cohort

\begin{tabular}{lcccc}
\hline \hline \multicolumn{1}{c}{ Visa Class } & \multicolumn{2}{c}{ Men } & \multicolumn{2}{c}{ Women } \\
& $\begin{array}{c}\text { Skin-Color } \\
\text { Difference }\end{array}$ & $N$ & $\begin{array}{c}\text { Skin-Color } \\
\text { Difference }\end{array}$ & $N$ \\
\hline Spouse of NB U.S. citizen & 1.566 & 106 & -.651 & 133 \\
Spouse of FB U.S. citizen sponsor & .269 & 104 & .267 & 193 \\
Parent of U.S. citizen & .265 & 116 & .194 & 97 \\
Adult married child of U.S. citizen & .315 & 31 & .363 & 25 \\
Spouse of adult child of U.S. citizen & .0527 & 42 & .273 & 37 \\
Sibling of U.S. citizen & .302 & 43 & .271 & 45 \\
Spouse of sibling of U.S. citizen & .132 & 29 & .541 & 31 \\
Spouse of LPR & .590 & 18 & .761 & 56 \\
Employment principal & .209 & 217 & .257 & 64 \\
Spouse of employment principal & .150 & 31 & -.0766 & 58 \\
Diversity principal & .887 & 117 & .0560 & 124 \\
Spouse of diversity principal & .390 & 43 & .674 & 32 \\
Refugee/asylee/parolee principal & .217 & 94 & .453 & 42 \\
Spouse of RAP principal & .450 & 16 & -.0116 & 31 \\
Legalization principal & .211 & 121 & -.0592 & 106 \\
All married respondents \& spouses & .487 & 1139 & .0659 & 1078 \\
\hline
\end{tabular}

Notes: Skin color is measured by the interviewer on an 11-point scale. Skin-color difference is defined as husband's skin color minus wife's skin color. Estimates based on weighted data. 
Table 24. English Fluency Among Children Age 8-12 and Their Immigrant Parents: Logit Estimates, NIS-2003 Cohort

\begin{tabular}{|c|c|c|c|}
\hline \multirow{2}{*}{ Regressor } & \multirow[t]{2}{*}{ Parents } & \multicolumn{2}{|c|}{ Children } \\
\hline & & $(1)$ & (2) \\
\hline $\operatorname{Sex}(1=$ female $)$ & $\begin{array}{l}-0.699 \\
(3.24)^{* * *}\end{array}$ & $\begin{array}{l}0.121 \\
(0.74)\end{array}$ & $\begin{array}{l}0.0631 \\
(0.38)\end{array}$ \\
\hline Age & $\begin{array}{l}0.0174 \\
(0.93)\end{array}$ & $\begin{array}{l}0.159 \\
(2.69)^{* *}\end{array}$ & $\begin{array}{l}0.142 \\
(2.36)^{*}\end{array}$ \\
\hline Spouse of NB citizen & 1.158 & NA & NA \\
\hline Biological child of U.S. citizen & NA & -.0860 & .0383 \\
\hline Not biological child of U.S. citizen & NA & .937 & .956 \\
\hline Spouse of FB citizen & .406 & -.211 & -.295 \\
\hline Parent of U.S. citizen & -.0474 & 1.283 & 1.269 \\
\hline Adult unmarried child of U.S. citizen & .608 & -.529 & -.495 \\
\hline Married child of U.S. citizen & 1.345 & \multirow{2}{*}{-.302} & \multirow{2}{*}{-.443} \\
\hline Spouse of adult child of U.S. citizen & .0544 & & \\
\hline Sibling of U.S. citizen & -.633 & \multirow{2}{*}{-.702} & \multirow{2}{*}{-1.569} \\
\hline Spouse of sibling of U.S. citizen & -.555 & & \\
\hline Spouse of LPR & .162 & -.261 & -.238 \\
\hline Child of LPR & .0108 & -.0437 & .0709 \\
\hline Employment principal & 1.463 & \multirow{2}{*}{.243} & \multirow{2}{*}{-.0954} \\
\hline Spouse of employment principal & 1.451 & & \\
\hline Diversity principal & .280 & \multirow{2}{*}{-.0511} & \multirow{2}{*}{-.0553} \\
\hline Spouse of diversity principal & -.345 & & \\
\hline Refugee/asylee/parolee & .620 & \multirow[b]{2}{*}{-.761} & \multirow[b]{2}{*}{-.987} \\
\hline $\begin{array}{l}\text { Spouse of refugee/asylee/parolee } \\
\text { principal }\end{array}$ & .659 & & \\
\hline Joint test chi ${ }^{2}$ & $\begin{array}{l}32.68^{* *} \\
(16 \mathrm{df})\end{array}$ & $\begin{array}{l}21.56^{*} \\
(12 \mathrm{df})\end{array}$ & $\begin{array}{c}20.72 \\
(12 \mathrm{df})\end{array}$ \\
\hline Adjustee & 1.001 & 1.625 & 1.518 \\
\hline Previous illegal experience & -.633 & .203 & .429 \\
\hline Joint test chi ${ }^{2}(2 \mathrm{df})$ & $6.78^{*}$ & $25.77 * * *$ & $23.69^{* * *}$ \\
\hline Childhood language Spanish & -3.261 & -1.664 & -1.500 \\
\hline $\begin{array}{l}\text { Childhood language English \& } \\
\text { Spanish }\end{array}$ & -2.442 & NA & NA \\
\hline
\end{tabular}




\begin{tabular}{|c|c|c|c|}
\hline Childhood language English \& other & -.969 & NA & NA \\
\hline Childhood language Spanish \& other & -2.269 & NA & NA \\
\hline Childhood language other & -2.168 & 0.224 & .289 \\
\hline Joint test chi $^{2}$ & $\begin{array}{l}23.01 * * * \\
(5 \mathrm{df})\end{array}$ & $\begin{array}{l}24.16^{* * *} \\
(2 \mathrm{df})\end{array}$ & $\begin{array}{l}25.75^{* * *} \\
(2 \mathrm{df})\end{array}$ \\
\hline Ukraine & -2.032 & -1.338 & -1.000 \\
\hline China & -1.407 & -1.766 & -1.674 \\
\hline India & -0.903 & .742 & 1.087 \\
\hline Korea & -3.290 & -1.485 & -.865 \\
\hline Philippines & -0.840 & .742 & 1.057 \\
\hline Vietnam & -2.287 & -1.361 & -1.071 \\
\hline Cuba & -1.361 & -1.084 & -.743 \\
\hline Dominican Republic & -1.419 & -0.878 & -0.672 \\
\hline El Salvador & -0.462 & -0.983 & -0.639 \\
\hline Guatemala & -0.647 & -1.094 & -0.775 \\
\hline Mexico & -.997 & -0.971 & -0.573 \\
\hline Joint test $\operatorname{chi}^{2}(11 \mathrm{df})$ & $32.61 * * *$ & $24.52 *$ & 16.90 \\
\hline $\begin{array}{l}\text { English official language of parental } \\
\text { origin country }\end{array}$ & $\begin{array}{l}2.115 \\
(3.23)^{* * *}\end{array}$ & $\begin{array}{c}1.661 \\
(3.21)^{* * *}\end{array}$ & $\begin{array}{l}.923 \\
(1.71)\end{array}$ \\
\hline Child entered U.S. at age $4+$ & NA & -.268 & -.0203 \\
\hline Child entered U.S. under age 4 & NA & .804 & .970 \\
\hline Child born in U.S. & NA & 1.005 & 1.108 \\
\hline Joint test $\operatorname{chi}^{2}(3 \mathrm{df})$ & NA & $13.21 * *$ & $10.89^{*}$ \\
\hline Parent interviewed in English & NA & NA & $\begin{array}{c}1.735 \\
(5.05)^{* * *}\end{array}$ \\
\hline Constant & $\begin{array}{r}-.547 \\
(.47)\end{array}$ & $\begin{array}{l}-.887 \\
(.97)\end{array}$ & $\begin{array}{c}-1.504 \\
1.69)\end{array}$ \\
\hline Log pseudolikelihood & -308.61 & -460.98 & -440.19 \\
\hline Observations & 870 & 998 & 998 \\
\hline
\end{tabular}

Notes: NA = not applicable. Standard errors in child regressions corrected for heteroskedasticity due to clustering within family. Absolute values of asymptotic $t$-ratio appear in parentheses under parameter estimates for numeric and binary variables. Joint tests reported for multiplecategory categorical variables.

$\left(* p<.05,{ }^{* *} p<.01, * * * p<.001\right.$; two-tailed tests for single coefficients, one-tailed for joint tests) 
Table A.1. Basic Survey Characteristics of Adult Sample: NIS-2003

\begin{tabular}{lccc}
\hline \hline \multicolumn{1}{c}{ Characteristic } & Men & Women & $\begin{array}{c}\text { All } \\
\text { Immigrants }\end{array}$ \\
\hline Total interviewed in Adult Sample & 4124 & 4449 & 8,573 \\
Not overseas & 3992 & 4260 & 8,252 \\
Interviewed in person & 1632 & 1797 & 3,429 \\
Interviewed by phone & 2484 & 2636 & 5,120 \\
Average number of months between & 3.91 & 3.91 & 3.91 \\
LPR \& interview & & & \\
\hline
\end{tabular}

Notes: Figures represent raw cases with no sampling weights. Overseas cases were administered an abbreviated questionnaire, and their spouses were not interviewed. 
A. Men

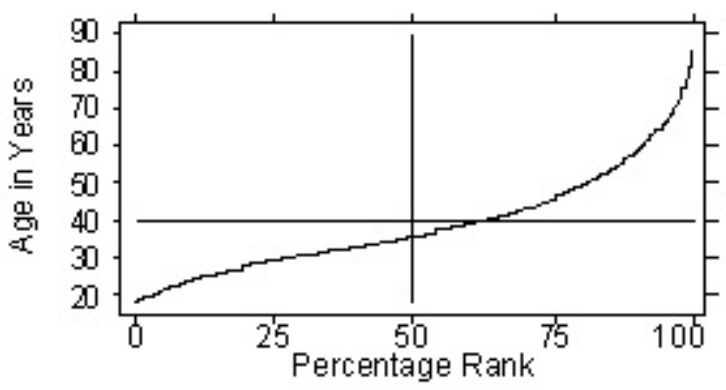

C. Men

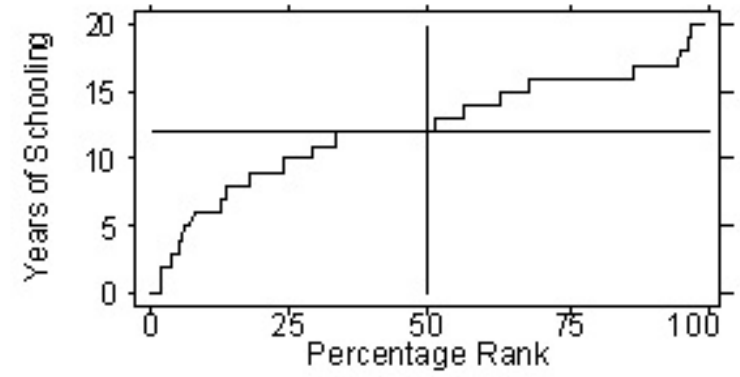

B. Women

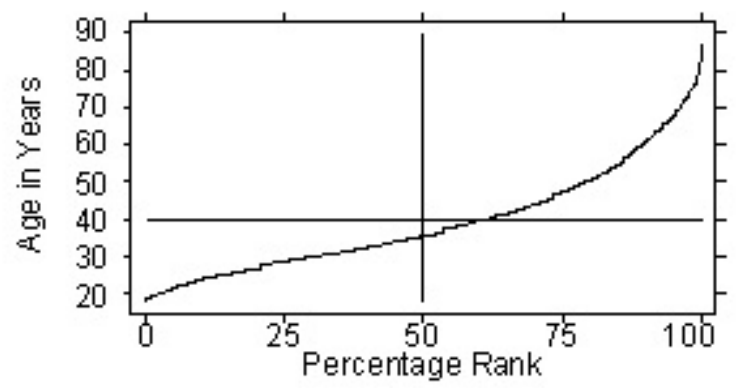

D. Women

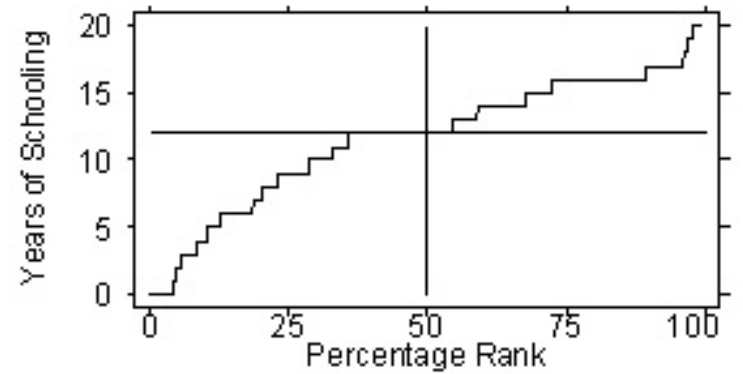

Figure 1. Quantile Functions of Age and Schooling Distributions, by Sex: NIS 2003 Cohort 


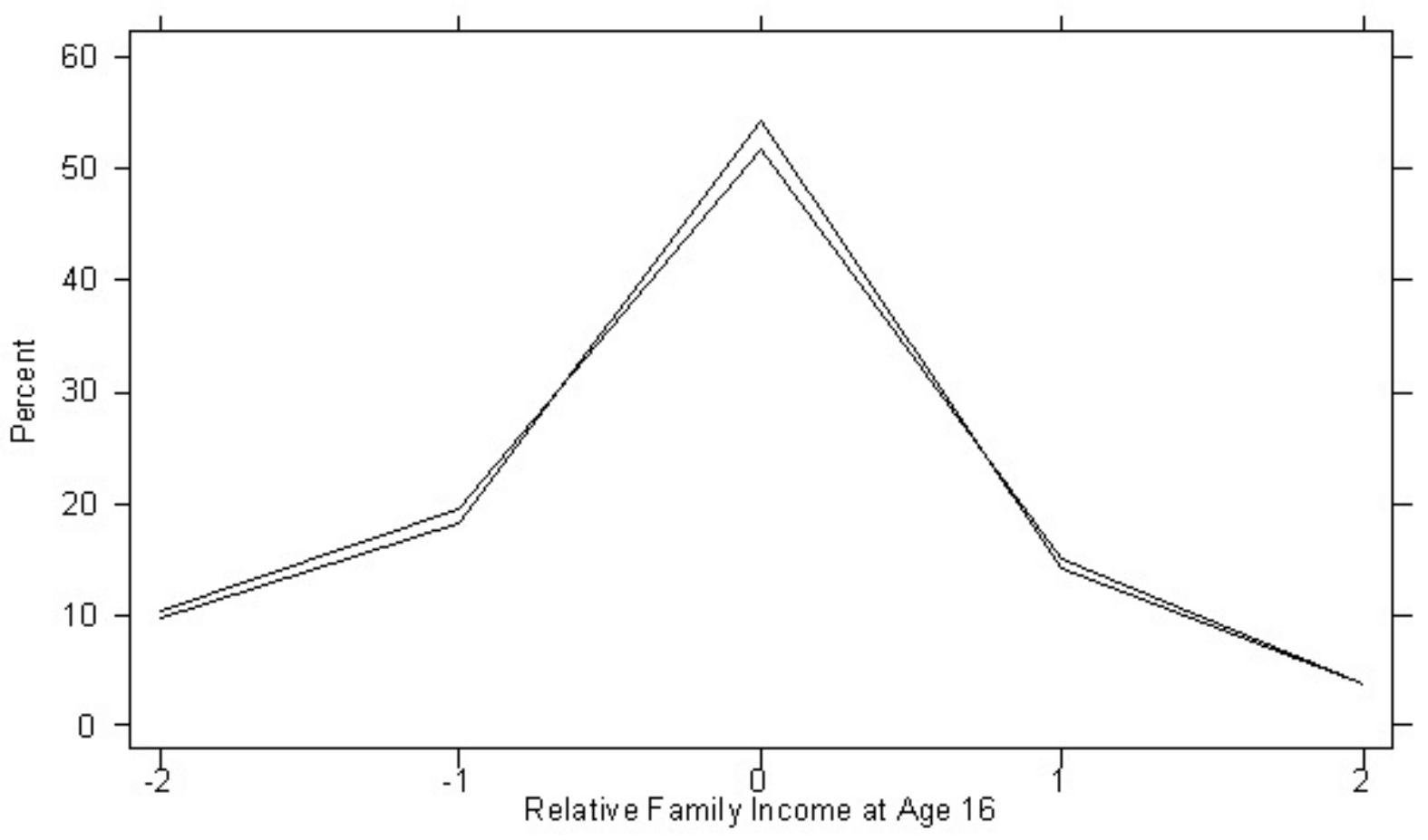

Figure 2. Parental Location in the Origin Country's Stratification Structure, by Immigrant Sex: NIS-2003 Cohort. The women's distribution has the higher mode. 
A. Spouses of NB U.S. Citizens New Arrivals

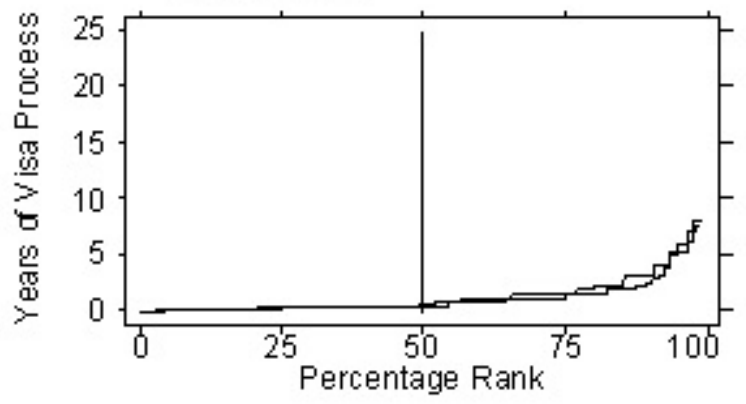

C. Siblings of U.S. Citiz ens New Arrivals

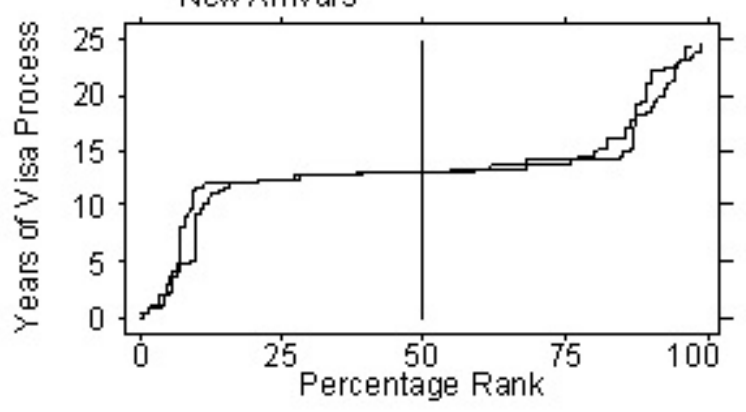

B. Spouses of NB U.S. Citizens Adjustees

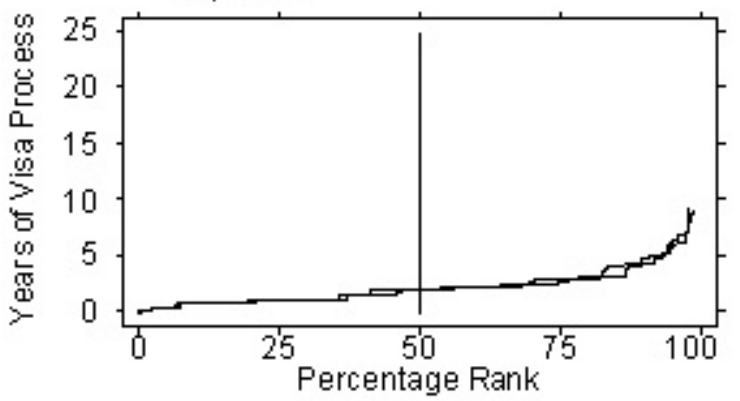

D. Siblings of U.S. Citzens Adjustees

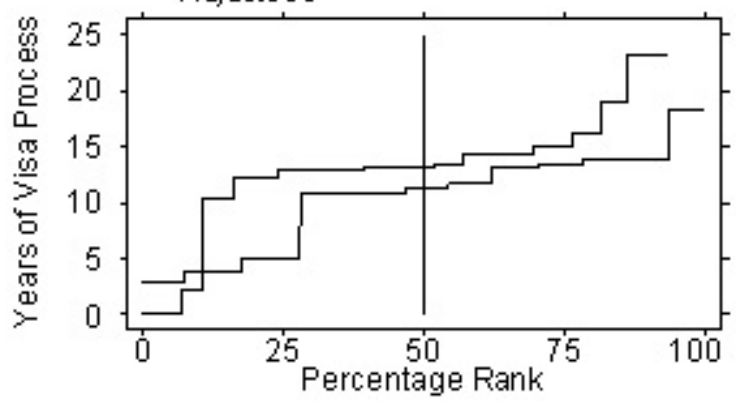

Figure 3. Two Extremes of Duration of Visa Process: Quantile Function of Duration Distribution Among Immigrant Spouses of Native-Born U.S. Citizens and Siblings of U.S. Citizens in the NIS-2003 Cohort. Panels A and C depict new arrivals, and Panels $\mathrm{B}$ and D depict adjustees. Each grid includes both the men's and women's distribution. 
A. Sponsors Native Born Women

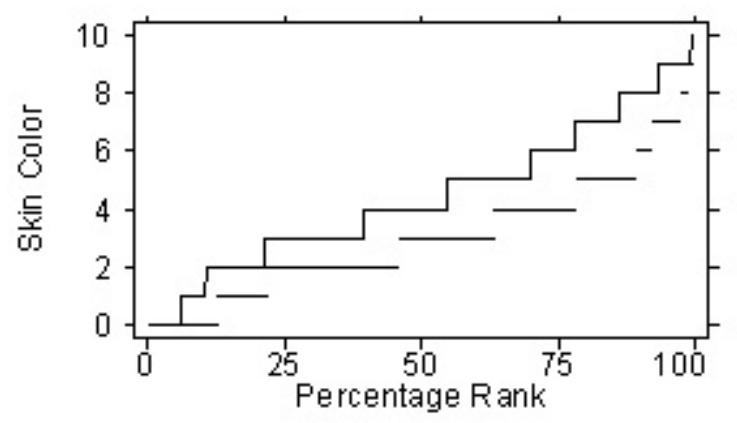

C. Sponsors Foreign-Born Women

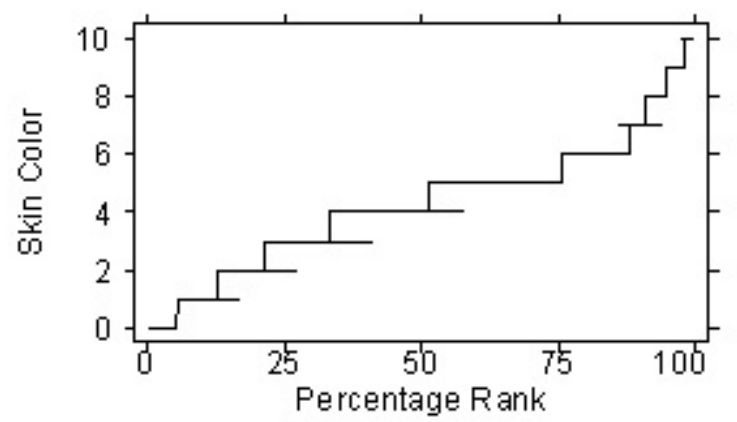

B. Sponsors Native-Born $M$ en

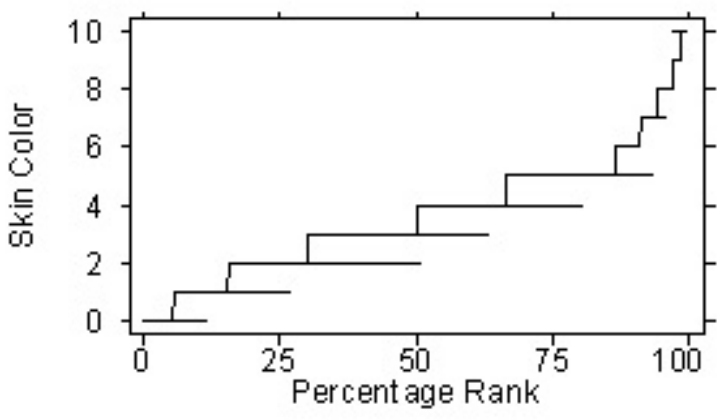

D. Sponsors F oreign-Born $M$ en

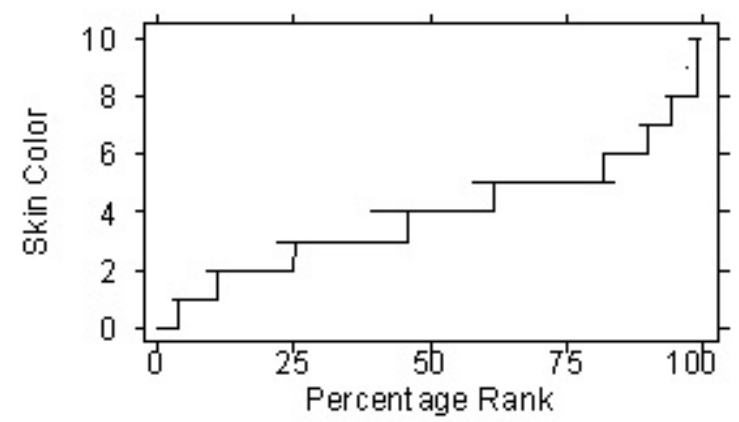

Figure 4. Quantile Functions of Skin-Color Distributions in Marriages Formed by U.S. Citizen Sponsors and Their Immigrant Spouses: NIS-2003 Cohort. Unconnected lines represent the sponsors' distributions. 
Scale of Skin Color Darkness

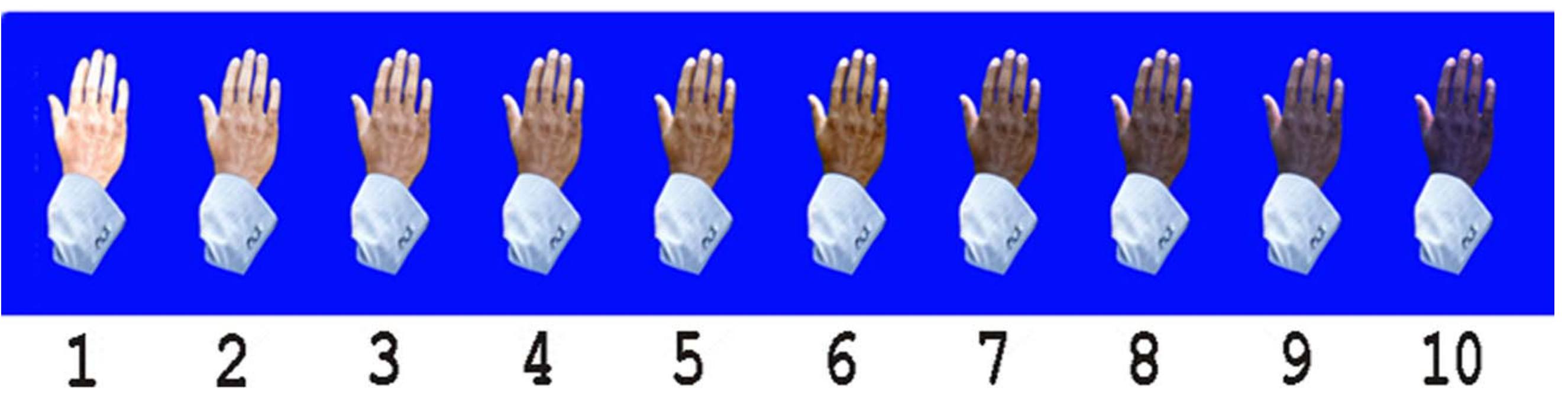

